Nathalia Sciscl

\title{
Prevalência e características da dor neuropática e neuropatia periférica em doentes submetidos à oxaliplatina para tratamento do câncer colorretal
}

Dissertação apresentada à Faculdade de Medicina da Universidade de São Paulo para obtenção do título de Mestre em Ciências

Programa de Neurologia

Orientador: Prof. Daniel Ciampi Araujo de Andrade

São Paulo

2016 
Dados Internacionais de Catalogação na Publicação (CIP)

Preparada pela Biblioteca da

Faculdade de Medicina da Universidade de São Paulo

Creprodução autorizada pelo autor

\section{Scisci, Nathalia}

Prevalência e características da dor neuropática e neuropatia periférica em doentes submetidos à oxaliplatina para tratamento do câncer colorretal / Nathalia Scisci. -- São Paulo, 2016.

Dissertação(mestrado)--Faculdade de Medicina daUniversidade de São Paulo.

Programa de Neurologia.

Orientador: Daniel Ciampi Araujo de Andrade.

Descritores: 1.Neuralgia 2.Doenças do sistema nervoso periférico 3.Neoplasias colorretais 4.Oxaliplatina 5.Qualidade de vida 6.Quimioterapia 7.Dor crônica

USP/FM/DBD-171/16 


\section{DEDICATÓRIA}

Ao meu esposo, Felipe, pelo apoio e amor.

A todos os meus familiares, principalmente aos meus pais, José Carlos e Rosana, pelo exemplo e ensinamentos desde a infância. Por terem priorizado os estudos de seus filhos acima de confortos ou luxos. 


\section{AGRADECIMENTOS}

Primeiramente a Deus, meu Pai Celestial, que desde o começo me guiou, colocou pessoas especiais em meu caminho e me socorreu nos momentos mais difíceis.

À minha família.

Ao meu orientador, Dr. Daniel Ciampi de Andrade, por ter acreditado em $\operatorname{mim}$. Silva.

Às enfermeiras e amigas, Daniella Parravano, Antonia Lillian e Valquíria

À Dra. Alexandra Zandonai, pelo exemplo, ajuda e carinho.

Ao Dr. Ricardo Galhardoni pela ajuda com os dados estatísticos.

À enfermeira Paula Malieno, colega de empreitadas.

Ao Grupo de Dor HCFMUSP, pelas aulas, reuniões e exemplo dos membros, que enriqueceram meu conhecimento e inspiraram.

Ao Dr. Paulo Hoff e Comissão de ética do Instituto do Câncer (ICESP) pela autorização da realização do estudo em suas dependências bem como toda a equipe de Pesquisa Clínica, em especial às enfermeiras Natalia Sartório e Carolina Saleima.

Ao Prof. Ricardo Nitrini, coordenador do Programa de Pós-Graduação do Departamento de Neurologia pela oportunidade para a realização desta pesquisa.

Ao Prof. Manoel Jacobsen Teixeira, Dra. Rachel Simões Pimenta Riechelmann e Dra. Angelina Maria Martins Lino, pelas críticas, comentários e sugestões durante o exame de qualificação.

À Sra. Thais Figueira, secretária do Programa de Pós-graduação do Departamento de Neurologia, pela atenção dispensada.

A todos os doentes que aceitaram fazer parte do estudo. 


\section{Normas adotadas:}

Esta dissertação está de acordo com as seguintes normas, em vigor no momento de sua publicação:

Referências: adaptado de International Committee of Medical Journals Editors (Vancouver).

Universidade de São Paulo. Faculdade de Medicina. Divisão de Biblioteca e Documentação. Guia de apresentação de dissertações, teses e monografias. Elaborado por Anneliese Carneiro da Cunha, Maria Julia de A. L. Freddi, Maria F. Crestana, Marinalva de Souza Aragão, Suely Campos Cardoso, Valéria Vilhena. 3ed. São Paulo: Divisão de Biblioteca e Documentação; 2011.

Abreviaturas dos títulos dos periódicos de acordo com List of Journals Indexed in Index Medicus. 


\section{SUMÁRIO}

Lista de abreviaturas

Lista de quadros

Lista de tabelas

Lista de figuras

1. INTRODUÇÃO. .18

2. OBJETIVOS .23

2.1 Objetivo Primário .23

2.2 Objetivos Secundários .23

3. REVISÃO DA LITERATURA. .24

3.1 Definição do Câncer .24

3.2 Histórico do câncer .24

3.3 Câncer no Brasil e no mundo.. .25

3.4 Câncer colorretal .28

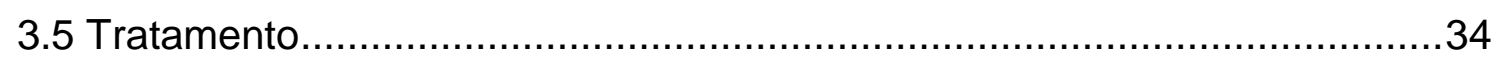

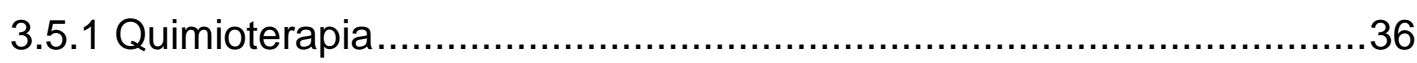

3.5.2 Efeitos adversos do tratamento quimioterápico ...............................38

3.6 Neuropatias periféricas induzidas por quimioterapia ..............................41

3.7 Dor neuropática induzida por quimioterapia..........................................43

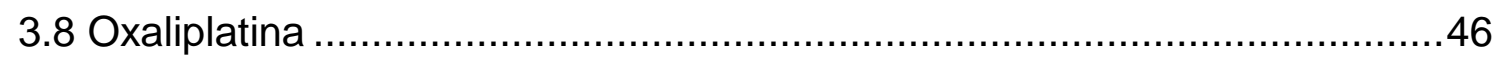

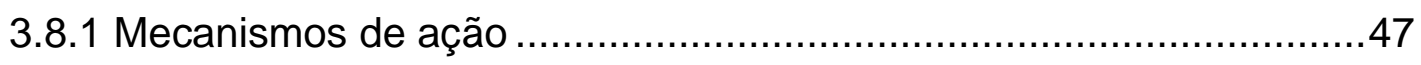

3.9 Incidência e características de DNIQ e NPIQ ...........................................52

4. CASUÍSTICA E MÉTODO

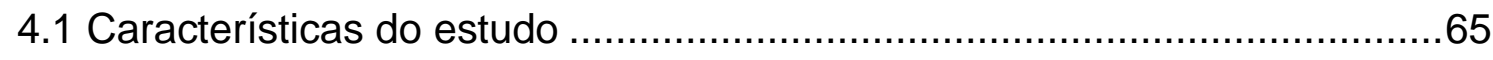


4.1.1 PreOx .65

4.1.2 Presente estudo

4.2 Fluxograma no modelo "Consort" do recrutamento, inclusão, exclusão e avaliação dos doentes. 68

4.3 Critérios de inclusão 69

4.4 Critérios de exclusão .69

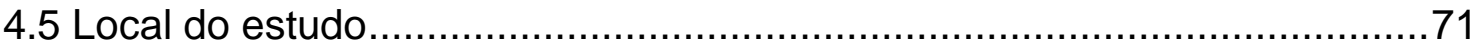

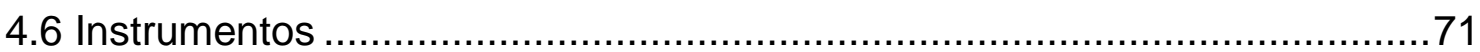

4.6.1 Ficha clínica sociodemográfica .................................................

4.6.2 Inventário breve de dor (BPI-Brief Pain Inventory) ............................72

4.6.3 Questionário de dor neuropática 4 (DN4) …....................................73

4.6.4 Pontuação total de neuropatia (TNS - Total Neuropathy Score) ........74

4.6.5 Inventário de sintomas de dor neuropática (ISDN) ….......................74

4.6.6 Questionário de dor McGill reduzido (MPQ) ................................75

4.6.7 Questionário de qualidade de vida da organização europeia para pesquisa e tratamento do câncer - C30 (EORTC QLQ-C30) ...............76

4.6.8 Escala hospitalar de ansiedade e depressão (HADS) ......................77

4.7 Forma de análise dos resultados ........................................................

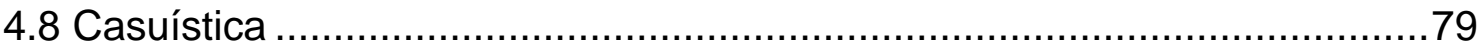

5. RESULTADOS

5.1 Análise descritiva das variáveis sociodemográficas relacionadas à doença oncológica

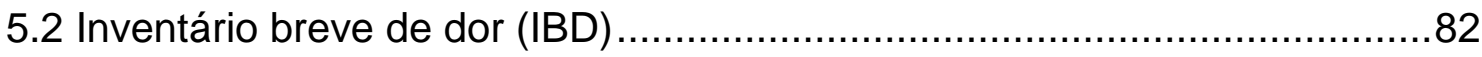

5.3 Questionário de dor neuropática (DN4) ……..................................... 85

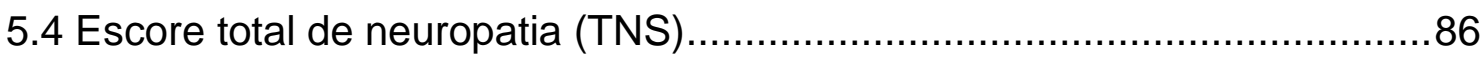

5.5 Inventário de sintomas de dor neuropática (ISDN) …..............................8

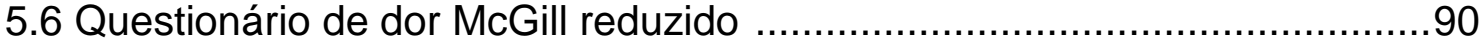

5.7 Auto-avaliação de saúde e qualidade de vida ...........................................93

5.8 Avaliação de ansiedade e depressão (HADS) ........................................97

5.9 Análises de correlações ....................................................................98 
6. DISCUSSÃO. 100

6.1 Caracterização da amostra estudada de acordo com as variáveis sociodemográficas e clínicas 100

6.2 Inventário breve de dor (BPI- Brief Pain Inventory) .................................103

6.3 Questionário de dor neuropática - 4 (DN4) ...........................................105

6.4 Escore total de neuropatia (Total neuropathy score -TNS) .....................106

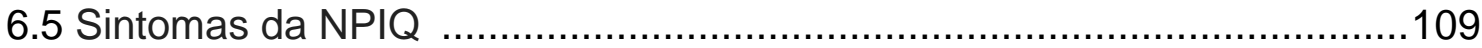

6.6 Inventário de sintomas de dor neuropática (ISDN) ….............................115

6.7 Questionário de dor McGill reduzido (MPQ) .........................................116

6.8 Avaliação de qualidade de vida .........................................................117

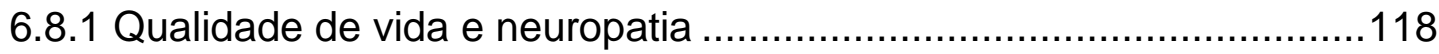

6.9 Escala hospitalar de ansiedade e depressão (HADS) ............................119

6.10 Análises de correlações......................................................................120

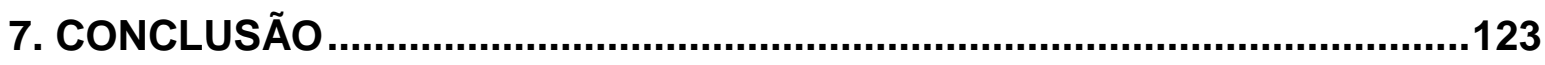

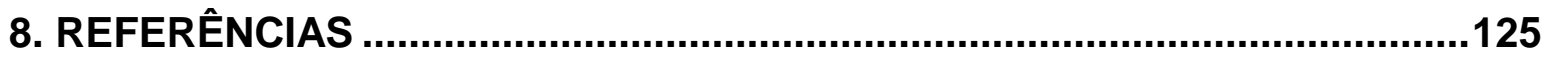

9. ANEXOS 


\section{LISTA DE ABREVIATURAS}

A.C.:

Antes de Cristo

AVC:

Acidente vascular cerebral

BPI:

Inventario breve de dor

CCR:

Câncer colorretal

CEA:

Antígeno carcinoembriônico

CTC:

Guia de critérios de toxicidade

CTEP:

Avaliação de tratamento de câncer

D.C.:

Depois de Cristo

DN4:

Questionário de dor neuropática

DNA:

Ácido desoxirribonucleico

DNIQ:

Dor neuropática induzida por quimioterapia

DRG:

Gânglios da raiz dorsal

ECOG:

Eastern cooperative oncology group performance status

ENMG:

Eletroneuromiografia

EORTC QLQ-C30: Questionário de qualidade de vida da Organização europeia para pesquisa e tratamento do câncer

FOLFIRI:

FOL- Ácido folínico, F - Fluorouracil, IRI - Irinotecano

FOLFOX:

FOL- Ácido folínico, F - Fluorouracil, OX - Oxaliplatina

FULV:

FU- Fluorouracil, LV- Leucovorin

FLOX:

F- Fluorouracil, L- Leucovorin, OX - Oxaliplatina

HADS:

Escala hospitalar de ansiedade e depressão

HCG:

Gonadotrofina coriônica humana

IASP:

Associação internacional para o estudo da dor

ICD:

Indice de classificação da dor

IL-1ß:

Interleucina 1 beta

ISDN:

Inventário de sintomas de dor neuropática 
KPS:

Karnofsky performance status scale

MMII:

Membros inferiores

MMSS:

Membros superiores

NADIR:

Tempo decorrido entre a administração da droga e a constatação do menor valor de contagem hematológica

NCI-CTC-AE: Critérios comuns de toxicidade do câncer

NCS: $\quad$ Estudo de condução nervosa

NPIQ: $\quad$ Neuropatia periférica induzida por quimioterapia

OXA: Oxaliplatina

PCS: $\quad$ Escala de catastrofismo associado à dor

QDMR: $\quad$ Questionário de dor McGill reduzido

QST: $\quad$ Teste sensitivo quantitativo

RNA: Ácido ribonucleico

RSC: Retossigmoidoscopia

SFM: $\quad$ Síndrome fibromiálgica

SUS: $\quad$ Sistema Único de Saúde

TCLE: $\quad$ Termo de consentimento livre-esclarecido

TNF: $\quad$ Fator de necrose tumoral

TNM: $\quad$ Tumor, nódulos e metástases

TNS: $\quad$ Total neuropathy score

TRP: $\quad$ Canais potenciais receptor transientes

VAS: $\quad$ Escala visual analógica 


\section{LISTA DE QUADROS}

Quadro 1 - Estadiamentos do câncer colorretal no modelo TNM (tumor, nódulo e metástase) segundo o American Joint Committee on Cancer (2002)

Quadro 2 - Medicações usualmente utilizadas para tratar DNIQ ..................... 45

Quadro 3 - Estudos que avaliaram NPIQ e DNIQ, seus autores, objetivos, tempo de avaliação, incidências de DNIQ e NPIQ, amostra, número de avaliações durante a quimioterapia, método, instrumentos utilizados, características encontradas e síntese dos achados principais ........................................................................... 54

Quadro 4 - Instrumentos específicos para avaliar a NPIQ e autores que utilizaram 101

Quadro 5 - Resultados de dois trabalhos que utilizaram o Inventário breve de dor, Guo et al (2014) e presente estudo, contendo as médias de pior dor, dor média e os aspectos de interferência na qualidade de vida: atividade de vida diária, humor, andar, trabalho básico, relacionamentos, sono e capacidade de aproveitar a vida em dois momento, na visita basal e após tratamento com oxaliplatina ..... 103 


\section{LISTA DE TABELAS}

Tabela 1 - Distribuição dos doentes em números absolutos $(\mathrm{N})$ e percentagens (\%), idades (em anos), renda familiar, estado civil, situação de trabalho, escolaridade e religião ................................................. 79

Tabela 2 - Descrição da amostra referente às características oncológicas quanto ao local da lesão, estadiamento, presença e locais de metástases em números absolutos e porcentagens 81

Tabela 3 - Distribuição das médias de dor utilizando o Inventário breve de dor dividido em quatro categorias, dor mais intensa na últimas 24 horas, dor mais fraca nas últimas 24 horas, dor média, dor atual e o quanto interfere nas atividades do dia-dia avaliadas nas cinco visitas, em médias, desvios padrões e graus de significância ......................... 82

Tabela 4 - Avaliação da média de interferência da dor nas atividades de vida diária utilizando o Inventário breve de dor (item 9 subdividido nos itens: atividade geral, humor, habilidade de caminhar, trabalho, relacionamento com outras pessoas, sono e habilidade para apreciar a vida) nas cinco visitas em médias, desvios padrões e graus de significância.... 83

Tabela 5 - Frequência de doentes com DN4 positivo ( $\geq 4$, o que indica possibilidade de dor neuropática presente) utilizando o questionário para diagnóstico de dor neuropática (DN4) em números absolutos, porcentagens e graus de significância durante as cinco visitas ....... 84 
Tabela 6 - Distribuiçao da intensidade de dor nos doentes utilizando o questionário para diagnóstico de dor neuropática (DN4) em médias, valores mínimos e máximos, desvios padrões e graus de significância durante as cinco visitas................................................ 85

Tabela 7 - Médias de dor neuropática utilizando o Escore total de neuropatia (TNS) avaliadas em três visitas, na visita basal, após o tratamento quimioterápico e após seguimento em médias, valores mínimos e máximos, desvios padrões e graus de significância 86

Tabela 8 - Médias de dor neuropática de acordo com o Inventário de sintomas de dor neuropática avaliadas nas cinco visitas, em médias, desvios padrões, valores mínimos e máximos e graus de significância 87

Tabela 9 - Números absolutos e porcentagens de doentes com pelo menos um sintoma do Inventário de sintomas de dor neuropática presente (VAS $>0$ ) avaliados nas cinco visitas e graus de significância 88

Tabela 10 - Distribuição dos descritores de dor neuropática (queimação, aperto, pressão, choque elétrico, apunhalada, dor ao toque, dor à pressão, frio doloroso, alfinetada/agulhada e dormência) avaliados (VAS >0) através do Inventário de sintomas de dor neuropática avaliados nas cinco visitas, em médias, desvios padrões e graus de significância

Tabela 11 - Distribuição de dor nas cinco visitas através do questionário de dor McGill resumido, nos três aspectos: afetivo, avaliativo e sensitivo, bem como no total, em médias, desvios padrões, valores mínimos e máximos e graus de significância 90 
Tabela 12 - Distribuição dos descritores de dor neuropática (latejante, pontada, choque, fina-agulhada, fisgada, queimação, que espalha, dolorida, cansativa-exaustiva, enjoada, sufocante, apavoranteenlouquecedora, aborrecida, incômoda e insuportável) avaliados através do questionário de dor McGill reduzido avaliados nas cinco visitas em números absolutos $(\mathrm{N})$, porcentagens $(\%)$ e graus de significância 91

Tabela 13 - Escore total de sintomas do questionário EORTC-QLQ30 (ANEXO 12) avaliados nas cinco visitas em médias, desvios padrões e graus de significância 93

Tabela 14 - Saúde geral e qualidade de vida dos doentes através de autoavaliação usando o questionário EORTC-QLQ30, questões 29 e 30 (ANEXO 12) avaliados nas cinco visitas em médias, desvios padrões e graus de significância avaliados nas cinco visitas 94

Tabela 15 - Qualidade de vida dos doentes através de auto-avaliação usando o questionário EORTC-QLQ30, questão 30 (ANEXO 12) que variava de 1 (muito ruim) a 7 (muito boa) em números absolutos $(\mathrm{N})$, porcentagens (\%) e graus de significância avaliados nas cinco visitas 95

Tabela 16 - Saúde geral dos doentes através de auto-avaliação usando o questionário EORTC-QLQ30, questão 29 (ANEXO 12) que variava de 1 (muito ruim) a 7 (muito boa) em números absolutos $(\mathrm{N})$, porcentagens (\%) e graus de significância avaliados nas cinco visitas 
Tabela 17 - Avaliação de ansiedade e depressão utilizando-se a Escala de ansiedade e depressão hospitalar avaliadas em três visitas, na visita basal, após o tratamento quimioterápico e após seguimento em médias, desvios padrões, valores mínimos e máximos e graus de

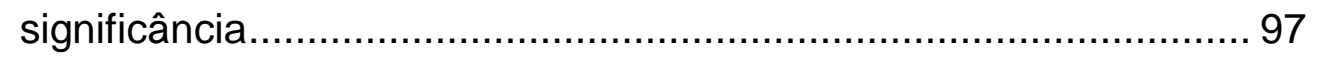




\section{LISTA DE FIGURAS}

Figura 1 - Estrutura química da oxaliplatina.................................................. 47

Figura 2 - Fluxograma no modelo Consort do recrutamento, inclusão, exclusão e

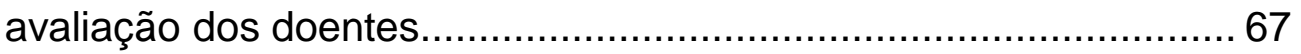




\section{RESUMO}

Scisci N. Prevalência e características da dor neuropática e neuropatia periférica em doentes submetidos à oxaliplatina para tratamento do câncer colorretal [dissertação]. São Paulo: Faculdade de medicina, Universidade de São Paulo; 2016.

Dor neuropática e neuropatia causadas pelo quimioterápico oxaliplatina são comuns e causam restrições às atividades funcionais e qualidade de vida. Muitos estudos têm quantificado e qualificado esses sintomas, porém raramente utilizando amostra expressiva e instrumentos validados e específicos para este fim. Neste estudo é proposta uma análise ampla, por instrumentos que quantificam e qualificam a dor e neuropatia relacionadas à oxaliplatina e suas características associadas. Objetivos: Identificar a prevalência de dor neuropática e neuropatia periférica em doentes com câncer colorretal recebendo tratamento com oxaliplatina durante os seis meses de tratamento quimioterápico e após seguimento (de 3 a 6 meses); avaliar, comparar e descrever as características da dor e neuropatia nesta população e avaliar seu impacto nas atividades de vida diária e qualidade de vida. Métodos: Foram incluídos 110 doentes (média 55,6 anos) com câncer colorretal durante o tratamento quimioterápico com oxaliplatina e seguidos por 3 a 6 meses após quimioterapia. Os doentes responderam ao questionário sócio-demográfico e a questionários específicos para dor e neuropatia antes da quimioterapia e bimestralmente por até seis meses durante a quimioterapia e em avaliação de seguimento realizada de 3 a 6 meses após o término da quimioterapia. Os instrumentos utilizados foram: Questionário de Qualidade de Vida da Organização Européia para Pesquisa e Tratamento do Câncer - C30 (EORTC QLQ-C30); Questionário de Dor McGill reduzido (QDMR), Inventário de Sintomas de Dor Neuropática (ISDN), Inventário Breve de Dor (BPI-Brief Pain Inventory) Questionário de Dor Neuropática 4 (DN4), Escala Hospitalar de Ansiedade e Depressão (HADS), Escore Total de Neuropatia (TNS - Total Neuropathy Score). Resultados: Em geral, a dor e neuropatia aumentaram durante o período de quimioterapia e diminuíram após fim do tratamento, permanecendo em níveis significativamente mais elevados após o fim do tratamento quimioterápico. A média de intensidade de dor (dor mais intensa) segundo o IBD foi 2,54 na V3 (após 4 meses de tratamento com oxaliplatina). A dor foi do tipo neuropática em $21,67 \%$ dos doentes ao fim da quimioterapia e em 10,00\% após fim do seguimento. As médias segundo o ISDN foram 0,67 no basal, 18,67 na V2, 17,77 na V3, 17,44 após quimioterapia e 11,03 após seguimento. A característica da dor mais frequente foi em choque elétrico, enjoada e incômoda segundo o QDMR e segundo o ISDN foram choque elétrico, frio doloroso e dormência. A qualidade de vida sofreu impacto negativo. Conclusões: Dor neuropática foi prevalente após a quimioterapia e após seguimento e se associou com interferência negativa sobre as atividades diárias. Estes dados poderão auxiliar 0 desenvolvimento de tratamentos individualizados da neuropatia relacionada à oxaliplatina.

Descritores: neuralgia; doenças do sistema nervoso periférico; neoplasias colorretais; oxaliplatina; qualidade de vida; quimioterapia; dor crônica. 


\section{ABSTRACT}

Scisci N. Prevalence and characteristics of neuropathic pain and peripheral neuropathy in patients receiving oxaliplatin for colorectal cancer treatment [dissertation]. São Paulo: "Faculdade de Medicina, Universidade de São Paulo", 2016.

Neuropathic pain and neuropathy caused by oxaliplatin chemotherapy are common and cause restrictions in activities of daily living and quality of life. Many studies have quantified and qualified these symptoms but only rarely used a comprehensive sample of patients and employed validated and specific instruments for pain assessment. In this study we proposed a comprehensive analysis by instruments that quantify and qualify the pain and neuropathy and its characteristics. Aim of Investigation: To identify the prevalence of neuropathic pain and peripheral neuropathy in patients with colorectal cancer receiving treatment with oxaliplatin during the six months of chemotherapeutic treatment and after follow-up (3 to 6 months); to evaluate, compare and describe pain and peripheral neuropathy characteristics in this population and evaluate their impact on activities of daily living. Methods:110 patients (mean 55.6 years) with colorectal cancer were included during the six months of chemotherapy with oxaliplatin and follow-up (3 to 6 months) after chemotherapeutic treatment. Patients answered socio-demographic questionnaires and specific assessment tools for pain and neuropathy evaluation at the baseline visit and every 2 months during chemotherapy and after follow-up (3-6 months). The instruments used were: The European Organization for Research and Treatment of Cancer QLQ-C30 (EORTC QLQ-C30); Reduced McGill Pain Questionnaire (MPQ), Neuropathic Pain Symptom Inventory (NPSI), Brief Pain Inventory (BPI) Neuropathic Pain Diagnostic Questionnaire (DN4), Hospital Anxiety and Depression Scale (HADS), Total Neuropathy Score (TNS), Results: In general, pain and neuropathy intensity increased during chemotherapy and decreased after the end of treatment (follow-up). The most severe pain according to the BPI was 2.54 in V3 (after 4 months treatment with oxaliplatin). Pain was neuropathic in $21.67 \%$ right after chemotherapy and in $10.00 \%$ after follow-up according to the DN4. The average sum of neuropathic pain symptoms according to the NPSI were 0.67 in V1, 18.67 in V2, 17.77 in V3, 17.44 after chemotherapy and 11.03 after follow-up. The most common characteristics of the pain was electric shocks, nauseating and fearful, according to MPQ and according to NPSI were electric shock, evoked by cold stimuli and tingling. Conclusions: Patients treated with oxaliplatin had significant pain and neuropathy that negatively interfeared with daily activities. These data may help tailor individualized treatment of chemotherapy related neuropathic pain.

Descriptors: neuralgia; peripheral nervous system diseases; colorectal neoplasms; oxaliplatin; quality of life; drug therapy; chronic pain. 


\section{INTRODUÇÃO}

Dor é uma experiência sensitiva e emocional desagradável decorrente ou descrita em termos de lesões teciduais reais ou potencias (IASP, 1992).

Dor aguda é a dor de início recente e de duração relacionada à agressão tecidual. Dor crônica é aquela que persiste após o tempo para a cura de uma lesão, ou que está associada a processos patológicos crônicos e apresenta-se com mais de três meses de duração (Merskey; Bogduk, 1994). No Brasil, a prevalência de dor crônica varia de $28 \%$ a $41 \%$ da população (Sá et al., 2008). A dor crônica acarreta alterações nas atividades físicas, no sono, na vida sexual, modificação do humor, baixa autoestima, pensamentos negativos, apreciação desesperançada da vida, altera relações familiares, de trabalho e de lazer (Pimenta, 1999). Esse tipo de dor também afeta a capacidade produtiva da população. A dor é a razão primária para a procura de cuidados de saúde nos EUA, país onde se estima que a dor seja responsável por 100 bilhões de dólares anuais de custos indiretos provocados pelo aumento do absenteísmo e produtividade reduzida no trabalho (McCarberg; Billington, 2006).

As síndromes dolorosas podem ser divididas em quatro grandes grupos: fisiológica, nociceptiva, disfuncional e neuropática (Teixeira, 2009). A síndrome neuropática é causada por lesão ou disfunção do sistema somatossensitivo (Jensen et al., 2011). É uma síndrome dolorosa geralmente crônica, incapacitante e de tratamento específico (Dworkin et al., 2003; Attal et al., 2006). A dor 
neuropática tem mecanismos patofisiológicos e resposta a tratamentos farmacológicos específicos (Woolf; Mannion, 1999). Entre as causas principais de dor neuropática encontram-se: diabetes, neuralgia pós herpética, lesão medular, acidente vascular encefálico, câncer e infecção do vírus da imunodeficiência humana, assim como condições comuns tais como radiculopatia compressiva lombar ou cervical, e lesões nervosas por traumatismo ou de ocorrência póscirúrgica. Estima-se que a dor neuropática afete de 5 a $8 \%$ da população global (Bouhassira et al., 2008; Mateos 2003; Galvez et al., 2005; Torrensa et al., 2006). No Brasil é estimado que a frequência de dor crônica com predominância de componentes neuropáticos seja de 4,2\% da população (Junior, Souza, 2003).

A neuropatia periférica é uma condição definida pela degeneração ou disfunção dos nervos periféricos, em seu trajeto da medula espinhal até a periferia, podendo ocasionar alterações motoras, sensitivas ou neurovegetativas e sua prevalência varia de 2 a $8 \%$ da população (Stubblefield et al., 2009, Martyn; Hughes, 1997). Podem ter etiologias hereditárias, metabólicas, tóxicas e idiopáticas (Kraychete; Sakata, 2011). Muitos fármacos quimioterápicos podem causar neuropatia tóxica (Kasper et al., 2015). A neuropatia periférica induzida por quimioterapia (NPIQ) é uma complicação frequente após uso de algumas das principais drogas utilizadas no tratamento do câncer. Tal toxicidade pode ser limitante ao uso de agentes antineoplásicos, trazendo a necessidade de redução de dose e até a interrupção do tratamento. Além de resultados inferiores em termos de resposta, recidiva e sobrevida podem ocasionar sintomas persistentes 
ou limitações funcionais, trazendo grande impacto negativo na qualidade de vida dos doentes (Stubblefield et al., 2009).

Várias quimioterapias (alcalóides, taxanas e baseadas em platina) causam dor neuropática como manifestação da neuropatia. Dor neuropática é definida como "dor desencadeada como consequência direta de uma lesão ou doença afetando o sistema somatossensorial (Treede et al 2008). Em algumas situações, como no caso das neuropatias de fibras finas (acometimento de fibras amielínicas ou pouco mielinizadas) a dor neuropática é o principal sintoma da neuropatia. A dor neuropática pode levar a prejuízo funcional, incluindo prejuízo da mobilidade e incapacidade para o trabalho, além de prejuízo da qualidade de vida como um todo, com alterações de humor e prejuízos no sono (Gilron et al, 2009).

Um dos agentes quimioterápicos que causam neuropatia periférica é a oxaliplatina, amplamente usada no tratamento do câncer colorretal. O câncer colorretal é o terceiro tipo de câncer mais frequente no mundo e acomete $7 \%$ da população dos países ocidentais (Mihajlović, Pechlivanoglou, 2013; Bouhassira et al, 2005; Habr-Gama, 2005).

Usualmente a neuropatia periférica induzida por quimioterapia (NPIQ) é predominantemente sensitiva e se manifesta por sintomas como parestesias e disestesias, sensibilidade ao frio ou dor, com acometimento simétrico e padrão de distribuição distal-proximal tipo luva e bota. Alguns doentes podem também apresentar alterações na propriocepção com risco aumentado de quedas. Os reflexos profundos costumam estar diminuídos ou abolidos (Afonseca et al., 2010). 
A NPIQ causada pela oxaliplatina é caracterizada por dois componentes distintos. Há a forma aguda, que acomete $80 \%$ a $100 \%$ dos doentes e pode se manifestar já nas primeiras horas de infusão da droga (Saif; Reardon, 2005, Cascinu et al., 2002). Os sintomas são desencadeados ou exacerbados pela exposição ao frio, reversíveis em horas ou dias. A toxicidade tardia acomete $15 \%$ a $20 \%$ dos doentes, está relacionada à dose cumulativa de 750 a $850 \mathrm{mg} / \mathrm{m}^{2}$, geralmente é mais grave e frequentemente causa interrupção do tratamento (Krarup-Hansen et al., 2007).

Há uma longa série de estudos que buscaram controlar os sintomas da dor neuropática e neuropatia induzida pela oxaliplatina. Em sua vasta maioria, estes estudos foram negativos (Wilson et al., 2002; Ishibashi et al., 2010; Chay et al., 2010; Madajewicz et al., 2010; Xu et al., 2013; Afonseca et al., 2013; Guo et al., 2014; Loprinzi et al., 2014). Isto deve-se provavelmente ao fato de que, até o momento, conhece-se pouco sobre os mecanismos causadores da dor neuropática relacionada à oxaliplatina. Há poucos relatos e estudos que pormenorizaram os diferentes sintomas relacionados à dor neuropática. Acreditase que o melhor conhecimento dos sintomas relacionados a cada tipo de dor neuropática poderia propiciar uma melhor "fenotipagem" dos doentes e conduzir a tratamentos mais refinados e eficazes (Max, 1990; Wolf et al., 1998; Welfert et al., 2014; Bouhassira et al., 2014)

Para melhor conhecer a neuropatia e dor neuropática induzidas por oxaliplatina é preciso avaliar sua incidência, além de identificar as características das mesmas. Até hoje, não se sabe ao certo a proporção de doentes que 
desenvolvem dor neuropática e não neuropática após uso da oxaliplatina, os principais sintomas associados e os fatores de risco clínicos para sua ocorrência. Apesar do grande numero de estudos que observaram o tema, não há muitos estudos que caracterizem a neuropatia ou dor neuropática utilizando instrumentos específicos. Há escassez de intervenções efetivas para tratamento e profilaxia da dor neuropática induzida por oxaliplatina, em parte devido à compreensão limitada dos reais mecanismos fisiopatológicos relacionados à ocorrência da neuropatia. Neste estudo é proposta uma análise ampla, por instrumentos que quantificam e qualificam a dor e neuropatia e suas características a fim de melhor caracterizar a dor e a neuropatia nestes doentes.

O conhecimento fenotípico da neuropatia e dor neuropática induzidas pela oxaliplatina é um passo fundamental para o desenvolvimento de estratégias profiláticas e terapêuticas contra a dor neuropática e neuropatia pós quimioterapia. 


\section{OBJETIVOS}

\subsection{Objetivo primário}

- Identificar a prevalência de dor neuropática e neuropatia periférica em doentes com câncer colorretal tratados com oxaliplatina durante os seis meses deste tratamento e após seguimento (de 3 a 6 meses).

\subsection{Objetivos secundários}

- Avaliar e comparar as características da neuropatia periférica e dor neuropática em doentes submetidos a tratamento quimioterápico com Oxaliplatina.

- Descrever as características clínicas da neuropatia periférica e dor neuropática neste cenário e avaliar seu impacto nas atividades de vida diária e na qualidade de vida.

- Avaliar correlações entre alterações na qualidade de vida e sintomas de dor neuropática ao fim da quimioterapia e ao fim do período de seguimento com características basais dos doentes antes do início do tratamento quimioterápico. 


\section{REVISÃO DA LITERATURA}

\subsection{Definição do câncer}

De acordo com a Organização Mundial da Saúde, câncer é o crescimento e a disseminação descontrolados de células. Ele pode afetar, praticamente, qualquer parte do corpo. Este crescimento descontrolado muitas vezes invade os tecidos normais circundantes podendo gerar metástases em locais distantes (WHO, 2008).

\subsection{Histórico do câncer}

As primeiras descrições conhecidas de câncer aparecem em papiros egípcios, descobertos e decifrados no final do século XIX. Eles forneceram o primeiro conhecimento direto da prática médica egípcia. Dois deles, conhecido como o "Edwin Smith" e "George Ebers", contêm descrições de câncer escrito por volta de 1600 a.C. (American Cancer Society, 2009). Hipócrates (460 a.C. - 370 a.C.) descreveu vários tipos de câncer, referindo-se a eles como carcinos, palavra grega (caranguejo ou lagostas). Este nome foi devido ao fato das projeções do 
tumor assemelharem-se a patas de caranguejo (Moss, Ralph, 2004). Celsus (25 a.C. - 50 d.C.) traduziu carcinos para o latim cancer, também significando caranguejo. Galen (século II d.C.) chamou os tumores benignos oncos e mais tarde, acrescentou o sufixo grego oma, que significa tumor, originando o termo carcinoma (American Cancer Society, 2009).

\subsection{Câncer no Brasil e no mundo}

O câncer é responsável por mais de $12 \%$ de todas as causas de óbito no mundo. Mais de 7 milhões de pessoas morrem anualmente da doença. Como a esperança de vida no planeta tem melhorado gradativamente, a incidência de câncer, estimada em 2002 em 11 milhões de casos novos, alcançará mais de 15 milhões em 2020 (International Union Against Cancer, 2005).

A explicação para este crescimento está na maior exposição dos indivíduos a fatores de risco cancerígenos (Ministério da Saúde, 2005). A redefinição dos padrões de vida, a partir da uniformização das condições de trabalho, nutrição e consumo desencadeados pelo processo global de industrialização, tem reflexos importantes no perfil epidemiológico das populações (Organização Pan-Americana da Saúde, 2002). As alterações demográficas, com redução das taxas de mortalidade e natalidade, indicam o prolongamento da expectativa de vida e 0 envelhecimento populacional, levando ao aumento da incidência de doenças crônico-degenerativas, especialmente as cardiovasculares e o câncer (Ministério 
da Saúde, 2005). O câncer constitui, assim, problema de saúde pública para o mundo desenvolvido - e também para nações em desenvolvimento, nas quais a soma de casos novos diagnosticados a cada ano atinge $50 \%$ do total observado nos cinco continentes (Organização Pan-Americana da Saúde, 2002).

No Brasil, a distribuição dos diferentes tipos de câncer sugere uma transição epidemiológica em andamento. Com o recente envelhecimento da população, que projeta o crescimento exponencial de idosos, é possível identificar um aumento expressivo na prevalência do câncer, o que demanda dos gestores do Sistema Único de Saúde (SUS) imenso esforço para a oferta de atenção adequada aos doentes. Esta perspectiva deixa clara a necessidade de grande investimento na promoção de saúde, na busca da modificação dos padrões de exposição aos fatores de risco para o câncer. Ao mesmo tempo em que é nítido o aumento da prevalência de cânceres associados ao melhor nível socioeconômico - mama, próstata e cólon e reto - simultaneamente, temos taxas de incidência elevadas de tumores geralmente associados à pobreza - colo do útero, pênis, estômago e cavidade oral. Esta distribuição certamente resulta de exposição diferenciada a fatores ambientais relacionados ao processo de industrialização, como agentes químicos, físicos e biológicos, e das condições de vida, que variam de intensidade em função das desigualdades sociais (INCA, 2006)

Os tipos de câncer de maior incidência no mundo são o de pulmão $(1,8$ milhão), o de mama (1,7 milhão), o de intestino (1,4 milhão) e o de próstata ( 1,1 milhão). Nos homens, os mais frequentes são o de pulmão (16,7\%), o de próstata 
(15,0\%), o de intestino (10,0\%), o de estômago (8,5\%) e o de fígado (7,5\%). Em mulheres, as maiores frequências encontradas são o de mama $(25,2 \%)$, o de intestino $(9,2 \%)$, o de pulmão $(8,7 \%)$, o de colo do útero $(7,9 \%)$ e o de estômago (4,8\%) (INCA, 2015).

A estimativa para o Brasil, biênio 2016-2017, aponta a ocorrência de cerca de 600 mil casos novos de câncer. Excetuando-se o câncer de pele não melanoma (aproximadamente 180 mil casos novos), ocorrerão cerca de 420 mil casos novos de câncer. O perfil epidemiológico observado assemelha-se ao da América Latina e do Caribe, onde os cânceres de próstata (61 mil) em homens e mama (58 mil) em mulheres serão os mais frequentes. Sem contar os casos de câncer de pele não melanoma, os tipos mais frequentes em homens serão próstata $(28,6 \%)$, pulmão $(8,1 \%)$, intestino $(7,8 \%)$, estômago $(6,0 \%)$ e cavidade oral $(5,2 \%)$. Nas mulheres, os cânceres de mama $(28,1 \%)$, intestino $(8,6 \%)$, colo do útero $(7,9 \%)$, pulmão $(5,3 \%)$ e estômago $(3,7 \%)$ figurarão entre os principais (INCA, 2015) 


\subsection{Câncer colorretal}

O câncer colorretal (CCR) é a terceira causa mais comum de câncer no mundo, atrás apenas de câncer de pulmão e de mama (Mihajlović et al., 2013). Apresenta incidência variável nos diferentes países, predominando nos economicamente mais ricos e industrializados como a América do Norte, a Europa setentrional, Nova Zelândia e Austrália. Incidências menores são registradas na América do Sul, sudoeste da Ásia, África equatorial e Índia. Nesta última, a incidência varia de 3,5 por 100 mil habitantes, enquanto nos EUA, no Estado de Connecticut, o CCR ocupa o segundo lugar dentre as neoplasias mais prevalentes em homens, seguindo-se apenas ao câncer do pulmão e o terceiro em mulheres, depois do câncer de mama e pulmão (Mihajlović, Pechlivanoglou, 2013; HabrGama,2005).

Estimam-se, para 2016, no Brasil, 16.660 casos novos de câncer de cólon e reto em homens e de 17.620 em mulheres. Esses valores correspondem a um risco estimado de 16,84 casos novos a cada 100 mil homens e 17,10 para cada 100 mil mulheres (INCA, 2015)

Os fatores de risco relacionados ao desenvolvimento da doença são: idade, sexo masculino, pólipos colônicos, história individual ou familiar de câncer colorretal, fatores ambientais (dieta com consumo exagerado de carne vermelha e gorduras, obesidade, tabagismo, sedentarismo e diabetes melito), colite ulcerativa e doença de Crohn ( Mihajlović et al., 2013 ). A história familiar é outro 
fator de risco importante para o aparecimento do câncer colorretal, mesmo que de forma esporádica. A presença de um parente de primeiro grau com a doença aumenta em 2 a 3 vezes o risco, particularmente se em idade jovem. As síndromes hereditárias incluem a polipose adenomatosa familiar, a síndrome do tumor colorretal hereditário não polipoide e as síndromes com pólipos hamartomatosos (Garicochea et al., 2004).

O câncer de cólon e reto é considerado uma doença do "estilo de vida", em que a incidência é maior em países com hábito alimentar rico em consumo de carnes vermelhas e carnes processadas, pouca ingestão de frutas, legumes e verduras, alta prevalência de obesidade e sobrepeso, inatividade física, consumo de álcool e tabagismo. Estudos apontam que o consumo de alimentos ricos em fibras, como frutas, hortaliças, cereais integrais, feijões e sementes, assim como a prática regular de atividade física são considerados fatores protetores contra a doença. A história familiar do câncer de colón e reto, a predisposição genética ao desenvolvimento de doenças crônicas do intestino e a idade são outros fatores de risco para o desenvolvimento da doença. Tanto na incidência quanto na mortalidade, observa-se aumento nas taxas com o avanço da idade. Apesar disso, a maioria dos cânceres de cólon e reto se dá de forma esporádica, surgindo de mutações somáticas e evolução do clone celular tumoral (INCA, 2015)

A maior concentração de câncer colorretal (CCR) ocorre nas regiões Sul e Sudeste do Brasil (Brasil, 2006). Em relação à mortalidade, no Brasil o CCR representa a quinta causa de óbitos para ambos os sexos (Habr-Gama A, 2005). Representa $13,4 \%$ da mortalidade para todas as idades e $21 \%$ para a faixa entre 
60 e 64 anos (Ministério da Saúde, 2001). O padrão de mortalidade para este câncer acompanha também o de incidência, observando-se taxas mais elevadas nas regiões Sul e Sudeste. $\mathrm{Na}$ análise da série histórica dos índices de mortalidade para o período compreendido entre 1979 e 2000, houve crescimento médio anual de $3,5 \%$. As taxas brutas passaram de 2,44 para 4,12 por 100.000 homens e de 2,80 para 4,29 por 100.000 mulheres, o que representou aumento de $69 \%$ e $60 \%$ respectivamente. Apesar do interesse deste assunto, no Brasil, como em muitos outros países, a taxa de sobrevida de cinco anos permanece estável em $50 \%$, podendo chegar a $70 \%$ quando o atendimento é realizado em centros especializados em cirurgia colorretal (Ministério da Saúde, 2005). Somente 41\% de todos os tumores colorretais são diagnosticados e tratados em estadio localizado, sem envolvimento linfático. O índice de sobrevida de cinco anos, quando o tumor é circunscrito à parede retal é de $70 \%$, baixando para $40 \%$ para aqueles com doença não localizada. Nos doentes cujo CCR é detectado em fase assintomática, o índice de sobrevida de cinco anos alcança 90\% (Habr-Gama, 2005).

O câncer colorretal não costuma apresentar sintomas nos estágios iniciais, o que pode dificultar sua detecção precoce. Dentre os sintomas mais comuns estão: dor abdominal, alteração do hábito intestinal, hematoquezia ou melena, bem como, fraqueza, anemia e perda de peso (Mihajlović et al., 2013). Conforme a localização, os tumores do cólon direito cursam com anemia, devido à perda sanguínea assintomática. Os tumores do cólon esquerdo alteram o hábito intestinal devido à obstrução, originária da consistência endurecida das fezes e do 
menor diâmetro do cólon. Alguns sintomas menos comuns são as fístulas para bexiga (causa infecção de repetição e/ou eliminação de fezes pela urina), vagina ou pele (Nebuloni et al., 2013).

A taxa de sobrevida global em cinco anos varia entre $40 \%$ e $50 \%$, não sendo observadas diferenças significativas entre países desenvolvidos e em desenvolvimento. Esse relativo bom prognóstico faz com que o câncer de cólon e reto seja o segundo tipo de câncer mais prevalente em todo o mundo, com aproximadamente 2,4 milhões de pessoas vivas diagnosticadas com essa neoplasia (Ministério da Saúde, 2007). As metástases à distância são frequentes no fígado, pulmões e peritônio. Metástases em ossos e sistema nervoso central são raras (Habr-Gama, 2005). A presença de doença inflamatória intestinal é fator de risco para o câncer colorretal. O risco de câncer com a retocolite ulcerativa está relacionado com a extensão e duração da doença, particularmente após 10 anos. Apesar de menos dados disponíveis, a doença de Crohn parece também ser um fator predisponente. Outras comorbidades predisponentes são a acromegalia e a ureterossigmoidostomia (Sociedade Brasileira de Cancerologia, 2011). A detecção precoce é considerada passo fundamental no manejo dos tumores de cólon nos dias atuais. A Sociedade Americana do Câncer recomenda o screening a partir dos 50 anos, com sangue oculto anual e retossigmoidoscopia (RSC) flexível a cada 5 anos ou enema opaco a cada 5 anos ou colonoscopia a cada 10 anos ou colonografia virtual a cada 5 anos (Habr-Gama, 2005). 
A história natural do câncer de cólon e reto propicia condições ideais para prevenção e detecção precoce da doença. Métodos endoscópicos (colonoscopia) e pesquisa de sangue oculto nas fezes são meios de detecção precoce para essa neoplasia, pois são capazes de detectar pólipos adenomatosos e diagnosticar o câncer em estágio inicial. A sobrevida do câncer de colón e reto é altamente dependente do estágio da doença. Em geral, quanto mais cedo diagnosticada a doença, maior a sobrevida. Países com alta expectativa de vida e com bom acesso aos serviços de saúde apresentam melhores taxas de sobrevida. A sobrevida média global em cinco anos aumentou em 22 países, e ficou em torno de $60 \%$ na maioria dos países desenvolvidos durante o período de 2005 a 2009 (INCA, 2015).

O diagnóstico é realizado por meio da biopsia durante a colonoscopia (a retosigmoidoscopia é insuficiente, já que a presença de tumores sincrônicos pode chegar a 5\%) e o estadiamento é realizado por meio do exame físico, das tomografias de tórax, abdome e pelve e dosagem do CEA (Sociedade Brasileira de Cancerologia, 2011). Recomenda-se para o estadiamento dos tumores colorretais os seguintes exames: raio-x de tórax, ultrasson ou tomografia de abdômen total e pelve (preferível), dosagem de CEA e exames laboratoriais, colonoscopia, toque retal, ressonância de pelve (ou ultrasson endoscópico) e tomografia de tórax para tumores de reto (Manual de condutas em oncologia, 2010). O sistema de estadiamento utilizado para definir extensão da doença ao diagnóstico é a classificação TNM, a seguir (Quadro 1): 
Quadro 1. Estadiamentos do câncer colorretal no modelo TNM (tumor, nódulo e metástase) segundo o American Joint Committee on Cancer (2002)

\begin{tabular}{|c|c|c|c|}
\hline Estadio & T & N & M \\
\hline 0 & Tis & N0 & M0 \\
\hline I & TI-2 & N0 & M0 \\
\hline IIA & T3 & N0 & M0 \\
\hline IIB & T4 & N0 & M0 \\
\hline IIIA & T1-2 & NI & M0 \\
\hline IIIB & T3-4 & NI & M0 \\
\hline IIIC & Qualquer T & N2 & MI \\
\hline IV & Qualquer T & Qualquer N & \\
\hline
\end{tabular}

FONTE: American Joint Committee on Cancer 2002

- TX: tumor não avaliável

- Tis: carcinoma in situ

- T1: tumor infiltra a submucosa

- T2: tumor infiltra a muscular própria

- T3: tumor infiltra até a subserosa ou gordura perirretal

- T4: tumor invade outros órgãos ou estruturas e/ou perfura o peritônio visceral

- N0: sem metástases linfonodais

- N1: metástases em 1 a 3 linfonodos regionais

- N2: metástases em 4 ou mais linfonodos regionais

- M0: sem metástases a distância 
- M1: metástases à distância

\subsection{Tratamento}

O tratamento cirúrgico é o de escolha para a maioria dos tumores colorretais e é oferecido a cerca de $90 \%$ dos doentes com câncer de colon (Lacy et al., 2008). O objetivo do tratamento cirúrgico é a ressecção ampliada do segmento colônico comprometido, incluindo a remoção dos linfonodos na área de

drenagem do mesmo. A extensão da ressecção é determinada pelo suprimento sanguíneo e a distribuição locorregional dos linfonodos. A ressecção deve incluir cinco centímetros de cólon de cada lado do tumor, apesar da margem comumente ser maior devido à ligadura arterial e isquêmica. O número de linfonodos ressecados durante a cirurgia revela a qualidade do procedimento, devendo ocorrer no mínimo a remoção de 12 linfonodos (Nebuloni et al., 2013).

O tratamento quimioterápico consiste na utilização de agentes químicos, isolados ou em combinação, com intuito de combater a doença. É uma modalidade de tratamento sistêmico da doença, que permite o tratamento também de metástases não detectáveis. Pode ser aplicada conforme a finalidade: adjuvante, neoadjuvante e paliativa (Mihajlović et al., 2013).

Os doentes com adenocarcinoma de cólon, estadios 0 e I, apresentam probabilidade de cura de $90 \%$ com a cirurgia. Os doentes com estadios de II em 
diante são, predominantemente, tratados com terapia quimioterápica (Scheithauer, 1993). A quimioterapia tem por princípio aumentar a sobrevida global, associandose a este benefício um incremento na qualidade de vida com a estabilização da doença (Grothey et al., 2005). Estão indicadas as quimioterapias baseadas em fluorouracil e leucovorim ou capecitabina associados com oxaliplatina ou irinotecano para doentes com câncer de colón metastático. Os esquemas considerados como primeira linha são baseados nos esquemas FOLFOX e FOLFIRI, que usam oxaliplatina e irinotecano, respectivamente (Andre et al., 2004).

Até recentemente, o fluorouracil era o único tratamento sistêmico efetivo para o câncer colorretal. O ácido folínico (leucovorin) pode potencializar o efeito do fluorouracil, por isso são utilizados em conjunto. A associação de fluorouracil e ácido folínico (FL) reduz o tamanho do tumor em $50 \%$ ou mais (resultado objetivo) em aproximadamente $20 \%$ dos doentes com câncer colorretal avançado e prolonga a mediana de sobrevida de aproximadamente 6 meses (somente com a cirurgia) para 11 meses. Quando utilizado na adjuvância, após ressecção completa do tumor que atingiu os linfonodos regionais (estadio III), FL aumenta a probabilidade de permanecer livre de doença, por cinco anos, de $42 \%$ para $58 \%$ e a sobrevida global em 5 anos, de 51\% para 64\%. O uso do FL em adjuvância, em doentes sem comprometimento de linfonodos regionais (estadio II) é controverso. Para esse estadio, a probabilidade de sobrevida livre de doença, em 5 anos, passa de $72 \%$ para $75 \%$ com o tratamento, sem alterar a sobrevida global em 5 anos, que gira em torno de $80 \%$ (Meyers et al., 2005). 


\subsubsection{Quimioterapia}

A quimioterapia é o método que utiliza compostos quimioterápicos no tratamento de doenças causadas por agentes biológicos. Quando aplicada ao câncer, a quimioterapia é chamada de quimioterapia antineoplásica ou quimioterapia antiblástica (Ministério da Saúde, 2005). O primeiro quimioterápico antineoplásico foi desenvolvido a partir do gás mostarda, usado nas duas guerras mundiais como arma química. Após a exposição de soldados a este agente, observou-se que eles desenvolveram hipoplasia medular e linfóide, o que levou ao seu uso no tratamento dos linfomas malignos. A partir da publicação, em 1946, dos estudos clínicos feitos com o gás mostarda e das observações sobre os efeitos do ácido fólico em crianças com leucemias, verificou-se avanço crescente da quimioterapia antineoplásica (Aguiar et al., 2008).

Atualmente, quimioterápicos mais ativos e menos tóxicos encontram-se disponíveis para uso na prática clínica. Os avanços verificados nas últimas décadas, na área da quimioterapia antineoplásica, têm facilitado consideravelmente a aplicação de outros tipos de tratamento de câncer e permitido maior número de curas (Ministério da Saúde, 2005). Aplicada em ciclos periódicos por via oral ou intravenosa, geralmente a sua administração não requer internação. A combinação de várias drogas quimioterápicas tem maior eficácia em promover maior resposta por dose administrada (Bonassa, 2005). A quimioterapia como tratamento antineoplásico sistêmico é classificada em três grandes setores: neoadjuvante, terapêutica e adjuvante (Chu, 2001). A quimioterapia pode ser 
utilizada em combinação com a cirurgia e a radioterapia. De acordo com as suas finalidades, é classificada de acordo com o Instituto Nacional do Câncer, 2006 em:

- Curativa - quando é usada com o objetivo de se conseguir o controle completo do tumor, como nos casos de doença de Hodgkin, leucemias agudas, carcinomas de testículo, coriocarcinoma gestacional e outros tumores.

- Adjuvante - quando se segue à cirurgia curativa, tendo como objetivo esterilizar células residuais locais ou circulantes, diminuindo a incidência de metástases à distância. Exemplo: quimioterapia adjuvante aplicada em caso de câncer de mama operado em estágio II

- Neoadjuvante ou prévia - quando indicada para se obter a redução parcial do tumor, visando permitir uma complementação terapêutica com a cirurgia e/ou radioterapia. Exemplo: quimioterapia pré-operatória aplicada em caso de sarcomas ósseos e de partes moles.

- Paliativa - não tem finalidade curativa. É usada com a finalidade de melhorar a qualidade da sobrevida do doente. É o caso da quimioterapia indicada para carcinoma indiferenciado de células pequenas do pulmão. 


\subsubsection{Efeitos adversos do tratamento quimioterápico}

Os agentes antineoplásicos vêm sendo amplamente utilizados no tratamento adjuvante ou paliativo de neoplasias malignas. Contudo, por ser uma forma de tratamento sistêmica, a quimioterapia atinge indiscriminadamente todas as células do organismo, principalmente células de rápida proliferação, produzindo efeitos adversos, os quais estão diretamente relacionados ao estado do doente, estadiamento da doença e também das drogas usadas (Bonassa, 2000).

Existem vários efeitos que podem ocorrer após a administração de fármacos citotóxicos. Cada quimioterápico tem seu perfil de toxicidade e os efeitos colaterais têm relação direta com a droga utilizada. São considerados efeitos secundários os sinais e sintomas que surgem após a sua administração e que se prolongam mesmo após a terapêutica ter cessado, podendo causar lesões reversíveis ou mesmo irreversíveis no doente (Bonassa, 2000). Os efeitos colaterais mais comuns são: a mielotoxicidade, fadiga, diarréia, toxicidade pulmonar, cardiotoxicidade, mucosite, náuseas e vômitos (Gimenez, 2003). A mielotoxicidade é um problema clínico muito frequente em vários regimes de quimioterapia, sendo dose e droga dependente. Representa o efeito secundário

mais importante e comum desses tratamentos e está ligada diretamente a capacidade da medula óssea em repor os elementos sanguíneos circulantes destruídos pelos mesmos (Bonassa, 2000).

Os componentes da medula óssea mais vulneráveis à quimioterapia são os leucócitos e as plaquetas. Desta forma, há um aumento de risco de ocorrência de 
sangramentos e infecções nos doentes que estão recebendo quimioterapia (Gimenez, 2003). A toxicidade hematológica se expressa sobre as três linhas medulares: hemácias, leucócitos e plaquetas. Em função da longa meia-vida de hemácias, o desenvolvimento de anemia é tardio. A concentração de hemoglobina guarda relação com a contagem de hemácias e é utilizada para monitorar a resposta à terapia. A neutropenia é a principal alteração hematológica vista em vários estudos sobre quimioterapia adjuvante. A literatura afirma que pessoas de raça negra apresentam valores aceitáveis mais baixos para normalidade de número de leucócitos (Starlin et al., 2004). O tempo decorrido entre a administração da droga e a constatação do menor valor de contagem hematológica chama-se NADIR. A recuperação medular deve seguir-se a esse período, até atingir valores próximos do normal. A maioria dos agentes antineoplásicos tem um NADIR que varia entre sete e catorze dias (Bonassa, 2000). De acordo com Chu e DeVita (2001) e Gimenez (2003), os quimioterápicos se classificam em:

- Agentes alquilantes: capazes de quebrar a sequência da molécula de DNA. Exemplos: ciclofosfamida, melfalan, mitomicina.

- Análogos da platina: interferem na replicação do DNA, atuam também na replicação do RNA e síntese de proteínas. São exemplos: cisplatina, carboplatina, oxaliplatina.

- Antimetabólicos: classe de drogas antineoplásicas com maior espectro de ação na prática oncológica. Exemplos: metotrexate, 5-fluorouracil. 
- Agentes que atuam na topoisomerase: inibem a topoisomerase I e II, impedindo a síntese de DNA. Exemplos: antracíclicos, análogos da campitotecina, mitoxantrona.

- Agentes que atuam nos microtúbulos: bloqueiam a progressão do ciclo celular agindo sobre os microtúbulos. Exemplos: alcalóides da vinca, taxanos, extramustine.

O regime de quimioterapia varia com o tipo e estágio da neoplasia e as condições clínicas do doente. É realizado em ciclos que podem ser constituídos apenas de um dia de aplicação até uma combinação de vários dias. Cada ciclo é repetido dentro de um intervalo pré-fixado de dias, cuja finalidade é a recuperação do organismo aos efeitos colaterais da quimioterapia (Gimenez, 2003). Os principais problemas nutricionais durante a quimioterapia relacionam-se a sintomas gastrointestinais causados pelo efeito das drogas tóxicas sobre as células da mucosa que se desenvolvem rapidamente, uma situação de anemia associada a efeitos da medula óssea, e a um efeito da toxicidade sistêmica generalizada sobre o apetite. Estomatite, náusea, diarréia e má absorção contribuem para várias intolerâncias alimentares (Perry, 2001).

Embora menos conhecidos, estudos sugerem que, além dos efeitos sistêmicos, a quimioterapia pode levar a alterações cognitivas nos doentes (Ahles, 2007; Tannock et al, 2004). Essas alterações, apesar de menos estudadas, têm recebido crescente atenção devido a repercussão que esses efeitos causam na vida daqueles que sobreviveram após um tratamento para o câncer. Estudos tem 
demonstrado associação entre quimioterapia e perda cognitiva, que podem persistir entre 17 e $34 \%$ dos doentes em longo prazo (Ahles, 2007). Estudo de Wieneke e Dienst (1995) aponta que $75 \%$ dos doentes apresentam prejuízo da função cognitiva após terem sido submetidos a tratamento com drogas antineoplásicas. As funções cognitivas são compostas por memória, raciocinio, atenção, aprendizado, imaginação, linguagem, cálculo e habilidades espaçovisuais, sendo fundamentais na relação do indivíduo consigo mesmo e com o meio em que vive (Brezden et al., 2000). O prejuízo cognitivo tem consequências diretas na vida do doente, interferindo nas atividades de vida diária relacionadas à capacidade do indivíduo em executar, de forma independente, as atividades consideradas essenciais à sua sobrevivência e, consequentemente, na manutenção de suas relações sociais, prejudicando, tambem, o desempenho profissional, causando grandes impactos na sua qualidade de vida (Hecktheuer, 2009).

\subsection{Neuropatias periféricas induzidas por quimioterapia}

A neuropatia periférica induzida por quimioterapia (NPIQ) é um dos efeitos colaterais mais comuns e indesejáveis no tratamento do câncer colorretal (Leonard et al., 2005, Land et al., 2007) e constitui um fator limitante para o uso de drogas potencialmente eficazes, sendo, muitas vezes, necessária a redução da dose ou a interrupção do tratamento (Wang et al., 2007, Gamelin et al., 2002) . A prevalência de neuropatia periférica relacionada ao uso de agentes 
quimioterápicos vem aumentando devido ao avanço na terapia adjuvante pósoperatória, que proporcionou uma maior sobrevida para os doentes com esta patologia (Land et al., 2007). Recentemente, a adição de oxaliplatina aos regimes já utilizados como primeira linha de tratamento tem se destacado, tanto pela sua eficácia, quanto pela neurotoxicidade que acarreta, e apresenta, como uma das principais complicações, a neuropatia periférica aguda ou crônica (Andre et al., 2009; Park et al., 2010).

Diferentes autores demonstraram a ocorrência de neuropatia periférica sensitiva associada ao uso da oxaliplatina (Wilson et al., 2002; Petrioli et al., 2006). Essa neuropatia é caracterizada por disestesia, hipoestesia e/ou parestesia distal, e esses sintomas estão correlacionados com a dose administrada, aumentando de intensidade e duração conforme o efeito cumulativo da droga (Leonard et al., 2005). A neuropatia sensitiva é reversível e responde à reduções de dose ou interrupção do tratamento, porém ela pode persistir durante meses, e, nestes casos, pode afetar a capacidade funcional do doente e a habilidade de realizar suas atividades de vida diária (Leonard et al., 2005; Gamelin et al., 2002). Os doentes submetidos a esquemas de quimioterapia contendo oxaliplatina também podem apresentar manifestações neurológicas agudas (Petrioli et al., 2006; Mathias et al., 2007). Estas iniciam durante a infusão, dentro de minutos ou horas, ou mesmo um a dois dias após a administração, apresentando resolução espontânea em poucos dias (Wang, et al., 2007; Andre et al., 2009). Os sinais e sintomas podem incluir disestesia, hipoestesia e parestesia induzidas pelo frio, os quais geralmente acometem mãos e pés, mas podem ocorrer também ao redor da 
boca e laringofaringe. Outras disfunções sensitivas e motoras também são relatadas, tais como diplopia, rigidez mandibular, cãibra ou espasmo muscular, fraqueza generalizada, neuromiotonia e outros sinais de hiperexcitabilidade de nervos periféricos (Leonard et al., 2005; Mathias et al., 2007). Este quadro de desconforto representa uma das principais queixas dos doentes em acompanhamento para neoplasia colorretal na clínica oncológica, interferindo em suas atividades de vida diária, com consequente perda de qualidade de vida.

\subsection{Dor neuropática induzida por quimioterapia}

Dor neuropática periférica induzida pela quimioterapia (DNIQ) é um efeito adverso grave da farmacoterapia quimioterápica. A DNIQ pode limitar a dosagem de fármacos quimioterápicos, atrasar ainda mais ciclos de tratamento, ou levar à interrupção da terapia. Os sintomas variam de dor pós-tratamento precoce, tal como a síndrome da dor aguda de paclitaxel, parestesias, ataxia sensorial, e alodinia mecânica e fria. As extremidades do corpo são afetadas, predominantemente, mas a dor pode continuar ao longo dos membros durante tratamentos subsequentes (Pachman et al., 2011; Grisold, et al., 2012). Medicações que causam DNIQ incluem os taxanos vulgarmente utilizados, e derivados de platina, alcalóides de vinca, bem como a ixabepilona mais raramente utilizados, bortezomibe e talidomida (Manji, 2011; Argyriou et al., 2012) Apesar dos mecanismos fisiopatológicos comuns, neuropatias induzidas por paclitaxel ou 
vincristina envolvem um componente inflamatório forte que parece ser menos grave durante DNIQ induzida por oxaliplatina. Estas inflamações resultam do componente a partir da ativação da microglia, astrócitos e células gliais satélites no corno dorsal da medula espinhal, o que leva à produção e libertação de mediadores proalgésicos, tais como o fator de necrose tumoral (TNF) e IL-1 $\beta$ (Peters et al., 2007; Zhu et al., 2013). Atualmente, não há opções de tratamento concorrentes disponíveis para a prevenção de DNIQ, e só existem algumas estratégias farmacológicas para seu tratamento (Hershman, 2014). As drogas analgésicas que já estão em uso para o tratamento da dor neuropática (Quadro 2), tais como amitriptilina ou gabapentina, não conseguiram aliviar DNIQ em ensaios clínicos randomizados, controlados por placebo (Rao et al., 2007; Kautio et al., 2009). 
Quadro 2. Medicações usualmente utilizadas para tratar DNIQ

\begin{tabular}{|c|c|c|c|c|c|}
\hline Substância & Dose & Duração & $\begin{array}{l}\text { Droga } \\
\text { associada à } \\
\text { DNIQ }\end{array}$ & $\begin{array}{l}\text { Número de } \\
\text { doentes }\end{array}$ & $\begin{array}{l}\text { Resultados em } \\
\text { estudos }\end{array}$ \\
\hline Amitriptilina & $\begin{array}{l}\text { Inicialmente, } \\
25 \mathrm{mg} / \text { dia } \\
\text { aumentados a } \\
\text { cada semana, } \\
\text { para no } \\
\text { máximo } \\
100 \mathrm{mg} / \mathrm{dia}\end{array}$ & 5 semanas & $\begin{array}{l}\text { Taxanos } \\
\text { Derivados de } \\
\text { platina } \\
\text { Alcalóides }\end{array}$ & 114 & $\begin{array}{l}\text { Nenhum } \\
\text { benefício ao } \\
\text { comparar com } \\
\text { placebo } \\
\text { (Kautio et al., } \\
\text { 2009) }\end{array}$ \\
\hline Gabapentina & $300 \mathrm{mg} / \mathrm{dia}$ & 6 semanas & $\begin{array}{l}\text { Taxanos } \\
\text { Derivados de } \\
\text { platina } \\
\text { Alcalóides }\end{array}$ & 115 & $\begin{array}{l}\text { Nenhum } \\
\text { benefício ao } \\
\text { comparar com } \\
\text { placebo } \\
\text { (Rao et al., 2007) }\end{array}$ \\
\hline Lamotrigina & $\begin{array}{l}\text { Inicialmente, } \\
25 \mathrm{mg} / \mathrm{dia} \\
\text { aumentados a } \\
\text { cada semana, } \\
\text { para no } \\
\text { máximo } \\
300 \mathrm{mg} / \mathrm{dia}\end{array}$ & 10 semanas & $\begin{array}{l}\text { Taxanos } \\
\text { Derivados de } \\
\text { platina } \\
\text { Alcalóides }\end{array}$ & 131 & $\begin{array}{l}\text { Nenhum } \\
\text { benefício ao } \\
\text { comparar com } \\
\text { placebo } \\
\text { (Rao et al., 2008) }\end{array}$ \\
\hline Duloxetina & $\begin{array}{l}\text { 30mg/dia por } 1 \\
\text { semana e } \\
60 \mathrm{mg} / \text { dia nas } \\
\text { semanas } \\
\text { seguintes }\end{array}$ & 4 semanas & $\begin{array}{l}\text { Taxanos } \\
\text { Derivados de } \\
\text { platina (na } \\
\text { maioria, } \\
\text { Oxaliplatina) }\end{array}$ & 181 & $\begin{array}{l}\text { Redução da } \\
\text { DNIQ } \\
\text { (Smith et al., } \\
\text { 2013) }\end{array}$ \\
\hline
\end{tabular}

Os resultados de estudos duplo-cegos, ensaios clínicos randomizados controlados com placebo que avaliaram a eficácia do tratamento para DNIQ causadas por derivados de platina (carboplatina, cisplatina e oxaliplatina), taxanos (paclitaxel e docetaxel) ou alcalóides de vinca (vincristina e vinblastina). Abreviações: DNIQ, dor neuropática induzida por quimioterapia. FONTE: Sisignano et al., 2014. P 697. Adaptado. 


\subsection{Oxaliplatina}

A oxaliplatina (oxalatoplatinum trans-I-diaminociclo-hexano, L-OHP) foi desenvolvida nos anos 70 como uma das dezenas de compostos de platina numa tentativa de obter análogos com um índice terapêutico mais favorável (Cvitkovic, 1998). Estes compostos causaram entusiasmo imediato quando eles pareciam não apresentar resistência cruzada com a cisplatina e carboplatina, e ter um perfil de atividade pré-clínica distinta desses dois últimos agentes. No entanto, o interesse nestes agentes diminuiu após a ocorrência de toxicidade neurológica grave nos estudos de fase I com tetraplatina (ormaplatina), o composto de platina mais promissor na época (Vandamme et al., 2014). Mais de uma década mais tarde, testes clínicos de oxaliplatina revelaram sua atividade antitumoral significativa e perfil de toxicidade favorável. De fato, a oxaliplatina mostrou-se eficaz contra o CCR, tanto como primeira linha e segunda linha de tratamento de tumores de 5-fluorouracil refratário (Machover et al., 1996). Além disso, a oxaliplatina foi eficaz contra o carcinoma de ovário avançado, tanto o pré-tratado quanto o não tratado (Chollet et al., 1996). É importante notar que a oxaliplatina não induz toxicidade renal ou hematológica associadas à cisplatina e carboplatina, os seus efeitos eméticos podem ser eficazmente controlados, e a sua toxicidade neurológica - em contraste com a maioria dos outros compostos de platina - é, na maioria dos casos, reversível (Machover et al., 1996; Chollet et al., 1996). 


\subsubsection{Mecanismos de ação}

Tal como todos os compostos de platina, a oxaliplatina deve ser convertida em espécies reativas em reações de deslocamento na corrente sanguínea e no ambiente intracelular. Assim, nucleófilos fracos tais como bicarbonatos de sangue ou de di-hidrogenofosfato intracelular deslocam o grupo oxalato (Cvitkovic, 1998; Fink et al., 1996), resultando na formação de intermediários instáveis que são facilmente hidrolizados para deslocar 1,2-DACH-platina. Esta última espécie é rapidamente convertida em monoaqua-1,2-DACH monochloroplatinum e 1,2$\mathrm{DACH}$, espécies de platina, que instantaneamente reagem com o DNA (Vandamme et al., 2014).

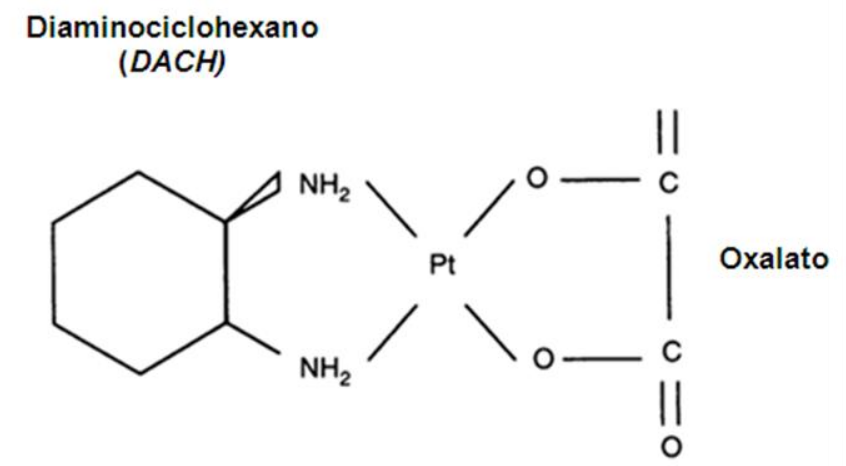

trans-1-dach (1R, 2R-dach) oxalatoplatino

Oxaliplatina

Fig 1. Estrutura química da Oxaliplatina segundo Bleiberg (1996). 
No entanto, ao contrário dos dois agentes citados anteriormente que atuam através de cis-diamina intermediária comum, os intermediários reativos de oxaliplatina retém o transportador 1,2-DACH. Isso tem duas consequências importantes. Em primeiro lugar, o anel de 1,2-DACH pode projetar para dentro do sulco maior de DNA, escapando do reconhecimento do complexo de reparação de emparelhamentos de enzimas (Fink et al., 1996). Em segundo lugar, a presença do volumoso grupo 1,2-DACH impede desvio replicativo, isto é, a síntese do DNA para além do local de dutos de DNA, tal como ocorre em linhas de células resistentes à cisplatina (Mamenta et al., 1994). O pobre reconhecimento de dutos de oxaliplatina pelo sistema de reparação de emparelhamentos pode explicar ainda mais a atividade seletiva da oxaliplatina, contra tumores que exibem incompatibilidade de reparação, tais como um subconjunto de carcinomas colorretais, ao contrário de cisplatina e carboplatina (Machover et al., 1996). Além disso, enquanto a perda de função desta reparação vai afetar a resposta apoptótica de células de tumor da cisplatina e carboplatina, isto não é o caso com a oxaliplatina. Acredita-se que os dutos DNA-platina formados inibem a replicação do DNA e a transcrição. Como tal, eles induzem a apoptose ou necrose em células cancerosas e se dividem rapidamente (Wafai et al., 2013). Entre as drogas anticâncer amplamente utilizada, os compostos de platina cisplatina e oxaliplatina são associados com várias formas de neurotoxicidade periférica. Dois padrões são exibidos: a forma aguda, neuropatia sensorial caracterizada por sintomas desencadeados pelo frio, e a neurotoxicidade cumulativa tardia que na maioria das vezes se manifesta como parestesias distais dolorosas e dormência nas 
extremidades e ataxia sensitiva, resultando em prejuízo funcional. A neuropatia aguda é devido a um efeito do sal de oxalato nos canais de sódio axonais. $O$ mecanismo patológico subjacente dos efeitos secundários tardios não é completamente compreendido (Xiao et al., 2012). Os compostos de platina têm uma elevada afinidade com o sistema nervoso periférico. Eles também podem afetar o sistema nervoso entérico. Estas interações podem resultar em alterações na secreção, o fluxo de sangue e motilidade (Wafai et al., 2013; Vera et al., 2011).

A oxaliplatina tem efeitos neuronais graves, tais como aumento da atividade dos canais iônicos dependentes de voltagem. Dentro das células, a oxaliplatina é degradada em oxalato e platina. Tais substâncias provocam anomalias na membrana neuronal e na atividade dos canais iônicos. Em camundongos, a injeção de oxalato provoca alodinia ao frio que parece ser aliviada pela infusão de uma combinação de $\mathrm{Ca}^{2}+\mathrm{Mg}^{2}$ (Gamelin, 2007; Sakurai et al., 2009). Vários canais potenciais receptor transientes (TRP) têm sido implicados em DNIQ. TRPA1 tem sido identificado como um mediador da alodínia mecânica ao frio, enquanto que o TRPV1, TRPM8 e TRPV4 são sensibilizados nos neurônios DRG (nos gânglios da raiz dorsal), deste modo reduzem o limiar de ativação destas células (Nassini et al., 2011). A oxaliplatina induz danos celulares. A ativação da p38 proteína quinase ativada por mitógenos, possivelmente por meio de reconhecimento de DNA causa danos em grupos de alta mobilidade (Scuteri, 2010). Se oxaliplatina pode induzir danos neuronais suficientes para provocar a expressão do marcador de dano neuronal ATF3, permanece o estresse oxidativo e inflamação controversial (Xiao et al., 2012). A produção de ROS foi 
observada em neurônios DGR isolectina IB4 durante a DNIQ induzida por oxaliplatina, possivelmente em resposta a disfunção mitocondrial (Zheng et al., 2011).

A maioria dos estudos se concentrou nas duas polineuropatias mais frequentes induzidas por oxaliplatina. A forma aguda, frequentemente manifestada por sintomas de "pressão fria", ocorre imediatamente após a infusão e geralmente é completamente reversível com o tempo de infusão prolongada ou o término da terapia. A segunda forma é a neurotoxicidade cumulativa com parestesia distal e dormência nas extremidades. Esta forma é dependente da dose (acima de 540 $\mathrm{mg} / \mathrm{m}^{2}$ ) e ocorre no final do processo de tratamento (Cersosimo, 2005). É a razão mais frequente para parar ou ajustar o tratamento e tem sequelas neurológicas de longo prazo que influenciam a qualidade de vida durante e após o tratamento. Consequentemente, esta é a complicação clínica mais importante. Apresentação de efeitos colaterais neurotóxicos que ocorrem após a interrupção da terapia tem sido descrita, raramente, nos casos (Argyriou et al., 2007).

O mecanismo subjacente da polineuropatia tardia induzida por oxaliplatina ainda é incerto. Acredita-se que a eficácia quimioterapêutica seja baseada na produção de DNA-platina que inibem a replicação do DNA e a transcrição. Como tal, eles induzem a apoptose ou necrose em células cancerosas e células que se dividem rapidamente (Xiao et al., 2012). Como neurônios sensoriais e gânglios da raiz dorsal são diferenciados e, portanto, amitótico, o mecanismo de lesão neuronal induzida por platina tem que ser diferente. A neurotoxicidade sensorial está provavelmente relacionada com o acesso de drogas ao invés de 
vulnerabilidade neuronal seletiva. A platina não pode atravessar a barreira sangue-cérebro. Suspeita-se que o principal local de acometimento seja o gânglio da raiz dorsal. Ambos os gânglios da raiz dorsal e neurônios pós-ganglionares autônomos não são protegidos pela barreira sangue-cérebro (Taieb et al., 2002). O desenvolvimento de modelos animais para o estudo prolongado de neurotoxicidade de platina tem sido difícil. A maioria dos animais tendem a desenvolver nefrotoxicidade grave antes da neurotoxicidade aparecer (Benarroch et al., 2008).

A neuropatia neurovegetativa devido ao uso de oxaliplatina foi relatada em estudos de casos. Taieb et al (2002) relataram quatro doentes com sinais neurológicos atípicos e sintomas após a quimioterapia contendo oxaliplatina. Alguns dos doentes experimentaram dificuldades de micção grave. Não é claro se isto é um resultado de uma neuropatia sensorial ou uma neuropatia neurovegetativa. A bexiga atônica pode dar resultado de dano para a parte sensorial do arco reflexo sacro, ou nas colunas da raiz dorsal ou posterior, ou, alternativamente, pode ser resultado de uma paralisia das fibras parassimpáticas que controlam a musculatura vesical (Taieb, 2002).

Apenas pesquisas limitadas têm sido feitas para avaliar possível neuropatia entérica como um efeito colateral da quimioterapia à base de platina. Houve alguns estudos sobre o efeito de oxaliplatina em neurônios mioentéricos e motilidade do cólon em modelos de ratos. A administração em longo prazo de oxaliplatina induz uma perda neuronal substancial que se correlaciona com uma redução da frequência e velocidade de propagação de complexos motores (Wafai 
et al., 2013). O modelo mais recente em ratos sugere que oxaliplatina também pode induzir a apoptose dos próprios neurônios mioentéricos, mas os mecanismos exatos ainda não foram estudados.

\subsection{Prevalência e características de DNIQ e NPIQ}

A seguir, quadro 3 comparativo de estudos que em geral, avaliaram prevalência e características de neuropatia induzida por oxaliplatina. A tabela contem os seguintes dados: autores e ano, título do trabalho, revista em que foi publicado, objetivos, qual a prevalência encontrada para DNIQ e para NPIQ, amostra, numero de visitas avaliativas durante a quimioterapia, métodos, instrumentos específicos para avaliar DNIQ e NPIQ e quais características foram encontradas. Após analizar as tabelas pode-se concluir que alguns apresentaram uma amostra pequena e que poucos estudos utilizaram instrumentos específicos para dor e/ou neuropatia, ou não citam quais caraterísticas foram encontradas.

A busca foi realizada através do site PubMed, e os descritores foram peripheral neuropathy, chemotherapy e colorrectal cancer, resultando em 377 trabalhos encontrados. Destes deletaram-se os que tinham animais não humanos como amostra (como ratos e chipanzés). Também foram excluídos trabalhos que avaliavam população com neuropatia previa ou trabalhos cuja avaliação ocorresse 
após o tempo de quimioterapia, não durante. Assim concluiu-se com um total de 26 trabalhos. 
Quadro 3. Estudos que avaliaram NPIQ e DNIQ, seus autores, objetivos, tempo de avaliação, prevalência de DNIQ e NPIQ, amostra, número de avaliações durante a quimioterapia, método, instrumentos utilizados, características encontradas e síntese dos achados principais.

\begin{tabular}{|c|c|c|c|c|c|c|c|c|c|c|}
\hline Autores & Objetivo & $\begin{array}{l}\text { Tempo de } \\
\text { avaliação }\end{array}$ & $\begin{array}{l}\text { Prevalencia } \\
\text { DNIQ }\end{array}$ & $\begin{array}{l}\text { Prevalencia } \\
\text { NPIQ }\end{array}$ & Amostra & $\begin{array}{l}\text { Número de } \\
\text { avaliações } \\
\text { durante qt }\end{array}$ & Método & $\begin{array}{l}\text { Intrumentos de } \\
\text { avaliação }\end{array}$ & Características & $\begin{array}{l}\text { Achados } \\
\text { principais }\end{array}$ \\
\hline $\begin{array}{l}\text { Machover } \\
\text { et al } \\
1996\end{array}$ & $\begin{array}{l}\text { Caracterizar e } \\
\text { avaliar a } \\
\text { incidencia de } \\
\text { toxicidade depois } \\
\text { do tratamento de } \\
\text { doentes com CCR } \\
\text { antes resistentes } \\
\text { a tratamentos com } \\
\text { fluoropirimidinas. }\end{array}$ & 6 meses & NA & $98 \%$ & 58 & 2 & $\begin{array}{l}58 \text { doentes. } \\
\text { Todos os } \\
\text { doentes tinham } \\
\text { tumor } \\
\text { progressivo. }\end{array}$ & Exame clinico & $\begin{array}{l}\text { Disestesia } \\
\text { Parestesia } \\
\text { Hipoestesia }\end{array}$ & $\begin{array}{l}\text { A incidencia de } \\
\text { neuropatia } \\
\text { sensorial } \\
\text { periferica foi de } \\
23 \% \text { com grau } 3 \\
\text { e } 8 \% \text { com grau } 4\end{array}$ \\
\hline $\begin{array}{l}\text { Cascinu } \\
\text { et al } \\
2002\end{array}$ & $\begin{array}{l}\text { Prevenir } \\
\text { neurotoxicidade } \\
\text { induzida por } \\
\text { oxaliplatina } \\
\text { avaliando a } \\
\text { eficácia de } \\
\text { glutationa (GSH). }\end{array}$ & 6 meses & $\overline{N A}$ & $\begin{array}{l}43 \% \\
\text { ativo } \\
79 \% \\
\text { placebo }\end{array}$ & 52 & 4 & $\begin{array}{l}\text { Doentes foram } \\
\text { randomizados } \\
\text { para receber } \\
\text { glutationa antes } \\
\text { da oxaliplatina } \\
\text { ou o tratamento } \\
\text { comum. } \\
\text { Realizada } \\
\text { avaliação } \\
\text { neurológica e } \\
\text { eletrofisiológica. }\end{array}$ & $\begin{array}{l}\text { NCl-CTCAE } \\
\text { Avaliação de } \\
\text { força e reflexos } \\
\text { Sural sensory } \\
\text { nerve } \\
\text { conduction }\end{array}$ & $\begin{array}{l}\text { Parestesia } \\
\text { Ataxia } \\
\text { Diminuição de } \\
\text { reflexos }\end{array}$ & $\begin{array}{l}\text { No quarto ciclo } \\
12,1 \% \text { do grupo } \\
\text { GSH } \\
\text { apresentaram } \\
\text { NPIQ e no } \\
\text { placebo } 18,9 \% \text {. } \\
\text { Depois do ciclo } \\
13,7 \% \text { do } \\
\text { placebo } \\
\text { apresentaram } \\
\text { neuropatia contra } \\
3,4 \% \text { do GSH. }\end{array}$ \\
\hline $\begin{array}{l}\text { Wilson } \\
\text { et al } \\
2002\end{array}$ & $\begin{array}{l}\text { Avaliar a } \\
\text { hipersensibilidade } \\
\text { aguda de nervo } \\
\text { periférico induzida } \\
\text { por oxaliplatina e } \\
\text { estabelecer a } \\
\text { dose máxima } \\
\text { tolerável de } \\
\text { adição de } \\
\text { carbamazepina. }\end{array}$ & 6 meses & $\mathrm{NA}$ & $100 \%$ & 25 & 3 & $\begin{array}{l}13 \text { doentes } \\
\text { receberam } \\
\text { FLOX e } 12 \\
\text { doentes } \\
\text { receberam } \\
\text { FLOX+carbama } \\
\text { zepina. Doentes } \\
\text { s examinados } \\
\text { atraves de } \\
\text { eletroneuromiog } \\
\text { rafia e NCS } \\
\text { antes e depois } \\
\text { da infusão. }\end{array}$ & $\begin{array}{l}\text { ENMG } \\
\text { Questionário } \\
\text { para avaliação } \\
\text { dos } \\
\text { sintomas. } \\
\text { NCS (estudo de } \\
\text { condução } \\
\text { nervosa) }\end{array}$ & $\begin{array}{l}\text { Parestesias } \\
\text { Disestesias } \\
\text { Hipersensibilida } \\
\text { de ao frio } \\
\text { Dor no braço } \\
\text { durante infusão } \\
\text { Ptose } \\
\text { Mudanças na } \\
\text { voz }\end{array}$ & $\begin{array}{l}\text { Em 100\% NPIQ } \\
\text { aguda } \\
\text { secundária a } \\
\text { oxaliplatina. } \\
\text { Carbamazepina } \\
\text { não alterou as } \\
\text { anormalidades } \\
\text { clínicas. }\end{array}$ \\
\hline
\end{tabular}

DNIQ: dor neuropática induzida por quimioterapia; NPIQ: neuropatia periférica induzida por quimioterapia; qt: quimioterapia; NA: não avaliado; NCI-CTC-AE: critérios comuns de toxicidade do câncer; mmss: membros superiores; mmii: membros inferiores; ENMG: eletroneuromiografia; McGill: questionário de dor McGill; QST: teste sensitivo quantitativo; FULV: Fluorouracil+Leucovorin; FLOX: F- Fluorouracil, L- Leucovorin, OX -Oxaliplatina-; CCR: câncer colorretal; FOLFOX: ácido folínico+Fluorouracil+Oxaliplatina; TNS: Total neuropathy score; GSH: grupo tratado com glutationa; NCS: estudo de condução nervosa; ISDN: Inventário de sintomas de dor neuropática; AVDs: Atividades de vida diária; EVA: escala visual analógica; FFG: ácido folínico, fluorouracil e gencitabina; IBD: inventário breve de dor; ECOG: Eastern cooperative oncology group performance status, OXY: oxicodona; EORTC QLQ: Questionário de qualidade de vida da Organização europeia para pesquisa e tratamento do câncer. 
Quadro 3. Estudos que avaliaram NPIQ e DNIQ, seus autores, objetivos, tempo de avaliação, prevalência de DNIQ e NPIQ, amostra, número de avaliações durante a quimioterapia, método, instrumentos utilizados, características encontradas e síntese dos achados principais.

\begin{tabular}{|c|c|c|c|c|c|c|c|c|c|c|}
\hline Autores & Objetivo & $\begin{array}{l}\text { Tempo de } \\
\text { avaliação }\end{array}$ & $\begin{array}{l}\text { Prevalência } \\
\text { DNIQ }\end{array}$ & $\begin{array}{l}\text { Prevalencia } \\
\text { NPIQ }\end{array}$ & Amostra & $\begin{array}{l}\text { Número de } \\
\text { avaliações } \\
\text { durante qt }\end{array}$ & Método & $\begin{array}{l}\text { Intrumentos de } \\
\text { avaliação }\end{array}$ & Características & $\begin{array}{l}\text { Achados } \\
\text { principais }\end{array}$ \\
\hline $\begin{array}{l}\text { Mattioli } \\
\text { et al } \\
2005\end{array}$ & $\begin{array}{l}\text { Avaliar a } \\
\text { segurança e } \\
\text { eficácia de } \\
\text { oxaliplatina e 5- } \\
\text { FU- } \\
\text { leucovorin/ácido } \\
\text { folínico } \\
\text { especificamente } \\
\text { em doentes } \\
\text { idosos com cancer } \\
\text { colorretal. }\end{array}$ & 24 meses & $\overline{N A}$ & $\begin{array}{l}6 \% \\
\text { grau } 3 \\
57 \% \\
\text { total }\end{array}$ & 77 & 12 & $\begin{array}{l}\text { Avaliação após } \\
\text { infusão de } \\
\text { oxaliplatina e 5- } \\
\text { FU/leucovorin/ác } \\
\text { ido folínico }\end{array}$ & $\begin{array}{l}\text { NCI-CTC-AE } \\
\text { Instrumental } \\
\text { Activity of Daily } \\
\text { Living }\end{array}$ & $\begin{array}{l}\text { Dor induzida } \\
\text { pelo frio } \\
\text { Disestesia } \\
\text { Parestesia }\end{array}$ & $\begin{array}{l}25 \% \text { dos } \\
\text { doentes } \\
\text { apresentaram } \\
\text { estabilização da } \\
\text { doença enquanto } \\
19 \text { doentes } \\
\text { progrediram. } \\
\text { NPIQ foi } \\
\text { encontrada em } \\
57 \% \text { sendo } \\
\text { desses, } 6 \% \text { em } \\
\text { grau } 3\end{array}$ \\
\hline $\begin{array}{l}\text { Leonard } \\
\text { et al } \\
2005\end{array}$ & $\begin{array}{l}\text { Avaliar a } \\
\text { incidência, } \\
\text { características e } \\
\text { duração de } \\
\text { neurotoxicidade } \\
\text { por oxaliplatina }\end{array}$ & 6 meses & $\overline{N A}$ & $\begin{array}{l}87,2 \% \\
\text { disestesia } \\
94,3 \% \\
\text { parestesia }\end{array}$ & 86 & 12 & $\begin{array}{l}\text { Foram aplicados } \\
\text { questionários } \\
\text { após cada ciclo } \\
\text { de } \\
\text { quimioterapia. }\end{array}$ & $\begin{array}{l}\text { ENMG } \\
\text { NCS } \\
\text { Upper extremity } \\
\text { symptoms } \\
\text { questionnaire } \\
\text { Lower extremity } \\
\text { symptoms } \\
\text { questionnaire } \\
\text { Oral/facial } \\
\text { symptoms } \\
\text { questionnaire }\end{array}$ & $\begin{array}{l}\text { Disestesia } \\
\text { Parestesia } \\
\text { Dormência } \\
\text { Formigamento }\end{array}$ & $\begin{array}{l}\text { Disestesia em } \\
87,2 \% \text { dos } \\
\text { doentes . A } \\
\text { parestesia, } \\
\text { sensações não } \\
\text { dolorosas mas } \\
\text { anormais, tais } \\
\text { como dormência } \\
\text { ou formigamento, } \\
94,3 \%\end{array}$ \\
\hline $\begin{array}{l}\text { Pietrangeli } \\
\text { et al } \\
2006\end{array}$ & $\begin{array}{l}\text { Avaliar presença } \\
\text { de neuropatia } \\
\text { persistente } \\
\text { induzida por } \\
\text { oxaliplatina }\end{array}$ & 6 meses & $\overline{N A}$ & $\begin{array}{l}100 \% \\
\text { durante Qt } \\
16 \% \\
\text { após } 5 \text { anos }\end{array}$ & 31 & 3 & $\begin{array}{l}\text { Avaliação antes } \\
\text { do tratamento, } \\
\text { durante, logo } \\
\text { após } \\
\text { descontinuação } \\
\text { e depois de } 5 \\
\text { anos }\end{array}$ & EMG & $\begin{array}{l}\text { Disestesia distal } \\
\text { Hiporreflexia } \\
\text { Hipopalestesia }\end{array}$ & $\begin{array}{l}\text { Além das } \\
\text { características } \\
\text { descritas, foram } \\
\text { observadas } \\
\text { hiporreflexia dos } \\
\text { tendões } \\
\text { profundos e } \\
\text { hipopalestesia }\end{array}$ \\
\hline
\end{tabular}

DNIQ: dor neuropática induzida por quimioterapia; NPIQ: neuropatia periférica induzida por quimioterapia; qt: quimioterapia; NA: não avaliado; NCI-CTC-AE: critérios comuns de toxicidade do câncer; mmss: membros superiores; mmii: membros inferiores; ENMG: eletroneuromiografia; McGill: questionário de dor McGill; QST: teste sensitivo quantitativo; FULV: Fluorouracil+Leucovorin; FLOX: F- Fluorouracil, L- Leucovorin, OX -Oxaliplatina-; CCR: câncer colorretal; FOLFOX: ácido folínico+Fluorouracil+Oxaliplatina; TNS: Total neuropathy score; GSH: grupo tratado com glutationa; NCS: estudo de condução nervosa; ISDN: Inventário de sintomas de dor neuropática; AVDs: Atividades de vida diária; EVA: escala visual analógica; FFG: ácido folínico, fluorouracil e gencitabina; IBD: inventário breve de dor; ECOG: Eastern cooperative oncology group performance status, OXY: oxicodona; EORTC QLQ: Questionário de qualidade de vida da Organização europeia para pesquisa e tratamento do câncer. 
Quadro 3. Estudos que avaliaram NPIQ e DNIQ, seus autores, objetivos, tempo de avaliação, prevalência de DNIQ e NPIQ, amostra, número de avaliações durante a quimioterapia, método, instrumentos utilizados, características encontradas e síntese dos achados principais.

\begin{tabular}{|c|c|c|c|c|c|c|c|c|c|c|}
\hline Autores & Objetivo & $\begin{array}{l}\text { Tempo de } \\
\text { avaliação }\end{array}$ & $\begin{array}{l}\text { Prevalência } \\
\text { DNIQ }\end{array}$ & $\begin{array}{l}\text { Prevalencia } \\
\text { NPIQ }\end{array}$ & Amostra & $\begin{array}{l}\text { Número de } \\
\text { avaliações } \\
\text { durante qt }\end{array}$ & Método & $\begin{array}{l}\text { Intrumentos de } \\
\text { avaliação }\end{array}$ & Características & $\begin{array}{l}\text { Achados } \\
\text { principais }\end{array}$ \\
\hline $\begin{array}{l}\text { Petrioli } \\
\text { et al } \\
2006\end{array}$ & $\begin{array}{l}\text { Avaliar se a } \\
\text { quimioterapia } \\
\text { FOLFOX4 e } \\
\text { capecitabina estão } \\
\text { associadas à } \\
\text { baixa incidência } \\
\text { de } \\
\text { neurotoxicidade } \\
\text { grave em doentes } \\
\text { com cancer } \\
\text { colorretal } \\
\text { metastático }\end{array}$ & 16 meses & NA & $87,50 \%$ & 33 & 4 & $\begin{array}{l}\text { Doentes foram } \\
\text { tratados com } \\
\text { FOLFOX4. Após } \\
\text { tratamento, os } \\
\text { doentes que } \\
\text { apresentaram } \\
\text { regressão da } \\
\text { doença ou que } \\
\text { permaneceram } \\
\text { estáveis } \\
\text { receberam } \\
\text { capecitabina } \\
\text { oral do dia 1-14 } \\
\text { a cada } 3 \\
\text { semanas. }\end{array}$ & $\begin{array}{l}\text { NCI-CTC } \\
\text { Oxaliplatin- } \\
\text { Specific } \\
\text { Neurotoxicity } \\
\text { Scale } \\
\text { Testes } \\
\text { para avaliação } \\
\text { proprioceptiva e } \\
\text { exteroceptiva. }\end{array}$ & $\begin{array}{l}\text { Disestesia } \\
\text { induzida pelo } \\
\text { frio }\end{array}$ & $\begin{array}{l}87.5 \% \\
\text { apresentaram } \\
\text { NPIQ durante o } \\
\text { tratamento. } 75 \% \\
\text { disestesia } \\
\text { induzida } \\
\text { pelo frio. } 3.1 \% \\
\text { evoluíram } \\
\text { com } \\
\text { incapacidade } \\
\text { funcional após } \\
\text { tratamento. }\end{array}$ \\
\hline $\begin{array}{l}\text { Argyriou } \\
\text { et al } \\
2006\end{array}$ & $\begin{array}{l}\text { Investigar a } \\
\text { patofisiologia da } \\
\text { neurotoxicidade } \\
\text { causada por } \\
\text { oxaliplatina }\end{array}$ & 6 meses & $\mathrm{NA}$ & $94 \%$ & 58 & $\begin{array}{l}12 \text { (antes e } \\
\text { depois de } \\
\text { cada } \\
\text { infusão) }\end{array}$ & $\begin{array}{l}\text { Doentes } \\
\text { avaliados a cada } \\
\text { ciclo do } \\
\text { tratamento, } \\
\text { antes de cada } \\
\text { infusão e após } \\
48 \mathrm{~h}\end{array}$ & $\begin{array}{l}\text { NCI-CTC-AE } \\
\text { Oxaliplatin- } \\
\text { Specific } \\
\text { Neurotoxicity } \\
\text { Scale }\end{array}$ & $\begin{array}{l}\text { Parestesia } \\
\text { Dormência } \\
\text { Diminuição da } \\
\text { sensibilidade } \\
\text { vibratória } \\
\text { Ausência/diminu } \\
\text { ição de reflexos } \\
\text { tendíneos } \\
\text { Ataxia }\end{array}$ & $\begin{array}{l}\text { 94\% dos doentes } \\
\text { apresentaram } \\
\text { neurotoxicidade } \\
\text { aguda. } 20 \% \\
\text { deles } \\
\text { experimentaram } \\
\text { neuropatia } \\
\text { crônica graves }\end{array}$ \\
\hline $\begin{array}{l}\text { Binder } \\
\text { et al } \\
2007\end{array}$ & $\begin{array}{l}\text { Determinar } \\
\text { caracteristicas } \\
\text { somatossensoriais } \\
\text { e os tipos de dor } \\
\text { em doentes com } \\
\text { NPIQ e relacionar } \\
\text { a fisiopatologia }\end{array}$ & 6 meses & $\overline{N A}$ & $56 \%$ & 16 & 2 & $\begin{array}{l}\text { Os doentes } \\
\text { foram alocados } \\
\text { em } 2 \text { grupos por } \\
\text { presença ou } \\
\text { ausência de dor } \\
\text { crônica e } \\
\text { avaliados antes } \\
\text { da qt e depois } \\
\text { de } 6 \text { meses }\end{array}$ & $\begin{array}{l}\text { Exame clínico } \\
\text { McGILL } \\
\text { Oxaliplatin } \\
\text { Questionnaire } \\
\text { QST }\end{array}$ & $\begin{array}{l}\text { Formigamento } \\
\text { Congelamento } \\
\text { Picadas }\end{array}$ & $\begin{array}{l}\text { Doentes } \\
\text { apresentaram } \\
\text { neuropatia em } \\
56 \%\end{array}$ \\
\hline
\end{tabular}

DNIQ: dor neuropática induzida por quimioterapia; NPIQ: neuropatia periférica induzida por quimioterapia; qt: quimioterapia; NA: não avaliado; NCI-CTC-AE: critérios comuns de toxicidade do câncer; mmss: membros superiores; mmii: membros inferiores; ENMG: eletroneuromiografia; McGill: questionário de dor McGill; QST: teste sensitivo quantitativo; FULV: Fluorouracil+Leucovorin; FLOX: F- Fluorouracil, L- Leucovorin, OX -Oxaliplatina-; CCR: câncer colorretal; FOLFOX: ácido folínico+Fluorouracil+Oxaliplatina; TNS: Total neuropathy score; GSH: grupo tratado com glutationa; NCS: estudo de condução nervosa; ISDN: Inventário de sintomas de dor neuropática; AVDs: Atividades de vida diária; EVA: escala visual analógica; FFG: ácido folínico, fluorouracil e gencitabina; IBD: inventário breve de dor; ECOG: Eastern cooperative oncology group performance status, OXY: oxicodona; EORTC QLQ: Questionário de qualidade de vida da Organização europeia para pesquisa e tratamento do câncer. 
Quadro 3. Estudos que avaliaram NPIQ e DNIQ, seus autores, objetivos, tempo de avaliação, prevalência de DNIQ e NPIQ, amostra, número de avaliações durante a quimioterapia, método, instrumentos utilizados, características encontradas e síntese dos achados principais.

\begin{tabular}{|c|c|c|c|c|c|c|c|c|c|c|}
\hline Autores & Objetivo & $\begin{array}{l}\text { Tempo de } \\
\text { avaliação }\end{array}$ & $\begin{array}{l}\text { Prevalência } \\
\text { DNIQ }\end{array}$ & $\begin{array}{l}\text { Prevalencia } \\
\text { NPIQ }\end{array}$ & Amostra & $\begin{array}{l}\text { Número de } \\
\text { avaliações } \\
\text { durante qt }\end{array}$ & Método & $\begin{array}{l}\text { Intrumentos de } \\
\text { avaliação }\end{array}$ & Características & $\begin{array}{l}\text { Achados } \\
\text { principais }\end{array}$ \\
\hline $\begin{array}{l}\text { Land } \\
\text { et al } \\
2007\end{array}$ & $\begin{array}{l}\text { Comparar FULV } \\
\text { versus FLOX em } \\
\text { cancer de colon. } \\
\text { Comparar a } \\
\text { neurotoxicidade } \\
\text { de ambos os } \\
\text { tratamentos. }\end{array}$ & 18 meses & NA & $\begin{array}{l}26 \% \\
\text { FLOX } \\
2.6 \% \\
\text { FULV. }\end{array}$ & 2492 & 3 & $\begin{array}{l}\text { Neurotoxicidade } \\
\text { foi registrada } \\
\text { através dos } \\
\text { efeitos } \\
\text { adversos. Os } \\
\text { doentes } \\
\text { completaram um } \\
\text { questionário em } \\
18 \text { meses de } \\
\text { acompanhament } \\
\text { o. }\end{array}$ & $\begin{array}{l}\text { Functional } \\
\text { Assessment } \\
\text { of Cancer } \\
\text { Therapy (FACT) } \\
\\
\text { Oxaliplatin- } \\
\text { Specific } \\
\text { Neurotoxicity } \\
\text { Scale }\end{array}$ & $\begin{array}{l}\text { Dor induzida } \\
\text { pelo frio } \\
\text { Dormência } \\
\text { Formigamento } \\
\text { Disestesia } \\
\text { Perestesia }\end{array}$ & $\begin{array}{l}\text { Durante a } \\
\text { terapia, os } \\
\text { doentes } \\
\text { recebendo } \\
\text { oxaliplatina } \\
\text { apresentaram } \\
\text { dor induzida pelo } \\
\text { frio em } 26 \% \text { e } \\
\text { fraqueza } 27,4 \%\end{array}$ \\
\hline $\begin{array}{l}\text { Argyriou } \\
\text { et al } \\
2007\end{array}$ & $\begin{array}{l}\text { Investigar a } \\
\text { incidência e } \\
\text { severidade da } \\
\text { NPIQ e determinar } \\
\text { seu padrão clínico } \\
\text { e eletrofisiológico }\end{array}$ & 6 meses & $\mathrm{NA}$ & $64 \%$ & 25 & 4 & $\begin{array}{l}\text { Doentes } \\
\text { monitorados } \\
\text { clinica e } \\
\text { eletrofisiologica } \\
\text { mente no basal } \\
\text { e } \\
\text { acompanhados } \\
\text { durante } \\
\text { quimioterapia }\end{array}$ & $\begin{array}{l}\text { Neurological } \\
\text { Sympton Score } \\
\text { Neurological } \\
\text { Disability Score } \\
\\
\text { Functional } \\
\text { Grading scale }\end{array}$ & $\begin{array}{l}\text { Dormência } \\
\text { Dor } \\
\text { Marcha instavel } \\
\text { Diminuiçao de } \\
\text { sensibilidade }\end{array}$ & $\begin{array}{l}\text { NPIQ em 64\% } \\
\text { dos doentes. } \\
\text { Todos com } \\
\text { sintomas } \\
\text { positivos, } \\
\text { enquanto dois } \\
\text { com sintomas } \\
\text { negativos, como } \\
\text { marcha instável } \\
\text { insensibilidade } \\
\text { em mãos e boca }\end{array}$ \\
\hline $\begin{array}{l}\text { Wang } \\
\text { et al } \\
2007\end{array}$ & $\begin{array}{l}\text { Avaliar a eficácia } \\
\text { de glutamina oral } \\
\text { na prevenção de } \\
\text { neuropatia } \\
\text { induzida por } \\
\text { oxaliplatina }\end{array}$ & 18 meses & $\mathrm{NA}$ & $\begin{array}{l}16.7 \% \\
\text { FLOX+gluta } \\
\text { mina } \\
38.6 \% \\
\text { FLOX }\end{array}$ & 86 & 7 & $\begin{array}{l}42 \text { doentes } \\
\text { receberam } \\
\text { glutamina e } 44 \\
\text { tratamento } \\
\text { normal (grupo } \\
\text { controle). Foram } \\
\text { avaliadas a } \\
\text { eficácia da } \\
\text { quimioterapia, } \\
\text { neurotoxicidade } \\
\text { e alterações } \\
\text { eletrofisiológicas }\end{array}$ & $\begin{array}{l}\text { NCI-CTC } \\
\text { Sensory } \\
\text { amplitude } \\
\text { potential } \\
\text { nerve } \\
\text { conduction } \\
\text { Velocity, } \\
\text { compound } \\
\text { muscle action } \\
\text { potential } \\
\text { F wave latency }\end{array}$ & $\begin{array}{l}\text { Dormência } \\
\text { Perestesia } \\
\text { Disestesia }\end{array}$ & $\begin{array}{l}\text { Doentes } \\
\text { experimentaram } \\
\text { parestesia e } \\
\text { disestesia em } \\
\text { mãos e pés } \\
\text { assim como } \\
\text { laringe e } \\
\text { mandíbula. } \\
\text { Houve diferança } \\
\text { significativa entre } \\
\text { tratamento } \\
\text { comum e adição } \\
\text { de glutamina }\end{array}$ \\
\hline
\end{tabular}

DNIQ: dor neuropática induzida por quimioterapia; NPIQ: neuropatia periférica induzida por quimioterapia; qt: quimioterapia; NA: não avaliado; NCI-CTC-AE: critérios comuns de toxicidade do câncer; mmss: membros superiores; mmii: membros inferiores; ENMG: eletroneuromiografia; McGill: questionário de dor McGill; QST: teste sensitivo quantitativo; FULV: Fluorouracil+Leucovorin; FLOX: F- Fluorouracil, L- Leucovorin, OX -Oxaliplatina-; CCR: câncer colorretal; FOLFOX: ácido folínico+Fluorouracil+Oxaliplatina; TNS: Total neuropathy score; GSH: grupo tratado com glutationa; NCS: estudo de condução nervosa; ISDN: Inventário de sintomas de dor neuropática; AVDs: Atividades de vida diária; EVA: escala visual analógica; FFG: ácido folínico, fluorouracil e gencitabina; IBD: inventário breve de dor; ECOG: Eastern cooperative oncology group performance status, OXY: oxicodona; EORTC QLQ: Questionário de qualidade de vida da Organização europeia para pesquisa e tratamento do câncer. 
Quadro 3. Estudos que avaliaram NPIQ e DNIQ, seus autores, objetivos, tempo de avaliação, prevalência de DNIQ e NPIQ, amostra, número de avaliações durante a quimioterapia, método, instrumentos utilizados, características encontradas e síntese dos achados principais.

\begin{tabular}{|c|c|c|c|c|c|c|c|c|c|c|}
\hline Autores & Objetivo & $\begin{array}{l}\text { Tempo de } \\
\text { avaliação }\end{array}$ & $\begin{array}{l}\text { Prevalência } \\
\text { DNIQ }\end{array}$ & $\begin{array}{l}\text { Prevalencia } \\
\text { NPIQ }\end{array}$ & Amostra & $\begin{array}{l}\text { Número de } \\
\text { avaliações } \\
\text { durante qt }\end{array}$ & Método & $\begin{array}{l}\text { Intrumentos de } \\
\text { avaliação }\end{array}$ & Características & $\begin{array}{l}\text { Achados } \\
\text { principais }\end{array}$ \\
\hline $\begin{array}{l}\text { Attal } \\
\text { et al } \\
2009\end{array}$ & $\begin{array}{l}\text { Identificar } \\
\text { aspectos da } \\
\text { neuropatia por } \\
\text { oxaliplatina em } \\
\text { comparação com } \\
\text { a cisplatina e } \\
\text { detectar preditores } \\
\text { da neuropatia } \\
\text { crônica. }\end{array}$ & 18 meses & NA & $96 \%$ & 48 & 3 & $\begin{array}{l}\text { Doentes } \\
\text { recebendo } \\
\text { terapia com } \\
\text { oxaliplatina ou } \\
\text { cisplatina foram } \\
\text { avaliados apos } \\
\text { administração } \\
\text { de qt e após } 2 \\
\text { semanas depois } \\
\text { dos ciclos } 3,6 \text { e } \\
9 .\end{array}$ & $\begin{array}{l}\text { ISDN } \\
\text { QST } \\
\text { NCI-CTC-AE }\end{array}$ & $\begin{array}{l}\text { Queimação } \\
\text { Pressão } \\
\text { Choque elétrico } \\
\text { Parestesia } \\
\text { Disestesia } \\
\text { Dor ao frio } \\
\text { Hiporeflexia } \\
\text { Ataxia } \\
\text { Déficit de } \\
\text { percepção } \\
\text { vibratória }\end{array}$ & $\begin{array}{l}\text { Doentes } \\
\text { apresentaram } \\
\text { algum dos } \\
\text { sintomas da } \\
\text { NPIQ em 96\% }\end{array}$ \\
\hline $\begin{array}{l}\text { Baek } \\
\text { et al } \\
2010\end{array}$ & $\begin{array}{l}\text { Analisar a } \\
\text { neurotoxicidade } \\
\text { em doentes } \\
\text { tratados com } \\
\text { Oxaliplatina }\end{array}$ & 6 meses & $\mathrm{NA}$ & $\begin{array}{l}42 \% \\
3 \text { meses } \\
85 \% \\
6 \text { meses de } \\
\text { tratamento }\end{array}$ & 366 & 12 & $\begin{array}{l}\text { Avaliada } \\
\text { incidência de } \\
\text { NPIQ em } \\
\text { doentes com } \\
\text { CCR recebendo } \\
\text { tratamento de } \\
\text { oxaliplatina }\end{array}$ & NCI-CTC-AE & $\begin{array}{l}\text { Parestesia } \\
\text { Disestesia }\end{array}$ & $\begin{array}{l}\text { Parestesia e } \\
\text { disestesia nas } \\
\text { extremidades. } \\
\text { Alguns casos de } \\
\text { comprometiment } \\
\text { o de } \\
\text { AVDs }\end{array}$ \\
\hline $\begin{array}{l}\text { Ishibashi } \\
\text { et al } \\
2010\end{array}$ & $\begin{array}{l}\text { Determinar se } \\
\text { infusão de Cálcio } \\
\text { e Magnesio é } \\
\text { efetiva contra } \\
\text { neurotoxicidade } \\
\text { causada por } \\
\text { oxaliplatina. }\end{array}$ & 10 meses & NA & $100 \%$ & 33 & 6 & $\begin{array}{l}\text { Doentes com } \\
\text { CCR recebendo } \\
\text { oxaliplatina } \\
\text { receberam } \\
\text { terapia oral de } \\
\text { Calcio e } \\
\text { Magnésio e } \\
\text { avaliados antes } \\
\text { e depois de } \\
\text { cada ciclo }\end{array}$ & $\begin{array}{l}\text { NCI-CTC } \\
\text { Neurotoxicity } \\
\text { Criteria } \\
\text { of Debiopharm } \\
\text { (DEB-NTC) }\end{array}$ & $\begin{array}{l}\text { Disestesia } \\
\text { Parestesia } \\
\text { aguda }\end{array}$ & $\begin{array}{l}\text { Em100\% } \\
\text { disestesia e } \\
\text { parestesia } \\
\text { aguda, em 6\% } \\
\text { sintomas } \\
\text { persistiram entre } \\
\text { Os ciclos, e 6\% } \\
\text { incapacidade } \\
\text { funcional }\end{array}$ \\
\hline $\begin{array}{l}\text { Chay } \\
\text { et al } \\
2010\end{array}$ & $\begin{array}{l}\text { Avaliar a eficácia } \\
\text { da infusão de } \\
\text { Calcio e Magnésio } \\
\text { em neuropatia } \\
\text { induzida por } \\
\text { oxaliplatina. }\end{array}$ & 6 meses & $\mathrm{NA}$ & $\begin{array}{l}77 \% \\
\text { ativo } \\
86 \% \\
\text { placebo }\end{array}$ & 27 & 4 & $\begin{array}{l}\text { Doentes } \\
\text { receberam } \\
\text { calcio gluconado } \\
1 \mathrm{~g}+15 \% \mathrm{e} \\
\text { sulfato de } \\
\text { magnezio } 1 \mathrm{~g} \\
\text { diluído em } 100 \\
\mathrm{~mL} \text { de dextrose } \\
5 \% \text { ou placebo. }\end{array}$ & $\begin{array}{l}\text { NCI-CTC, } \\
\text { Oxaliplatin- } \\
\text { Specific } \\
\text { Neurotoxicity } \\
\text { Scale } \\
\text { NCS }\end{array}$ & $\begin{array}{l}\text { Parestesia } \\
\text { Disestesia } \\
\text { induzida pelo } \\
\text { frio } \\
\text { Dormência }\end{array}$ & $\begin{array}{l}\text { Com doses mais } \\
\text { elevadas, os } \\
\text { doentes } \\
\text { apresentaram } \\
\text { dormência que } \\
\text { persistiu entre os } \\
\text { ciclos. } 11 \% \\
\text { neuropatia grau } \\
3 \text {. }\end{array}$ \\
\hline
\end{tabular}

DNIQ: dor neuropática induzida por quimioterapia; NPIQ: neuropatia periférica induzida por quimioterapia; qt: quimioterapia; NA: não avaliado; NCI-CTC-AE: critérios comuns de toxicidade do câncer; mmss: membros superiores; mmii: membros inferiores; ENMG: eletroneuromiografia; McGill: questionário de dor McGill; QST: teste sensitivo quantitativo; FULV: Fluorouracil+Leucovorin; FLOX: F- Fluorouracil, L- Leucovorin, OX -Oxaliplatina-; CCR: câncer colorretal; FOLFOX: ácido folínico+Fluorouracil+Oxaliplatina; TNS: Total neuropathy score; GSH: grupo tratado com glutationa; NCS: estudo de condução nervosa; ISDN: Inventário de sintomas de dor neuropática; AVDs: Atividades de vida diária; EVA: escala visual analógica; FFG: ácido folínico, fluorouracil e gencitabina; IBD: inventário breve de dor; ECOG: Eastern cooperative oncology group performance status, OXY: oxicodona; EORTC QLQ: Questionário de qualidade de vida da Organização europeia para pesquisa e tratamento do câncer. 
Quadro 3. Estudos que avaliaram NPIQ e DNIQ, seus autores, objetivos, tempo de avaliação, prevalência de DNIQ e NPIQ, amostra, número de avaliações durante a quimioterapia, método, instrumentos utilizados, características encontradas e síntese dos achados principais.

\begin{tabular}{|c|c|c|c|c|c|c|c|c|c|c|}
\hline Autores & Objetivo & $\begin{array}{l}\text { Tempo de } \\
\text { avaliação }\end{array}$ & $\begin{array}{l}\text { Prevalência } \\
\text { DNIQ }\end{array}$ & $\begin{array}{l}\text { Prevalencia } \\
\text { NPIQ }\end{array}$ & Amostra & $\begin{array}{l}\text { Número de } \\
\text { avaliações } \\
\text { durante qt }\end{array}$ & Método & $\begin{array}{l}\text { Intrumentos de } \\
\text { avaliação }\end{array}$ & Características & $\begin{array}{l}\text { Achados } \\
\text { principais }\end{array}$ \\
\hline $\begin{array}{l}\text { Madajewicz } \\
\text { et al } \\
2010\end{array}$ & $\begin{array}{l}\text { Avaliar a eficacia } \\
\text { de acido folinico, } \\
\text { 5-fluorouracil, } \\
\text { gencitabina e } \\
\text { acido folinico, } \\
\text { fluorouracil e } \\
\text { oxaliplatina } \\
\text { (FOLFOX4) mais } \\
\text { bevacizumabe } \\
\text { 5mg/kg em } \\
\text { doentes com CCR }\end{array}$ & 20 meses & $\mathrm{NA}$ & $42 \%$ & 84 & 4 & $\begin{array}{l}\text { Doentes foram } \\
\text { randomizados } \\
\text { para o grupo } \\
\text { FFG ou } \\
\text { FOLFOX4. Foi } \\
\text { adicionado } \\
\text { bevacizumabe } \\
5 \mathrm{mg} / \mathrm{kg} \text { a cada } 2 \\
\text { semanas. } \\
\text { Avaliados os } \\
\text { efeitos } \\
\text { adversos. }\end{array}$ & $\mathrm{NCl}-\mathrm{CTC}$ & $\mathrm{NA}$ & $\begin{array}{l}\text { NPIQ foi mais } \\
\text { frequente no } \\
\text { FOLFOX (42\%) } \\
\text { do que FFG } \\
(2,4 \%)\end{array}$ \\
\hline $\begin{array}{l}\text { Hill } \\
\text { et al } \\
2010\end{array}$ & $\begin{array}{l}\text { Detectar } \\
\text { neurotoxidade } \\
\text { aguda durante } \\
\text { quimioterapia } \\
\text { através de } \\
\text { questionario } \\
\text { neurofisiológico da } \\
\text { hiperexcitabilidade } \\
\text { do nervo motor. }\end{array}$ & 6 meses & $55 \%$ & $\begin{array}{l}100 \% \\
\text { (algum } \\
\text { sintomas de } \\
\text { neuropatia) }\end{array}$ & 22 & 2 & $\begin{array}{l}\text { Avaliação antes } \\
\text { de infusão de } \\
\text { oxaliplatina+cap } \\
\text { ecitabina ou } \\
\text { carboplatina+pa } \\
\text { clitaxel } \\
\text { (cisplatina), nos } \\
\text { dias } 2 \text { a } 4 \text { ou } 14 \\
\text { a } 20 \text { depois da } \\
\text { infusão e ao } \\
\text { término do } \\
\text { tratamento. }\end{array}$ & $\begin{array}{l}\text { ENGM } \\
\text { Questionário } \\
\text { para avaliação } \\
\text { dos } \\
\text { sintomas. }\end{array}$ & $\begin{array}{l}\text { Parestesia } \\
\text { Sensação de } \\
\text { aperto na } \\
\text { mandíbula } \\
\text { ou garganta } \\
\text { Cãibras } \\
\text { musculares }\end{array}$ & $\begin{array}{l}\text { Parestesia } \\
\text { induzida pelo frio } \\
\text { em } 100 \% \text {, } \\
\text { sensação de } \\
\text { aperto na } \\
\text { mandíbula ou } \\
\text { garganta em } \\
68 \% \text {, dor no } \\
\text { membro superior } \\
\text { no local da } \\
\text { infusão em } 55 \% \text {. }\end{array}$ \\
\hline $\begin{array}{l}\text { Grothey } \\
\text { et al } \\
2011\end{array}$ & $\begin{array}{l}\text { Associar } \mathrm{Ca} / \mathrm{Mg} \mathrm{a} \\
\text { redução de NPIQ } \\
\text { por Oxaliplatina } \\
\text { em doentes com } \\
\text { câncer colorretal. }\end{array}$ & 6 meses & $\mathrm{NA}$ & $\begin{array}{l}22 \% \\
\mathrm{CA} / \mathrm{Mg} \\
41 \% \\
\text { Placebo } \\
\text { (grau 2) }\end{array}$ & 102 & 10 & $\begin{array}{l}\text { Doentes foram } \\
\text { designados para } \\
\mathrm{Ca} / \mathrm{Mg} \text { ou } \\
\text { placebo. O } \\
\text { desfecho } \\
\text { primário foi a } \\
\text { percentagem de } \\
\text { doentes com } \\
\text { grau } 2 \text { ou maior } \\
\text { NPIQ a qualquer } \\
\text { momento } \\
\text { durante ou após } \\
\text { a terapia }\end{array}$ & $\begin{array}{l}\text { NCI CTC } \\
\text { Oxaliplatin- } \\
\text { specific scale } \\
\text { EVA }\end{array}$ & $\begin{array}{l}\text { Sensibilidade ao } \\
\text { frio } \\
\text { Desconforto ao } \\
\text { engolir itens } \\
\text { gelados } \\
\text { Cãibras }\end{array}$ & $\begin{array}{l}\text { NPIQ menos } \\
\text { frequente nos } \\
\text { doentes que } \\
\text { adicionaram } \\
\text { Ca/Mg. }\end{array}$ \\
\hline
\end{tabular}

DNIQ: dor neuropática induzida por quimioterapia; NPIQ: neuropatia periférica induzida por quimioterapia; qt: quimioterapia; NA: não avaliado; NCI-CTC-AE: critérios comuns de toxicidade do câncer; mmss: membros superiores; mmii: membros inferiores; ENMG: eletroneuromiografia; McGill: questionário de dor McGill; QST: teste sensitivo quantitativo; FULV: Fluorouracil+Leucovorin; FLOX: F- Fluorouracil, L- Leucovorin, OX -Oxaliplatina-; CCR: câncer colorretal; FOLFOX: ácido folínico+Fluorouracil+Oxaliplatina; TNS: Total neuropathy score; GSH: grupo tratado com glutationa; NCS: estudo de condução nervosa; ISDN: Inventário de sintomas de dor neuropática; AVDs: Atividades de vida diária; EVA: escala visual analógica; FFG: ácido folínico, fluorouracil e gencitabina; IBD: inventário breve de dor; ECOG: Eastern cooperative oncology group performance status, OXY: oxicodona; EORTC QLQ: Questionário de qualidade de vida da Organização europeia para pesquisa e tratamento do câncer. 
Quadro 3. Estudos que avaliaram NPIQ e DNIQ, seus autores, objetivos, tempo de avaliação, prevalência de DNIQ e NPIQ, amostra, número de avaliações durante a quimioterapia, método, instrumentos utilizados, características encontradas e síntese dos achados principais.

\begin{tabular}{|c|c|c|c|c|c|c|c|c|c|c|}
\hline Autores & Objetivo & $\begin{array}{l}\text { Tempo de } \\
\text { avaliação }\end{array}$ & $\begin{array}{l}\text { Prevalência } \\
\text { DNIQ }\end{array}$ & $\begin{array}{l}\text { Prevalencia } \\
\text { NPIQ }\end{array}$ & Amostra & $\begin{array}{l}\text { Número de } \\
\text { avaliações } \\
\text { durante qt }\end{array}$ & Método & $\begin{array}{l}\text { Intrumentos de } \\
\text { avaliação }\end{array}$ & Características & $\begin{array}{l}\text { Achados } \\
\text { principais }\end{array}$ \\
\hline $\begin{array}{l}\text { Vincenzi } \\
\text { et al } \\
2013\end{array}$ & $\begin{array}{l}\text { Identificar fatores } \\
\text { clinicos que } \\
\text { predigam o } \\
\text { desenvolvimento } \\
\text { de NPIQ e sua } \\
\text { duração. }\end{array}$ & 6 meses & $\overline{N A}$ & $52 \%$ & 169 & 2 & $\begin{array}{l}\text { Os doentes } \\
\text { incluidos foram } \\
\text { os com CCR e } \\
\text { tratados com } \\
\text { terapia FOLFOX } \\
\text { IV adjuvante. } \\
\text { Incidência, grau } \\
\text { e duração da } \\
\text { neuropatia } \\
\text { foram } \\
\text { registrados }\end{array}$ & NCl-CTC-AE & $\begin{array}{l}\text { Parestesia } \\
\text { Alteração } \\
\text { sensorial }\end{array}$ & $\begin{array}{l}\text { A duração da } \\
\text { NPIQ foi } \\
\text { associada à } \\
\text { idade, sendo } \\
\text { maior nos } \\
\text { jovens, e } \\
\text { tambem } \\
\text { associada à } \\
\text { hipoalbuminemia } \\
\text { e } \\
\text { hipomagnesemia }\end{array}$ \\
\hline $\begin{array}{l}\text { Argyriou } \\
\text { et al } \\
2012\end{array}$ & $\begin{array}{l}\text { Testar se a idade } \\
\text { interfere no risco } \\
\text { para neuropatia } \\
\text { periferica em } \\
\text { doentes com CCR } \\
\text { tratados com } \\
\text { oxaliplatina }\end{array}$ & 6 meses & $\mathrm{NA}$ & $\begin{array}{l}80-85 \% \\
\text { NPIQ aguda } \\
68-70 \% \\
\text { NPIQ } \\
\text { acumulada }\end{array}$ & 145 & 3 & $\begin{array}{l}\text { Doentes foram } \\
\text { divididos em } \\
\text { dois grupos de } \\
\text { acordo com a } \\
\text { idade e } \\
\text { avaliados }\end{array}$ & $\begin{array}{l}\text { Motor and } \\
\text { Neurosensory } \\
\text { NCI-CTCAE } \\
\text { TNS }\end{array}$ & $\mathrm{NA}$ & $\begin{array}{l}\text { Não houve } \\
\text { diferença } \\
\text { significativa na } \\
\text { incidencia de } \\
\text { NPIQ aguda } \\
(85 \% \text { vs } 80 \% \text { e e } \\
\text { acumulada }(68 \% \\
\text { vs } 70 \%) \text {. A } \\
\text { severidade dos } \\
\text { sintomas } \\
\text { também foi } \\
\text { similar }\end{array}$ \\
\hline $\begin{array}{l}\text { Afonseca } \\
\text { et al } \\
2013\end{array}$ & $\begin{array}{l}\text { Avaliar a eficácia } \\
\text { de vitamina E na } \\
\text { prevenção de } \\
\text { neuropatia } \\
\text { periférica causada } \\
\text { por oxaliplatina. }\end{array}$ & 6 meses & $\mathrm{NA}$ & $\begin{array}{l}83 \% \\
\text { Vit E } \\
68 \% \\
\text { Placebo }\end{array}$ & 44 & 3 & $\begin{array}{l}\text { Os doentes } \\
\text { receberam } \\
\text { vitamina } \mathrm{E} \text { ou } \\
\text { placebo e } \\
\text { avaliados } \\
\text { Ambos os } \\
\text { grupos } \\
\text { receberam } \\
\text { calcio e } \\
\text { magnesio. }\end{array}$ & $\begin{array}{l}\text { NCI-CTCAE } \\
\text { Oxaliplatin Scale }\end{array}$ & $\mathrm{NA}$ & $\begin{array}{l}\text { NPIQ grau } 1 \text { ou } 2 \\
\text { teve incidencia } \\
\text { de } 83 \% \text { no grupo } \\
\text { ativo e } 68 \% \text { no } \\
\text { grupo placebo. }\end{array}$ \\
\hline
\end{tabular}

DNIQ: dor neuropática induzida por quimioterapia; NPIQ: neuropatia periférica induzida por quimioterapia; qt: quimioterapia; NA: não avaliado; NCI-CTC-AE: critérios comuns de toxicidade do câncer; mmss: membros superiores; mmii: membros inferiores; ENMG: eletroneuromiografia; McGill: questionário de dor McGill; QST: teste sensitivo quantitativo; FULV: Fluorouracil+Leucovorin; FLOX: F- Fluorouracil, L- Leucovorin, OX -Oxaliplatina-; CCR: câncer colorretal; FOLFOX: ácido folínico+Fluorouracil+Oxaliplatina; TNS: Total neuropathy score; GSH: grupo tratado com glutationa; NCS: estudo de condução nervosa; ISDN: Inventário de sintomas de dor neuropática; AVDs: Atividades de vida diária; EVA: escala visual analógica; FFG: ácido folínico, fluorouracil e gencitabina; IBD: inventário breve de dor; ECOG: Eastern cooperative oncology group performance status, OXY: oxicodona; EORTC QLQ: Questionário de qualidade de vida da Organização europeia para pesquisa e tratamento do câncer. 
Quadro 3. Estudos que avaliaram NPIQ e DNIQ, seus autores, objetivos, tempo de avaliação, prevalência de DNIQ e NPIQ, amostra, número de avaliações durante a quimioterapia, método, instrumentos utilizados, características encontradas e síntese dos achados principais.

\begin{tabular}{|c|c|c|c|c|c|c|c|c|c|c|}
\hline Autores & Objetivo & $\begin{array}{l}\text { Tempo de } \\
\text { avaliação }\end{array}$ & $\begin{array}{l}\text { Prevalência } \\
\text { DNIQ }\end{array}$ & $\begin{array}{l}\text { Prevalencia } \\
\text { NPIQ }\end{array}$ & Amostra & $\begin{array}{l}\text { Número de } \\
\text { avaliações } \\
\text { durante qt }\end{array}$ & Método & $\begin{array}{l}\text { Intrumentos de } \\
\text { avaliação }\end{array}$ & Características & $\begin{array}{l}\text { Achados } \\
\text { principais }\end{array}$ \\
\hline $\begin{array}{l}\text { Guo } \\
\text { et al } \\
2014\end{array}$ & $\begin{array}{l}\text { Testar se o ácido } \\
\text { alfa-lipóico pode } \\
\text { diminuir a } \\
\text { severidade dos } \\
\text { sintomas da NPIQ } \\
\text { em doentes } \\
\text { submetidos a } \\
\text { quimioterapia com } \\
\text { base de platina }\end{array}$ & 12 meses & $\begin{array}{l}\text { NA } \\
\text { (apesar do } \\
\text { IBD) }\end{array}$ & $88 \%$ & 243 & 4 & $\begin{array}{l}\text { Doentes } \\
\text { randomizados } \\
\text { em placebo ou } \\
\text { ativo (recebendo } \\
\text { AAL). A NPIQ foi } \\
\text { avaliada atraves } \\
\text { do Instrumento } \\
\text { de terapia de } \\
\text { Cancer/Grupo } \\
\text { de Oncologia } \\
\text { Ginecologica/Ne } \\
\text { urotoxicidades }\end{array}$ & $\begin{array}{l}\text { FACT/GOG-Ntx } \\
\text { IBD } \\
\text { NCI-CTCAE }\end{array}$ & $\mathrm{NA}$ & $\begin{array}{l}\text { Só } 70 \text { doentes } \\
\text { concluíram. Não } \\
\text { foi encontrada } \\
\text { diferença } \\
\text { significativa nos } \\
\text { sintomas de } \\
\text { neuropatia nos } 2 \\
\text { grupos. }\end{array}$ \\
\hline $\begin{array}{l}\text { Coriat } \\
\text { et al } \\
2014\end{array}$ & $\begin{array}{l}\text { Investigar a } \\
\text { eficácia de } \\
\text { Mangafodipir na } \\
\text { prevenção de } \\
\text { neuropatia } \\
\text { periferica induzida } \\
\text { por Oxaliplatina }\end{array}$ & 6 meses & NA & $77 \%$ & 45 & $\begin{array}{l}8 \text { (a cada } \\
\text { ciclo) }\end{array}$ & $\begin{array}{l}\text { Comparação de } \\
\text { sintomas } \\
\text { neuropáticos de } \\
\text { doentes } \\
\text { infundidos com } \\
\text { oxaliplatina e } \\
\text { doentes } \\
\text { recebendo } \\
\text { adição de } \\
\text { Mangafodipir na } \\
\text { quimioterapia. } \\
\text { Monitoramento } \\
\text { durante } 8 \text { ciclos. }\end{array}$ & $\begin{array}{l}\text { NCI-CTCAE } \\
\text { ECOG }\end{array}$ & $\begin{array}{l}\text { Hipoestesia } \\
\text { Nocicepção } \\
\text { Sensibilidade ao } \\
\text { frio } \\
\text { Desconforto ao } \\
\text { engolir }\end{array}$ & $\begin{array}{l}\text { Observou-se que } \\
\text { os doentes do } \\
\text { grupo do } \\
\text { mangofodipir } \\
\text { toleraram doses } \\
\text { mais altas de } \\
\text { oxaliplatina. }\end{array}$ \\
\hline $\begin{array}{l}\text { Nagashima } \\
\text { et al } \\
2014\end{array}$ & $\begin{array}{l}\text { Avaliar a eficácia } \\
\text { e tolerabilidade de } \\
\text { oxicodona em } \\
\text { neuropatia } \\
\text { periferica induzida } \\
\text { por oxaliplatina e } \\
\text { seu efeito na } \\
\text { terapia FOLFOX. }\end{array}$ & 8 meses & $\mathrm{NA}$ & $98 \%$ & 64 & $\begin{array}{l}4 \text { (a cada } \\
\text { ciclo) }\end{array}$ & $\begin{array}{l}\text { Oxicodona foi } \\
\text { administrado a } \\
29 \text { doentes } \\
\text { (grupo OXY) e a } \\
35 \text { doentes não } \\
\text { foi adicionado } \\
\text { oxicodona no } \\
\text { esqema } \\
\text { FOLFOX (grupo } \\
\text { não-OXY) }\end{array}$ & $\begin{array}{l}\text { NCl-CTCAE } \\
\text { EVA }\end{array}$ & $\mathrm{NA}$ & $\begin{array}{l}\text { Todos } \\
\text { apresentaram } \\
\text { NPIQ. A maioria } \\
\text { em grau } 1 \text { ou } 2 . \\
\text { Grau } 3 \text { foi } \\
\text { observado em } \\
3,1 \% \text { dos } \\
\text { doentes do grupo } \\
\text { não-OXY }\end{array}$ \\
\hline
\end{tabular}

DNIQ: dor neuropática induzida por quimioterapia; NPIQ: neuropatia periférica induzida por quimioterapia; qt: quimioterapia; NA: não avaliado; NCI-CTC-AE: critérios comuns de toxicidade do câncer; mmss: membros superiores; mmii: membros inferiores; ENMG: eletroneuromiografia; McGill: questionário de dor McGill; QST: teste sensitivo quantitativo; FULV: Fluorouracil+Leucovorin; FLOX: F- Fluorouracil, L- Leucovorin, OX -Oxaliplatina-; CCR: câncer colorretal; FOLFOX: ácido folínico+Fluorouracil+Oxaliplatina; TNS: Total neuropathy score; GSH: grupo tratado com glutationa; NCS: estudo de condução nervosa; ISDN: Inventário de sintomas de dor neuropática; AVDs: Atividades de vida diária; EVA: escala visual analógica; FFG: ácido folínico, fluorouracil e gencitabina; IBD: inventário breve de dor; ECOG: Eastern cooperative oncology group performance status, OXY: oxicodona; EORTC QLQ: Questionário de qualidade de vida da Organização europeia para pesquisa e tratamento do câncer. 
Quadro 3. Estudos que avaliaram NPIQ e DNIQ, seus autores, objetivos, tempo de avaliação, prevalência de DNIQ e NPIQ, amostra, número de avaliações durante a quimioterapia, método, instrumentos utilizados, características encontradas e síntese dos achados principais.

\begin{tabular}{|c|c|c|c|c|c|c|c|c|c|c|}
\hline Autores & Objetivo & $\begin{array}{l}\text { Tempo de } \\
\text { avaliação }\end{array}$ & $\begin{array}{l}\text { Prevalência } \\
\text { DNIQ }\end{array}$ & $\begin{array}{l}\text { Prevalencia } \\
\text { NPIQ }\end{array}$ & Amostra & $\begin{array}{l}\text { Número de } \\
\text { avaliações } \\
\text { durante qt }\end{array}$ & Método & $\begin{array}{l}\text { Intrumentos de } \\
\text { avaliação }\end{array}$ & Características & $\begin{array}{l}\text { Achados } \\
\text { principais }\end{array}$ \\
\hline $\begin{array}{l}\text { Loprinzi } \\
\text { et al } \\
2014\end{array}$ & $\begin{array}{l}\text { Testar } \\
\text { definitivamente se } \\
\text { calcio/magnésio } \\
\text { reduzem } \\
\text { neurotoxicidade } \\
\text { causada por } \\
\text { oxaliplatina }\end{array}$ & 6 meses & $\mathrm{NA}$ & $\begin{array}{l}\text { Grupo } \\
\text { placebo:45 } \\
\% \\
\text { Ca/Mg: } 43 \%\end{array}$ & 353 & 3 & $\begin{array}{l}\text { Doentes em } \\
\text { terapia FOLFOX } \\
\text { foram } \\
\text { aleatoriamente } \\
\text { designados para } \\
\text { cálcio/magnésio } \\
\text { IV antes e } \\
\text { depois de } \\
\text { oxaliplatina, um } \\
\text { placebo antes e } \\
\text { depois, ou } \\
\text { cálcio/magnésio } \\
\text { antes e depois } \\
\text { do placebo }\end{array}$ & $\begin{array}{l}\text { EORTC QLQ- } \\
\text { CIPN20 } \\
\text { NCI-CTCAE }\end{array}$ & $\begin{array}{l}\text { Sensibilidade ao } \\
\text { frio } \\
\text { Desconforto ao } \\
\text { engolir gelado } \\
\text { Cãibras } \\
\text { musculares } \\
\text { Desconforto na } \\
\text { garganta }\end{array}$ & $\begin{array}{l}\text { Não houve } \\
\text { diferença } \\
\text { significativa entre } \\
\text { os grupos, } \\
\text { portantoo autor } \\
\text { não apoia o uso } \\
\text { de CA/Mg na } \\
\text { prevenção de } \\
\text { NPIQ }\end{array}$ \\
\hline
\end{tabular}

DNIQ: dor neuropática induzida por quimioterapia; NPIQ: neuropatia periférica induzida por quimioterapia; qt: quimioterapia; NA: não avaliado; NCI-CTC-AE: critérios comuns de toxicidade do câncer; mmss: membros superiores; mmii: membros inferiores; ENMG: eletroneuromiografia; McGill: questionário de dor McGill; QST: teste sensitivo quantitativo; FULV: Fluorouracil+Leucovorin; FLOX: F- Fluorouracil, L- Leucovorin, OX -Oxaliplatina-; CCR: câncer colorretal; FOLFOX: ácido folínico+Fluorouracil+Oxaliplatina; TNS: Total neuropathy score; GSH: grupo tratado com glutationa; NCS: estudo de condução nervosa; ISDN: Inventário de sintomas de dor neuropática; AVDs: Atividades de vida diária; EVA: escala visual analógica; FFG: ácido folínico, fluorouracil e gencitabina; IBD: inventário breve de dor; ECOG:

Eastern cooperative oncology group performance status, OXY: oxicodona; EORTC QLQ: Questionário de qualidade de vida da Organização europeia para pesquisa e tratamento do câncer. 
Diversos autores analisaram a gravidade e a duração da neuropatia associada ao tratamento com oxaliplatina (Land et al., 2007). Para esta finalidade, os instrumentos mais utilizados foram a escala de neurotoxicidade do Instituto Nacional do Câncer (USA) e uma escala desenvolvida especificamente para avaliar a neurotoxicidade secundária a essa droga. Esta última possui um sistema de graduação, no qual doentes com grau 1 apresentam parestesia e disestesia de curta duração; grau 2 são aqueles que cursam com parestesia e disestesia persistindo entre os ciclos de tratamento e grau 3 quando esses sintomas evoluem para incapacidade funcional (Grothey et al., 2005; Gamelin et al., 2002). Para avaliar a presença e características da NPIQ e DNIQ, a maioria dos autores utilizaram do simples exame clínico e do $\mathrm{NCl}-\mathrm{CTC}$, que não caracteriza, apenas classifica o evento em graus, de 1 até 5 . Dentre os 24 estudos aqui relacionados, apenas 3 utilizaram escalas específicas e validadas para neuropatia e dor neuropática induzidas por quimioterapia. Argyriou et al (2012) utilizou a Pontuação Total de Neuropatia (TNS); Binder et al (2007) o questionário de dor McGill e Attal et al (2009) que utilizou o Inventário de sintomas de dor neuropática. Apesar de tantos estudos que avaliaram a neuropatia periférica induzida por quimioterapia, raros estudos procuraram avaliar a dor neuropática em si.

Resumindo, câncer colorretal é altamente prevalente, e a oxaliplatina, causa uma neuropatia com dor. Não há tratamento. Não é claro se há picos de neuropatia durante a quimioterapia. Não são claras quais as características mais prevalentes. 
Conhecendo esse "fenótipo" da dor seria possível criar um tratamento baseado nestes sintomas e assim, atender ao doente de uma maneira mais eficaz. 


\section{CASUÍSTICA E MÉTODO}

\subsection{Características do estudo}

Estudo prospectivo, observacional, proveniente de estudo temático aprovado pelo Comitê de Ética, em sessão no dia 09/02/2011 protocolo no 007/11 (anexo 3) intitulado: "Ensaio clínico, randomizado, duplo-cego, fase 3, controlado com placebo, para avaliar a eficácia e segurança da pregabalina na prevenção e redução da neuropatia dolorosa induzida por oxaliplatina" (PreOx) (anexos 1 e 2).

\subsubsection{PreOx}

O estudo Pre-Ox foi ensaio clínico de fase III, aleatorizado, duplamente encoberto, e controlado por placebo. Os doentes elegíveis para o estudo apresentavam câncer colorretal com indicação de início de quimioterapia adjuvante com regime FLOX modificado. No estudo PREOX, um total de 220 doentes foram aleatorizados em proporção de 1: 1 a um de dois grupos de tratamento: pregabalina ou placebo. Os doentes receberam a medicação três dias antes e três dias após a infusão de oxaliplatina (nas semanas 1, 3, e 5 a partir de cada um dos três ciclos, em um total de nove sessões). Ou seja, receberam tratamento profilático durante 54 dias 
distribuídos em seis meses (180 dias) de tratamento. Este estudo ainda está em fase de análise, porém os resultados parciais foram predominantemente negativos, o que mostra que o uso de pregabalina náo teve qualquer impacto na neuropatia ou dor neuropática. Não houve, no estudo PreOx, qualquer efeito da pregabalina sobre sintomas de neuropatia periférica, resultados de estudos de condução nervosa ou dor neuropática (de Andrade et al.,2015).

\subsubsection{Presente estudo}

O presente estudo incluiu exclusivamente doentes do braço placebo do estudo PreOx, ou seja, aqueles que não receberam tratamento profilático com pregabalina. O presente estudo constituiu-se da aplicação de questionários, escalas e avaliações clínicas durante os seis meses de tratamento quimioterápico, ou seja, período em que recebem nove infusões de Oxaliplatina espassadas em 21 dias e por seguimento clínico após tratamento quimioterápico de 3 a 6 meses. Assim, cada doente permaneceu no estudo por no mínimo 5 meses ( 1 ciclo de quimioterapia e ao menos 3 meses de seguimento) e no máximo 12 meses ( 3 ciclos de quimioterapia mais 6 meses de seguimento). Foi apresentado termo de consentimento livre e esclarecido (anexo 4) ao doente no momento da consulta médica, quando oferecido o tratamento. As dúvidas foram esclarecidas e TCLE assinado antes que qualquer procedimento fosse realizado. 


\subsection{Fluxograma no modelo "Consort" do recrutamento, inclusão, exclusão e avaliação dos doentes.}

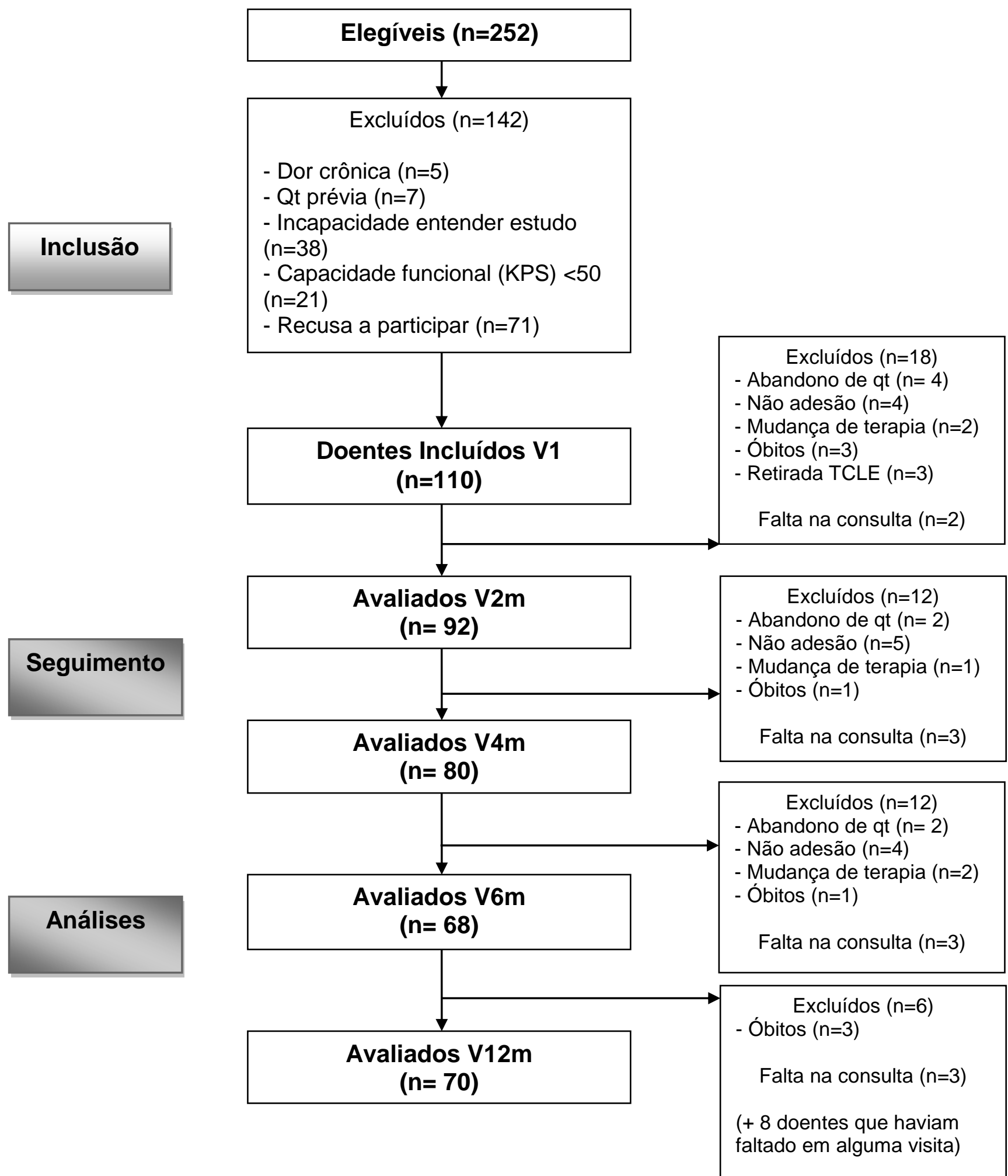

Figura 2. Fluxograma no modelo "Consort" do recrutamento, inclusão, exclusão e avaliação dos doentes 


\subsection{Critérios de inclusão}

Os critérios de inclusão foram os seguintes:

- Câncer colorretal confirmado histologicamente ou citologicamente.

- Indicação de regime de quimioterapia incluindo oxaliplatina (FLOX modificado).

- Idade superior a dezoito anos.

- Capacidade funcional (Karnofsky performance status) superior a 50.

- Capacidade de entender o desenho do estudo.

- Consentir em participar do estudo, mediante assinatura voluntária do Termo de consentimento livre-esclarecido (TCLE) (Anexo 3).

\subsection{Critérios de exclusão}

Os critérios de exclusão foram os seguintes:

- História de exposição à quimioterapia neurotóxica.

- Sinais e sintomas sugestivos de neuropatia periférica ou dor neuropática.

- Neuropatia periférica atual grau $\geq 3$, segundo classificação do NCI-CTC-AE. 
- Funcionamento renal inadequado, evidenciado por exames laboratoriais realizados até 1 semana antes da randomização: Creatinina Sérica $>2.0$ $\mathrm{mg} / \mathrm{dL}$.

- Gravidez (beta HCG positivo).

- Avaliado pelo investigador como incapaz ou indisponível para aderir aos procedimentos e exigências do protocolo.

- História de recebimento de qualquer produto investigacional nos últimos 28 dias antes da randomização.

- Presença de metástases cerebrais.

- História de reações alérgicas atribuídas aos componentes da pregabalina ou da droga em si.

- Comorbidade não controlada, mas não limitada a, infecção ativa, insuficiência cardíaca crônica, angina pectoris instável, arritmia cardíaca, doença psiquiátrica ou situação social que pudesse limitar a adesão aos procedimentos do protocolo.

- Presença de dor (VAS >0) ou resposta "sim" à questão 1 do Inventário Breve de Dor, " Presença de dor nas últimas 24 horas?". 


\subsection{Local do estudo}

O estudo foi realizado no Instituto do câncer do estado de São Paulo (ICESP) e Setor de Eletroneuromiografia do Departamento de Neurologia HCFMUSP. Os doentes foram recrutados no ambulatório da oncologia clínica (tumores sólidos).

\subsection{Instrumentos}

Utilizaram-se as seguintes escalas e questionários para avaliação de dor e seu impacto funcional:

\subsubsection{Ficha clínica sociodemográfica}

Ficha que busca as informações pessoais e clínicas, tais como: nome, idade, sexo, data de nascimento, nível educacional, estado civil, situação conjugal, religião, situação de trabalho, renda, dados clínicos (câncer), doenças prévias, Karnofski performance status (KPS), ECOG, exame físico, sinais vitais, escala de consumo de bebida alcóolica (CAGE) (Anexo 5). 


\subsubsection{Inventario breve de dor - versão curta (BPI- Brief Pain Inventory- short form)}

Desenvolvido primeiramente na língua inglesa por Cleeland (Cleeland, Ryan, 1994) o Inventário breve de dor (BPI) foi validado para a língua portuguesa por Ferreira et al em 2010. Trata-se de instrumento breve e de fácil compreensão que avalia a intensidade da dor e a sua interfência no cotidiano do doente. Também avalia a eficácia do tratamento corrente, a intensidade e localização da dor. Pode ser dividido em duas partes: a primeira refere-se à média de dor, com pontuação de zero a dez; a segunda refere-se a interferência da dor no cotidiano com escore de zero a setenta pontos. O Inventário breve de dor (IBD) está disponível em dois formatos: o formulário breve IBD, que é utilizado para os ensaios clínicos e é a versão utilizada para as traduções de língua estrangeira; e a forma longa, que contém itens adicionais descritivos que podem ser clinicamente úteis (por exemplo, itens que ampliam os possíveis descritores de dor, tais como ardor, formigamento, etc.). $\mathrm{O}$ propósito do IBD é avaliar a gravidade da dor e o impacto da dor em funções diárias. A população alvo são os doentes com dor por doenças ou condições crônicas, como câncer, osteoartrite e dor lombar, ou com dor de condições agudas, como a dor pósoperatória. No IBD avalia-se a gravidade da dor, o impacto da dor na função diária, a localização da dor, medicamentos para a dor e quantidade de alívio da dor nas últimas 24 horas ou na última semana. Pode ser realizado por entrevista ou autorelato. O tempo gasto é de 5 minutos na forma breve e 10 minutos na longa (Anexo 9). 


\subsubsection{Questionário de dor neuropática - 4 (DN4)}

Desenvolvido por Bouhassira et al em 2005 e validado para a língua portuguesa por Santos et al em 2010, o questionário DN4 é um instrumento simples e objetivo com a propriedade de rastrear a dor neuropática. Composto por dez itens, sendo sete obtidos a partir da entrevista com o doente, e três itens obtidos através do exame físico. Considera-se a presença de dor neuropática o escore maior ou igual a quatro pontos em dez. Os autores compararam doentes com dor neuropática (traumáticas, de lesão do nervo, neuralgia pós-herpética e dor pós-AVC) com doentes com dor não neuropática (osteoartrite, artropatias inflamatórias e dor nas costas). Eles observaram que vários sintomas (descritores de dor e parestesia /disestesia) e sinais (dor evocado e déficits sensoriais) foram significativamente mais frequentes no grupo de dor neuropática. A nota de corte de 4 tem um valor preditivo de $86 \%$, sensibilidade de $82,9 \%$ e uma especificidade de $89,9 \%$. DN4 pode ajudar o clínico a determinar a predominância da dor neuropática em um doente com dor mista ou alguém com sintomas equivocados. O DN4 tem 10 perguntas que são facilmente respondidas por "sim" ou "não". Os pontos das respostas positivas no DN4 têm todos o mesmo valor (=1) (Anexo 6). 


\subsubsection{Escore total de neuropatia (Total neuropathy score -TNS)}

O TNS em sua versão completa foi originalmente desenvolvido e validado para neuropatia diabética e inclui a avaliação motora, sensorial, e de sinais e sintomas neurovegetativos, a determinação quantitativa do limiar de percepção de vibração, e o exame neurofisiológico de um motor e um nervo sensorial na perna (Cornblath et al, 1999, Chaudhry et al., 2003). É comumente utilizado em doentes oncológicos para avaliação de neuropatia relacionada à quimioterapia (Anexo 11).

\subsubsection{Inventário de Sintomas de Dor Neuropática (ISDN)}

O Inventário de Sintomas de Dor Neuropática (ISDN ou NPSI, Neuropathic Pain Symptom Inventory) foi desenvolvido na França e Bélgica (Bouhassira et al., 2004) e validado para a língua portuguesa em 2011 (de Andrade et al., 2011). Esse instrumento avalia os diferentes sintomas de dor neuropática. Contem dez descritores com valores de 0 a 10 que permitem discriminação e quantificação de cinco dimensões clínicas distintas e relevantes em síndromes de dores neuropáticas, com valor total de 0 a 100. O ISDN permite a discriminação e quantificação distinta e clinicamente relevante das dimensões de síndromes de dor neuropática (dor espontânea em curso, dor paroxística, dor evocada e parestesia / disestesia) que são 
sensíveis para tratamento. A dor pode ser caracterizada por queimação, aperto ou pressão no indivíduo. A dor em queimação representa o componente superficial, enquanto a pressão e dor em aperto representa o componente profundo do curso da dor espontânea. Os autores recomendam o uso das propriedades psicométricas do ISDN para caracterizar subgrupos de doentes com dor neuropática e verificar a resposta dos doentes para vários agentes farmacológicos ou intervenções. A versão final do ISDN inclui 12 itens; 10 são descritores dos diferentes sintomas, e 2 avaliam a duração da dor contínua e paroxística espontânea. A intensidade total de pontuação é calculada como a soma das pontuações dos 10 descritores. Aumento ou diminuição no escore total do ISDN está relacionado a mudanças na dor do doente. O ISDN avalia os sintomas de doentes com dor neuropática, determina a eficácia dos diferentes tratamentos e ajuda a elucidar os mecanismos de efeito de tais tratamentos. O ISDN avalia dimensões e diferentes sintomas da dor neuropática (Anexo 8).

\subsubsection{Questionário de Dor McGill reduzido (QDMR)}

O Questionário de dor McGill reduzido (McGill Pain Questionaire-MPQ) (Melzack, 1975) traduzido e adaptado para a língua portuguesa por Pimenta e Teixeira (Pimenta; Teixeira, 1996) visa a avaliar as dimensões da experiência dolorosa. A forma abreviada do Questionário de dor McGill (QDMR) foi desenvolvida. 
O principal componente do QDMR é composto por 15 descritores (11 sensoriais; 4 afetivos) que são classificados em uma escala de intensidade como $0=$ nenhum, $1=$ leve, 2 = moderada ou 3 = grave. Três pontuações de dor são derivadas a partir da soma dos valores de classificação da intensidade das palavras escolhidas para descritores sensoriais, afetivas e avaliativas. O QDMR inclui também o índice atual intensidade da dor do QDMR padrão e uma escala visual analógica (VAS) (Anexo 7).

\subsubsection{Questionário de qualidade de vida da organização européia para pesquisa e tratamento do câncer - C30 (EORTC QLQ-C30)}

O EORTC QLQ-C30 é um questionário desenvolvido para avaliar a qualidade de vida de doentes com câncer. O QLQ-C30 (versão 3) incorpora cinco escalas funcionais (física, função cognitiva, emocional e social), três escalas de sintomas (fadiga, dor, náuseas e vómitos), uma escala global do estado de saúde/qualidade de vida (de 1 a 7 , sendo 1 = péssima e 7 = ótima), e um número de itens únicos que avaliam sintomas adicionais comumente relatados por doentes com câncer (dispneia, perda de apetite, insônia, constipação e diarréia) e percebido impacto financeiro da doença. (Anexo 12) 


\subsubsection{Escala hospitalar de ansiedade e depressão (HADS)}

Hospital Anxiety and Depression Scale (HADS) foi originalmente desenvolvido por Zigmond e Snaith (1983) e é comumente usado pelos médicos para determinar os níveis de ansiedade e depressão que um doente está experimentando. A HADS é

uma escala de quatorze itens que gera dados ordinais. Sete dos itens estão relacionados com a ansiedade e sete referem-se à depressão. Zigmond e Snaith criaram este desfecho especificamente para evitar a dependência de aspectos destas condições que também são sintomas somáticos comuns de doença, por exemplo, fadiga e insônia ou hipersonia. O objetivo dos autores foi criar uma ferramenta para a detecção de ansiedade e depressão em pessoas com problemas de saúde física. Cada um dos itens é graduado de zero a três, de modo a compor pontuação máxima de 21 pontos para cada uma das escalas. Escores mais altos indicam mais sintomas. Pontuação $\geq 11$ indica provável presença de depressão ou ansiedade, entre 8-10 possível presença das doenças e $<7$ não há indícios de depressão ou ansiedade (Zigmond, 1983, Marcolino et al., 2007) (Anexo 10). 


\subsection{Forma de análise dos resultados}

Foram incluídos na análise todos os doentes alocados no grupo placebo do estudo PreOx. O processamento e análise dos dados foram efetuados pelo software Statistical Package for the Social Sciences (SPSS) versão 20.0. As medidas descritivas foram analisadas quanto à variabilidade (desvio padrão, mínimo, máximo), tendência central (média e mediana). No que concerne aos instrumentos aplicados, seu banco de dados foi construído no software estatístico SPSS versão 20.0, foi alimentado com os dados coletados. Aferiu-se a normalidade dos dados através do teste de Kolmogorov Smirnov.

Neste estudo adotou-se o nível de significância de 5\% para todos os testes estatísticos. Utilizou-se a análise de variância (Anova) de medidas repetidas para dados de distribuição normal, assim comoo teste t de Student. Também utilizou-se os testes de Kruskal Wallis seguido de Wilcoxon para avaliação de dados não paramétricos. Porcentagens foram comparadas através do teste Chi quadrado e correlações entre sintomas neuropáticos e escores de qualidade de vida foram obtidos através do teste de Spearman. 


\subsection{Casuística}

A amostra foi constituída de 110 doentes. Dos 110 doentes que participaram do estudo presente, 64 eram do sexo feminino. A idade variou de 29 a 74 anos, com uma média de 55,60. A renda familiar teve uma média de 2.222,45 reais. A maioria dos doentes era casada e tinha ensino fundamental completo. A tabela 1 apresenta todos os dados sócio-demográficos. 
Tabela 1 - Distribuição dos doentes em números absolutos $(\mathrm{N})$ e percentagens (\%), idades (em anos), renda familiar, estado civil, situação de trabalho, escolaridade e religião $\begin{array}{lll}\text { Características } & \text { Categorias } & (\mathrm{N}=110)\end{array}$

\begin{tabular}{|c|c|c|c|}
\hline \multirow[t]{2}{*}{ Idade (em anos) } & Média e DP & \multicolumn{2}{|c|}{$55,60 \pm 10,69$} \\
\hline & Mínima e máxima & \multicolumn{2}{|c|}{$(29-77)$} \\
\hline \multirow{3}{*}{$\begin{array}{l}\text { Renda familiar } \\
\text { (em reais) }\end{array}$} & Média e DP & \multicolumn{2}{|c|}{$2222,45 \pm 2160,51$} \\
\hline & Mínima e máxima & \multicolumn{2}{|c|}{$(00,00-10.000,00)$} \\
\hline & & $\mathbf{N}$ & $\%$ \\
\hline \multirow[t]{6}{*}{ Estado civil } & Casado & 55 & 50,0 \\
\hline & Separado & 5 & 4,5 \\
\hline & Viúvo & 18 & 16,4 \\
\hline & Divorciado & 9 & 8,2 \\
\hline & Solteiro & 19 & 17,3 \\
\hline & União Consensual & 4 & 3,6 \\
\hline \multirow[t]{7}{*}{ Situação de Trabalho } & Aposentado & 24 & 21,6 \\
\hline & Licença saúde & 25 & 22,5 \\
\hline & Desempregado & 18 & 16,5 \\
\hline & Dona de casa & 13 & 11,9 \\
\hline & Autônomo & 14 & 12,8 \\
\hline & Empregado & 12 & 11,0 \\
\hline & Informal & 4 & 3,7 \\
\hline \multirow[t]{5}{*}{ Escolaridade } & Ensino Fundamental & 61 & 55,5 \\
\hline & Ensino Médio & 30 & 27,3 \\
\hline & Superior & 8 & 7,3 \\
\hline & Pós-graduação & 3 & 2,7 \\
\hline & Analfabeto & 8 & 7,3 \\
\hline \multirow[t]{4}{*}{ Religião } & Católico & 66 & 60,0 \\
\hline & Evangélico & 35 & 31,8 \\
\hline & Espírita & 2 & 1,8 \\
\hline & Outro & 7 & 6,4 \\
\hline
\end{tabular}

Resultados expressos no modelo de números absolutos e porcentagens. 


\section{RESULTADOS}

\subsection{Análise descritiva das variáveis sociodemográficas relacionadas à doença} oncológica

O presente estudo incluiu doentes (58,18\% mulheres; média de idade 55,6 anos) com neoplasia colorretal confirmada por biópsia, sendo que 38,18\% não apresentavam metástases, 50,5\% com disseminação regional e como local de metástase mais frequente o fígado (14,7\%). As demais características da doença oncológica dos doentes estão expressas na tabela 2. A média do tempo de diagnóstico foi de 4,6 meses. 
Tabela 2. Descrição da amostra referente às características oncológicas quanto ao local da lesão, estadiamento, presença e locais de metástases em números absolutos e porcentagens.

\begin{tabular}{|c|c|c|}
\hline Características & Categorias & $\mathrm{N}=110$ \\
\hline \multirow[t]{4}{*}{ Local } & Cólon & $60(54,6 \%)$ \\
\hline & Reto & $24(21,8 \%)$ \\
\hline & Junção retossigmóide & $20(18,2 \%)$ \\
\hline & Colorretal não especificado & $06(05,5 \%)$ \\
\hline \multirow[t]{7}{*}{ Estadiamento } & I & $02(01,8 \%)$ \\
\hline & IIA & $03(02,7 \%)$ \\
\hline & IIB & $06(05,5 \%)$ \\
\hline & IIIA & $04(03,6 \%)$ \\
\hline & IIIB & $39(35,5 \%)$ \\
\hline & IIIC & $25(22,7 \%)$ \\
\hline & IV & $31(28,2 \%)$ \\
\hline \multirow[t]{3}{*}{ Metástase } & Ausência & $42(38,2 \%)$ \\
\hline & Presença & $32(29,1 \%)$ \\
\hline & Não identificado & $36(32,7 \%)$ \\
\hline \multirow[t]{3}{*}{ Extenção } & Tumor local & $28(25,2 \%)$ \\
\hline & Disseminaçao regional & $56(50,5 \%)$ \\
\hline & Disseminaçao sistemica & $25(22,5 \%)$ \\
\hline \multirow[t]{8}{*}{ Local da metástase } & Trato gastrointestinal & $13(11,9 \%)$ \\
\hline & Pulmão & $11(10,0 \%)$ \\
\hline & Sistema genital & $2(1,8 \%)$ \\
\hline & Sistema urinário & $1(0,9 \%)$ \\
\hline & Coluna vertebral & $5(4,6 \%)$ \\
\hline & Fígado & $16(14,7 \%)$ \\
\hline & Rins & $2(1,8 \%)$ \\
\hline & Outros & $5(4,6 \%)$ \\
\hline
\end{tabular}

Resultados expressos no modelo de números absolutos e porcentagens.

\subsection{Inventário breve de dor (IBD)}

O Inventário breve de dor categoriza a dor em 4 tipos, dor mais intensa nas últimas 24 horas, dor mais fraca nas últimas 24 horas, dor mais fraca nas últimas 24 horas, dor média e dor atual. As médias de dor através do BPI foram maiores durante a visita 3. Na tabela 3 estão expressas todas as médias nas cinco visitas. 
Tabela 3 - Distribuição das médias de dor utilizando o Inventário breve de dor dividido em quatro categorias, dor mais intensa na últimas 24 horas, dor mais fraca nas últimas 24 horas, dor média, dor atual e o quanto interfere nas atividades do dia-dia avaliadas nas cinco visitas, em médias, desvios padrões padrões e graus de significância

\begin{tabular}{|c|c|c|c|c|c|c|}
\hline IBD & Vbasal & V2 & V3 & V4 & Vfinal & $p^{*}$ \\
\hline Categorias & $\mathrm{N}=110$ & $\mathrm{~N}=92$ & $\mathrm{~N}=69$ & $\mathrm{~N}=59$ & $\mathrm{~N}=70$ & \\
\hline $\begin{array}{l}\text { Dor mais intensa } \\
(24 \mathrm{~h})\end{array}$ & 00 & $1,17 \pm 2$ & $2,54 \pm 3,66^{\star *}$ & $1,85 \pm 3$ & $0,71 \pm 2,39 \infty$ & $<0,0001$ \\
\hline Dor mais fraca (24h) & $0,00 \pm 0,00$ & $0,59 \pm 1,43$ & $1,41 \pm 1,43^{\star *}$ & $1,24 \pm 2,39^{\star *}$ & $0,59 \pm 2,04$ & 0,006 \\
\hline Dor média & $0,00 \pm 0,00$ & $0,78 \pm 1,66^{* *}$ & $2,00 \pm 2,81^{* *}$ & $1,44 \pm 2,56^{\star *}$ & $0,63 \pm 2,13$ & 0,001 \\
\hline Dor atual & $0,00 \pm 0,00$ & $0,28 \pm 1,03$ & $0,88 \pm 2,01$ & $0,35 \pm 1,18$ & $0,40 \pm 1,78$ & 0,102 \\
\hline \multicolumn{7}{|c|}{$\begin{array}{l}\text { IBD: Inventário breve de dor; Vbasal: visita basal; V2: visita após } 2 \text { meses de quimioterapia; V3: visita após } 4 \\
\text { meses de quimioterapia; V4: visita após } 6 \text { meses de quimioterapia; Vfinal: visita de seguimento pós quimioterapia; } \\
\text { DP: Desvio padrão. p: grau de significância; *Anova de medidas repetidas (Bonferroni); }{ }^{*} \text { grau de significância } \\
<0,05 \text { comparando com Vbasal; } \infty \text { grau de significância }<0,05 \text { entre V3 e Vfinal; agrau de significância }<0,05 \text { entre } \\
\text { V2 e Vfinal; § grau de significância }<0,05 \text { entre V4 e Vfinal; £ grau de significância <0,05 entre V2 e V3. }\end{array}$} \\
\hline
\end{tabular}

O Inventário breve de dor também contempla uma avaliação de qualidade de vida através de escala de 1 a 10 onde o doente assinala quanto a dor está interferindo em atividades frequentes (atividade geral, humor, habilidade de caminhar, trabalho, relacionamento com outras pessoas, sono e habilidade para apreciar a vida). A avaliação da interferência mostrou aumento durante o tratamento quimioterápico conforme mostra a tabela 4. 
Tabela 4 - Avaliação da média de interferência da dor nas atividades de vida diária utilizando o Inventário breve de dor (item 9 subdividido nos itens: atividade geral, humor, habilidade de caminhar, trabalho, relacionamento com outras pessoas, sono e habilidade para apreciar a vida) nas cinco visitas em médias, desvios padrões e graus de significância

\begin{tabular}{|c|c|c|c|c|c|c|}
\hline & Vbasal & V2 & V3 & V4 & Vfinal & $p^{*}$ \\
\hline IBD Interferência & $\mathrm{N}=110$ & $\mathrm{~N}=92$ & $\mathrm{~N}=69$ & $\mathrm{~N}=59$ & $\mathrm{~N}=70$ & \\
\hline AVD & $0,00 \pm 0,00$ & $0,83 \pm 2,25$ & $1,60 \pm 3,17^{\star \star}$ & $0,58 \pm 1,79$ & $0,65 \pm 2,33$ & 0,044 \\
\hline Humor & $0,00 \pm 0,00$ & $0,60 \pm 1,98$ & $1,32 \pm 2,82$ & $0,10 \pm 0,63$ & $0,48 \pm 2,10$ & 0,027 \\
\hline Andar & $0,00 \pm 0,00$ & $0,35 \pm 1,56$ & $0,37 \pm 1,65$ & $0,45 \pm 1,70$ & $0,67 \pm 2,41$ & 0,453 \\
\hline Trabalho básico & $0,00 \pm 0,00$ & $0,85 \pm 2,30$ & $1,47 \pm 3,05^{\star *}$ & $0,77 \pm 216$ & $0,67 \pm 2,41$ & 0,851 \\
\hline Relacionamentos & $0,00 \pm 0,00$ & $0,25 \pm 1,29$ & $0,58 \pm 2,24$ & $0,00 \pm 0,00$ & $0,48 \pm 2,10$ & 0,251 \\
\hline Sono & $0,00 \pm 0,00$ & $0,30 \pm 1,32$ & $0,68 \pm 2,11$ & $0,35 \pm 1,56$ & $0,48 \pm 2,10$ & 0,440 \\
\hline Aproveitar vida & $0,00 \pm 0,00$ & $0,28 \pm 1,09$ & $0,85 \pm 2,56$ & $0,00 \pm 0,00$ & $0,49 \pm 2,12$ & 0,114 \\
\hline TOTAL & $0,00 \pm 0,00$ & $3,53 \pm 1,54$ & $6,33 \pm 2,20$ & $2,30 \pm 1,02$ & $4,00 \pm 2,43$ & 0,126 \\
\hline
\end{tabular}

BPI: Inventário breve de dor; Vbasal: visita basal; V2: visita após 2 meses de quimioterapia; V3: visita após 4 meses de quimioterapia; V4: visita após 6 meses de quimioterapia; Vfinal: visita de seguimento pós quimioterapia; DP: Desvio padrão. p: grau de significância; *Anova de medidas repetidas (Bonferroni); AVD: atividades de vida diária; **grau de significância <0,05 comparando com Vbasal; agrau de significância $<0,05$ entre V2 e Vfinal; œgrau de significância $<0,05$ entre V3 e Vfinal; § grau de significância $<0,05$ entre V4 e Vfinal; $£$ grau de significância $<0,05$ entre V2 e V3. 


\subsection{Questionário de dor neuropática (DN4)}

A proposta do questionário DN4 é identificar se determinada dor tem caráter neuropático e isso se dá quanto 4 ou mais sintomas estão presentes dentro de uma lista de 10. A tabela 5 mostra quantos doentes apresentaram DN4 positivo, isso é, apresentavam quatro ou mais sintomas nas 5 visitas. Observa-se diferenças estatisticamente significantes em comparação com a visita basal e também entre V3 e após seguimento (Vfinal).

Tabela 5 - Frequência de doentes com DN4 positivo ( $\geq 4$, o que indica possibilidade de dor neuropática presente) utilizando o questionário para diagnóstico de dor neuropática (DN4) em números absolutos, porcentagens e graus de significância durante as $\mathbf{5}$ visitas

\begin{tabular}{lrcccc}
\hline & Vbasal & V2 & V3 & V4 & Vfinal \\
\hline DN4 Positivo & $\mathrm{N}=110$ & $\mathrm{~N}=92$ & $\mathrm{~N}=69$ & $\mathrm{~N}=59$ & $\mathrm{~N}=70$ \\
& & & & & \\
& $0(0,00 \%)$ & $14(15,22 \%)$ & $17(24,64 \%)^{* *}$ & $13(21,67 \%)^{* *}$ & $7(10,00 \%)^{\infty}$
\end{tabular}

DN4: questionário de dor neuropática; Vbasal: visita basal; V2: visita após 2 meses de quimioterapia; V3: visita após 4 meses de quimioterapia; V4: visita após 6 meses de quimioterapia; Vfinal: visita de seguimento pós quimioterapia; DP: desvio padrão; :: maior ou igual. p: grau de significância; *teste chi-quadrado; ${ }^{\star *}$ grau de significância <0,05 comparando com vbasal; agrau de significância <0,05 entre V2 e Vfinal; $\infty$ grau de significância $<0,05$ entre V3 e Vfinal; § grau de significância $<0,05$ entre V4 e Vfinal; £ grau de significância $<0,05$ entre V2 e V3.

A tabela 6 mostra os resultados do questionário de dor DN4 através de médias e desvios padrões e os valores de significância. Nota-se similarida aos resultados da tabela anterior, isto é, a prevalência aumentou até a visita 3 e diminuiu em seguida. 
Tabela 6 - Distribuiçao da intensidade de dor nos doentes utilizando o questionário para diagnóstico de dor neuropática (DN4) em médias, desvios padrões, valores mínimos e máximos e graus de significância durante as 5 visitas

\begin{tabular}{|c|c|c|c|c|c|c|}
\hline & Vbasal & V2 & V3 & $\overline{V 4}$ & Vfinal & $p^{*}$ \\
\hline \multirow[t]{3}{*}{ DN4 } & $\mathrm{N}=110$ & $\mathrm{~N}=92$ & $\mathrm{~N}=69$ & $\mathrm{~N}=59$ & $\mathrm{~N}=70$ & \\
\hline & $0,02 \pm 0,15$ & $1,15 \pm 2,67^{\star *}$ & $1,53 \pm 2,44^{* *}$ & $1,27 \pm 2,22^{\star *}$ & $0,63 \pm 1,80 a$ & $<0,0001$ \\
\hline & $0,00-2,00$ & $0,00-9,00$ & $0,00-7,00$ & $0,00-7,00$ & $0,00-8,00$ & \\
\hline \multicolumn{7}{|c|}{$\begin{array}{l}\text { DN4: questionário para diagnóstico de dor neuropática; Vbasal: visita basal; V2: visita após } 2 \text { meses de } \\
\text { quimioterapia; V3: visita após } 4 \text { meses de quimioterapia; V4: visita após } 6 \text { meses de quimioterapia; Vfinal: visita } \\
\text { de seguimento pós quimioterapia; DP: desvio padrão; } \geq \text { : maior ou igual. p: grau de significância; *Anova de } \\
\text { medidas repetidas; **grau de significância }<0,05 \text { comparando com vbasal; agrau de significância }<0,05 \text { entre V2 e } \\
\text { Vfinal; } \infty \text { grau de significância }<0,05 \text { entre V3 e Vfinal; } § \text { grau de significância }<0,05 \text { entre V4 e Vfinal; £ grau de } \\
\text { significância }<0,05 \text { entre V2 e V3. }\end{array}$} \\
\hline
\end{tabular}

\subsection{Escore total de neuropatia (TNS)}

A aplicação do instrumento TNS foi realizada na primeira visita, após quimioterapia e após seguimento. Observou-se aumento na amplitude sural e amplitude peroneal, como descritos na tabela 7 . 
Tabela 7 - Médias de dor neuropática utilizando o Escore total de neuropatia (TNS) avaliadas em três visitas, na visita basal, após tratamento quimioterápico e após seguimento em médias, desvios padrões, valores mínimos e máximos e graus de significância

$$
\begin{array}{llll}
\text { Vbasal } & \text { V4 } & \text { Vfinal }
\end{array}
$$

TNS

$$
\begin{array}{cccc}
\mathrm{N}=92 & \mathrm{~N}=47 & \mathrm{~N}=39 & \\
1,15 \pm 2,28 & 3,63 \pm 3,78^{\star *} & 4,12 \pm 3,76^{\star \star} & <0,0001 \\
0,00-15,00 & 0,00-16,00 & 0,00-15,00 &
\end{array}
$$

TNS: Escore total de neuropatia; Vbasal: visita basal; V2: visita após 2 meses de quimioterapia; V3: visita após 4 meses de quimioterapia; V4: visita após 6 meses de quimioterapia; Vfinal: visita de seguimento pós quimioterapia; DP: desvio padrão; $\geq$ : maior ou igual. p: grau de significância; *Anova de medidas repetidas; *kgrau de significância <0,05 comparando com Vbasal; agrau de significância $<0,05$ entre V2 e Vfinal; $\infty$ grau de significância $<0,05$ entre V3 e Vfinal; § grau de significância $<0,05$ entre V4 e Vfinal; £ grau de significância $<0,05$ entre V2 e V3.

Nota-se que os números de amostra das visitas V4 e após seguimento são muito menores do que em relação aos outros questionários. Isso ocorreu pois parte do TNS constitui-se de exame eletrofisiológico e muitos doentes recusaram-se a participar após a quimioterapia.

Em relação aos graus, no basal $96,7 \%$, após quimioterapia $89,4 \%$ e após seguimento $89,7 \%$ apresentaram grau 1. Como grau 2 foram 2,2\% no basal, $8,5 \%$ após quimioterapia e 2,7\% após seguimento. Como grau 3, 1,1\% no basal, 2,1\% após quimioterapia e 2,6\% após seguimento. Não houve diferença estatística. 


\subsection{Inventário de sintomas de dor neuropática (ISDN)}

Realizou-se análise das médias do Inventário de sintomas de dor neuropática. Nota-se que as médias aumentam significantemente após a primeira visita e que diminuiram nas visitas seguintes, no entanto, foi significantemente mais intensa ao fim do seguimento em relação ao início do estudo, tendo um pico durante o tratamento quimioterápico $(\mathrm{V} 2)$. A seguir, tabela $8 \mathrm{com}$ os resultados das médias e desvios padrões.

Tabela 8 - Médias de dor neuropática de acordo com o Inventário de sintomas de dor neuropática avaliadas nas cinco visitas, em médias, desvios padrões, valores mínimos e máximos e graus de significância

\begin{tabular}{ccccccc}
\hline & Vbasal & V2 & V3 & V4 & Vfinal & $\boldsymbol{p}^{*}$ \\
\hline ISDN & $\mathrm{N}=110$ & $\mathrm{~N}=92$ & $\mathrm{~N}=69$ & $\mathrm{~N}=59$ & $\mathrm{~N}=70$ & \\
& $0,67 \pm 3,21$ & $18,67 \pm 18,62^{* *}$ & $17,77 \pm 18,03^{* *}$ & $17,44 \pm 16,83^{* *}$ & $11,03 \pm 14,57^{* *}$ & $<0,0001$ \\
& $(0,00-19,00)$ & $(0,00-55,00)$ & $(0,00-81,00)$ & $(0,00-64,00)$ & $(0,00-70,00)$ & \\
\hline
\end{tabular}

ISDN: Inventario de sintomas de dor neuropática; Vbasal: visita basal; V2: visita após 2 meses de quimioterapia; V3: visita após 4 meses de quimioterapia; V4: visita após 6 meses de quimioterapia; Vfinal: visita de seguimento pós quimioterapia; $p$ : grau de significância; *Anova de medidas repetidas (Bonferroni); ${ }^{* *}$ grau de significância $<0,05$ comparando com Vbasal; agrau de significância <0,05 entre V2 e Vfinal; $\infty$ grau de significância <0,05 entre V3 e Vfinal; § grau de significância <0,05 entre V4 e Vfinal; £ grau de significância <0,05 entre V2 e V3.

Este inventário tambem foi analisado por números absolutos e porcentagens de doentes que relatam ao menos um dos sintomas. Nota-se diferenças estatisticamente significativas de todas as visitas em relação à visita basal e entre as visitas V3 e após seguimento. A tabela 9 mostra estes resultados. 
Tabela 9 - Números absolutos e porcentagens de doentes com pelo menos um sintoma do Inventário de sintomas de dor neuropática presente (VAS $>0$ ) avaliados nas cinco visitas e graus de significância

\begin{tabular}{cccccc}
\hline & Vbasal & V2 & V3 & V4 & Vfinal \\
\hline ISDN & $\mathrm{N}=110$ & $\mathrm{~N}=92$ & $\mathrm{~N}=69$ & $\mathrm{~N}=59$ & $\mathrm{~N}=70$ \\
& $3(2,7 \%)$ & $70(77,8 \%)^{* *}$ & $53(77,9 \%)^{* *}$ & $47(82,5 \%)^{* *}$ & $33(47,1 \%)^{* *} \infty$
\end{tabular}

ISDN: Inventário de sintomas de dor neuropática; Vbasal: visita basal; V2: visita após 2 meses de quimioterapia; V3: visita após 4 meses de quimioterapia; V4: visita após 6 meses de quimioterapia; Vfinal: visita de seguimento pós quimioterapia; $p$ : grau de significância; *teste chi-quadrado; **grau de significância $<0,05$ comparando com Vbasal; agrau de significância $<0,05$ entre V2 e Vfinal; $\infty$ grau de significância $<0,05$ entre V3 e Vfinal; § grau de significância $<0,05$ entre V4 e Vfinal; £ grau de significância $<0,05$ entre V2 e V3.

Avaliando-se cada item do ISDN, é possível verificar que as características com maior prevalência são frio doloroso, choque elétrico, dormência e alfinetada/agulhada. A seguir tabela $10 \mathrm{com}$ os resultados de todas as características em médias e desvios-padrões de acordo com o ISDN. Nota-se prevalência significativa após a primeira visita e que diminui nos momentos seguintes, porém continua presente. 
Tabela 10 - Distribuição dos descritores de dor neuropática (queimação, aperto, pressão, choque elétrico, apunhalada, dor ao toque, dor à pressão, frio doloroso, alfinetada/agulhada e dormência) avaliados (VAS > 0) através do Inventário de sintomas de dor neuropática avaliados nas cinco visitas, em médias, desvios padrões e graus de significância

\begin{tabular}{|c|c|c|c|c|c|c|}
\hline ISDN & Vbasal & V2 & V3 & V4 & Vfinal & $p^{\star}$ \\
\hline Descritores & $\mathrm{N}=110$ & $\mathrm{~N}=92$ & $\mathrm{~N}=69$ & $\mathrm{~N}=59$ & $\mathrm{~N}=70$ & \\
\hline Queimação & $0,00 \pm 0,00$ & $0,61 \pm 1,72$ & $1,41 \pm 2,80^{* *}$ & $0,95 \pm 2,20$ & $0,63 \pm 2,13$ & 0,023 \\
\hline Aperto & $0,00 \pm 0,00$ & $0,24 \pm 1,11$ & $1,00 \pm 2,32$ & $1,12 \pm 2,31$ & $0,68 \pm 2,25$ & 0,047 \\
\hline Pressão & $0,00 \pm 0,00$ & $0,32 \pm 1,15$ & $0,90 \pm 2,28$ & $1,15 \pm 2,65$ & $0,61 \pm 2,22$ & 0,063 \\
\hline Choque elétrico & $0,15 \pm 0,93$ & $3,85 \pm 2,99$ ** & $3,37 \pm 3,07^{\star *}$ & $3,51 \pm 3,13^{* *}$ & $0,68 \pm 1,87^{* *} \alpha \infty \S$ & $<0,0001$ \\
\hline Apunhalada & $0,00 \pm 0,00$ & $0,23 \pm 1,00$ & $0,48 \pm 1,72$ & $0,20 \pm 0,99$ & $0,08 \pm 0,47$ & 0,271 \\
\hline Dor ao toque & $0,00 \pm 0,00$ & $0,68 \pm 1,94$ & $2,05 \pm 3,20^{* *}$ & $0,83 \pm 2,33$ & $0,15 \pm 0,65 \infty$ & 0,001 \\
\hline Dor à pressão & $0,00 \pm 0,00$ & $0,70 \pm 1,96$ & $1,90 \pm 3,25^{\star *}$ & $1,03 \pm 2,62$ & $0,70 \pm 2,01$ & 0,008 \\
\hline Frio doloroso & $0,00 \pm 0,00$ & $4,27 \pm 3,63^{\star \star}$ & $4,34 \pm 3,33^{* *}$ & $4,24 \pm 3,6^{\star *}$ & $1,85 \pm 3,07^{* *} \alpha \infty \S$ & $<0,0001$ \\
\hline $\begin{array}{l}\text { Alfinetada/ } \\
\text { Agulhada }\end{array}$ & $0,15 \pm 0,93$ & $1,37 \pm 2,34^{* *}$ & $2,15 \pm 3,08^{* *}$ & $1,68 \pm 2,64^{* *}$ & $1,07 \pm 2,80$ & 0,003 \\
\hline Dormência & $0,34 \pm 1,52$ & $3,05 \pm 3,02^{* *}$ & $2,90 \pm 3,15^{\star *}$ & $2,83 \pm 3,15^{* *}$ & $2,39 \pm 2,89^{* *}$ & $<0,0001$ \\
\hline
\end{tabular}

ISDN: Inventário de sintomas de dor neuropática; Vbasal: visita basal; V2: visita após 2 meses de quimioterapia; V3: visita após 4 meses de quimioterapia; V4: visita após 6 meses de quimioterapia; Vfinal: visita de seguimento pós quimioterapia; DP: Desvio padrão; *Anova de medidas repetidas (Bonferroni); ${ }^{* *}$ grau de significância $<0,05$ comparando com Vbasal; agrau de significância $<0,05$ entre V2 e Vfinal; $\infty$ grau de significância $<0,05$ entre V3 e Vfinal; § grau de significância $<0,05$ entre V4 e Vfinal

\subsection{Questionário de dor McGill reduzido}

Os resultados da avaliação com o questionário de dor McGill reduzido revelam leve aumento dos escores durante a quimioterapia e retorno às médias baixas após o seguimento de 3 a 6 meses. Esse padrão se repete em todos os 3 aspectos, porém de forma mais expressiva no aspecto sensitivo (médias de 0,10 na Vbasal, 2,71 na 
V2, 2,62 na V3, 2,31 após quimioterapia e 1,12 após seguimento. A seguir, tabela 11 com os resultados nos 3 aspectos avaliativos: afetivo, avaliativo e sensitivo e o total nos 5 momentos de avaliação. Verificou-se como significativa a diferença em relação ao basal e o aspecto "sensitivo" foi significantemente diferente da visita ao fim do estudo em relação ao fim da quimioterapia. A tabela 11 mostra os resultados em médias de cada aspecto nas 5 visitas.

Tabela 11 - Distribuição de dor nas cinco visitas através do questionário de dor McGill resumido, nos três aspectos: afetivo, avaliativo e sensitivo, bem como no total, em médias, desvios padrões, valores mínimos e máximos e graus de significância

\begin{tabular}{lcccccc}
\hline & Vbasal & V2 & V3 & V4 & Vfinal & $p^{*}$ \\
& & & & & & \\
\hline McGill & $\mathrm{N}=110$ & $\mathrm{~N}=92$ & $\mathrm{~N}=69$ & $\mathrm{~N}=59$ & $\mathrm{~N}=70$ & \\
& & & & & & \\
Afetiva & $0,00 \pm 0,00$ & $1,30 \pm 1,56^{\star *}$ & $1,39 \pm 1,45^{\star *}$ & $1,34 \pm 1,27^{\star *}$ & $0,88 \pm 1,13^{\star *}$ & $<0,0001$ \\
& $0,00-0,00$ & $0,00-5,00$ & $0,00-5,00$ & $0,00-5,00$ & $0,00-4,00$ & \\
Avaliativa & $0,00 \pm 0,00$ & $0,60 \pm 0,54^{* *}$ & $0,79 \pm 0,60^{* *}$ & $0,72 \pm 0,50^{\star *}$ & $0,58 \pm 0,54^{* *}$ & $<0,0001$ \\
& $0,00-0,00$ & $0,00-2,00$ & $0,00-2,00$ & $0,00-2,00$ & $0,00-2,00$ & \\
Sensitiva & $0,10 \pm 0,64$ & $2,71 \pm 2,27^{* *}$ & $2,62 \pm 2,41^{* *}$ & $2,31 \pm 2,12^{* *}$ & $1,12 \pm 2,00$ a & $<0,0001$ \\
& $0,00-4,00$ & $0,00-8,00$ & $0,00-8,00$ & $0,00-7,00$ & $0,00-7,00$ & \\
Total & $0,18 \pm 1,14$ & $4,71 \pm 3,92^{\star *}$ & $4,94 \pm 3,86^{* *}$ & $4,32 \pm 3,15^{\star *}$ & $2,60 \pm 3,65^{\star *}$ & $<0,0001$ \\
& $0,00-7,00$ & $0,00-14,00$ & $0,00-13,00$ & $0,00-13,00$ & $0,00-14,00$ & \\
\hline
\end{tabular}

McGill: Questionário de dor McGill reduzido; Vbasal: visita basal; V2: visita após 2 meses de quimioterapia; V3: visita após 4 meses de quimioterapia; V4: visita após 6 meses de quimioterapia; Vfinal: visita de seguimento pós quimioterapia; $p$ : grau de significância; *Anova de medidas repetidas; **grau de significância $<0,05$ comparando com Vbasal; agrau de significância $<0,05$ entre V2 e Vfinal; $\infty$ grau de significância $<0,05$ entre V3 e Vfinal; § grau de significância $<0,05$ entre V4 e Vfinal; £ grau de significância $<0,05$ entre V2 e V3.

A fim de melhor se avaliar as características da dor relacionada à oxaliplatina avaliou-se o QDMR em cada item, separadamente. Os doentes referiram a dor como incômoda, aborrecida e enjoada e do tipo choque e agulhada, principalmente. A seguir, tabela 12 com todos os resultados. 
Tabela 12 - Distribuição dos descritores de dor neuropática (latejante, pontada, choque, finaagulhada, fisgada, queimação, que espalha, dolorida, cansativa-exaustiva, enjoada, sufocante, apavorante-enlouquecedora, aborrecida, incômoda e insuportável) avaliados através do questionário de dor McGill reduzido avaliados nas cinco visitas em números absolutos (N), porcentagens(\%) e graus de significância

\begin{tabular}{|c|c|c|c|c|c|}
\hline & Vbasal & V2 & V3 & V4 & Vfinal \\
\hline Características & $\mathrm{N}=110$ & $\mathrm{~N}=92$ & $\mathrm{~N}=69$ & $\mathrm{~N}=59$ & $\mathrm{~N}=70$ \\
\hline Latejante & $0(0,0 \%)$ & $18(19,6 \%)^{* *}$ & $14(17,7 \%)^{\star *}$ & $19(32,8 \%)^{* *}$ & $6(8,7 \%)$ \\
\hline Pontada & $1(0,9 \%)$ & $28(30,4 \%)^{\star *}$ & $22(31,9 \%)^{\star *}$ & $18(31,0 \%)^{* *}$ & $9(13,0 \%)^{\infty}$ \\
\hline Choque & $3(2,7 \%)$ & $61(66,3 \%)^{\star *}$ & $42(60,9 \%)^{\star *}$ & $36(62,1 \%)^{* *}$ & $14(20,3 \%)^{\mathfrak{d} \infty} \S$ \\
\hline Fina-agulhada & $1(0,9 \%)$ & $31(33,7 \%)^{\star \star}$ & $28(40,6 \%)$ & $21(36,2 \%)^{\star *}$ & $14(20,3 \%)$ \\
\hline Fisgada & $1(0,9 \%)$ & $21(22,8 \%)^{\star *}$ & $21(30,4 \%)^{\star \star}$ & $15(25,9 \%)$ & $10(14,5 \%)$ \\
\hline Queimação & $0(0,0 \%)$ & $12(13,0 \%)$ & $15(21,7 \%)^{\star *}$ & $11(19,0 \%)$ & $8(11,6 \%)$ \\
\hline Espalha & $1(0,9 \%)$ & $13(14,1 \%)^{\star \star}$ & $16(23,2 \%)^{\star *}$ & $11(19,0 \%)$ & $4(5,8 \%)^{\infty}$ \\
\hline Dolorida & $0(0,0 \%)$ & $24(26,1 \%)^{* *}$ & $27(39,1 \%)^{\star *} £$ & $20(34,5 \%)^{* *}$ & $9(13,0 \%)^{\infty}$ \\
\hline Cansativa-exaustiva & $2(1,8 \%)$ & $26(28,3 \%)$ & $24(34,8 \%)^{\star \star}$ & $23(39,7 \%)^{* *}$ & $11(16,2 \%)^{\infty}$ \\
\hline Enjoada & $2(1,8 \%)$ & $39(42,4 \%)^{\star *}$ & $29(42,0 \%)^{\star *}$ & $31(53,4 \%)^{\star *}$ & $19(27,5 \%)^{\infty}$ \\
\hline Sufocante & $1(0,9 \%)$ & $7(7,6 \%)$ & $12(17,4 \%)^{\star \star}$ & $6(10,3 \%)$ & $3(4,3 \%)$ \\
\hline $\begin{array}{l}\text { Apavorante- } \\
\text { enlouquecedora }\end{array}$ & $0(0,0 \%)$ & $4(4,3 \%)$ & $9(13,0 \%)$ & $3(5,2 \%)$ & $3(4,3 \%)$ \\
\hline Aborrecida & $1(0,9 \%)$ & $32(34,8 \%)^{\star *}$ & $37(53,6 \%)^{\star \star}$ & $29(50,0 \%)^{\star \star}$ & $17(24,6 \%)^{* \star} \infty$ \\
\hline Incômoda & $2(1,8 \%)$ & $57(62,0 \%)^{\star *}$ & $44(63,8 \%)^{\star *}$ & $42(72,4 \%)^{\star *}$ & $28(40,6 \%)$ \\
\hline Insuportável & $0(0,0 \%)$ & $8(8,7 \%)$ & $8(11,6 \%)$ & $3(5,2 \%)$ & $3(4,3 \%)$ \\
\hline \multicolumn{6}{|c|}{$\begin{array}{l}\text { McGill: Questionário de dor McGill reduzido; Vbasal: visita basal; V2: visita após } 2 \text { meses de quimioterapia; V3: } \\
\text { visita após } 4 \text { meses de quimioterapia; V4: visita após } 6 \text { meses de quimioterapia; Vfinal: visita de seguimento pós } \\
\text { quimioterapia; N: numero de doentes que refereriram esse item como presente. p: grau de significância; *Chi- } \\
\text { square test; }{ }^{* *} \text { grau de significância }<0,05 \text { comparando com Vbasal; agrau de significância }<0,05 \text { entre V2 e Vfinal; } \\
\text { œgrau de significância }<0,05 \text { entre V3 e Vfinal; } § \text { grau de significância }<0,05 \text { entre V4 e Vfinal; } £ \text { grau de } \\
\text { siqnificância }<0,05 \text { entre V2 e V3. }\end{array}$} \\
\hline
\end{tabular}


Na tabela 12 se observou que a partir da V2 ocorre manifestação dos sinais e sintomas de dor, com as principais características relatadas pelos participantes como choque (66,3\%), incômoda (62\%) e enjoada (42,4\%). No decorrer das demais visitas, observa-se um declínio dos sinais e sintomas. Entretanto, após seguimento ainda esteve presente dor com as características de incômoda (40,6\%), enjoada $(27,5 \%)$ e aborrecida (24,6\%). Verificou-se que os descritores "choque", "pontada", "finaagulhada", "dolorida", "cansativa-exaustiva", "aborrecida" e "incômoda" foram os mais relatados, sendo que o descritor "choque" teve queda significativa entre as avaliações ao término da quimioterapia e ao fim do seguimento.

\subsection{Auto-avalição de saúde e qualidade de vida}

O questionário EORTC-QLQ-C30 avalia a qualidade de vida do paciente através de sintomas como diarreia, prisão de ventre, náusea, problemas em dormir,

fraqueza entre outros, e o doente escolhe entre os escores de 1 (não apresentou 0 sintoma) a 4 (grave). A tabela 13 mostra as médias dos escores da primeira parte do EORTC-QLQ. 
Tabela 13 - Escore total de sintomas do questionário EORTC-QLQ30 (ANEXO 13) avaliados nas cinco visitas em médias, desvios padrões e graus de significância

\begin{tabular}{lcccccc}
\hline EORTC & Vbasal & V2 & V3 & V4 & Vfinal & $\boldsymbol{p}^{\star}$ \\
\hline & $\mathrm{N}=110$ & $\mathrm{~N}=92$ & $\mathrm{~N}=69$ & $\mathrm{~N}=59$ & $\mathrm{~N}=70$ & \\
$\begin{array}{l}\text { Escore total } \\
\text { de sintomas }\end{array}$ & $39,36 \pm 8,36$ & $43,11 \pm 11,72$ & $41,46 \pm 11,66$ & $39,80 \pm 12,01$ & $40,15 \pm 13,11$ & 0,181 \\
$\begin{array}{l}\text { Mínimo e } \\
\text { máximo }\end{array}$ & $28,00-75,00$ & $28,00-94,00$ & $28,00-78,00$ & $28,00-82,00$ & $28,00-79,00$ & \\
\hline EORTC-QLQ30: & The European Organization for Research and Treatment of Cancer; Vbasal: visita basal; V2:
\end{tabular}

visita após 2 meses de quimioterapia; V3: visita após 4 meses de quimioterapia; V4: visita após 6 meses de quimioterapia; Vfinal: visita de seguimento pós quimioterapia; $p$ : grau de significância; *Anova de medidas repetidas (Bonferroni); ** grau de significância $<0,05$ comparando com Vbasal; agrau de significância $<0,05$ entre V2 e Vfinal; œgrau de significância $<0,05$ entre V3 e Vfinal; § grau de significância $<0,05$ entre V4 e Vfinal; £ grau de significância $<0,05$ entre V2 e V3.

A segunda parte do instrumento EORTC-QLQ consiste em uma autoavaliação de saúde geral e qualidade de vida. Avaliando pela média geral pode-se observar na tabela 14 que não houve mudança expressiva durante o estudo. A tabela 14 mostra os resultados avaliados na visita basal, visita 2 (após 2 meses), visita 3 (após 4 meses), visita 4 (após tratamento com oxaliplatina) e visita final (após 3 a 6 meses de acompanhamento após quimioterapia). Pode-se notar que os escores foram diminuindo com o tempo. 
Tabela 14 - Saúde geral e qualidade de vida dos doentes através de auto-avaliação usando o questionário EORTC-QLQ30, questões 29 e 30 (ANEXO 13) avaliados nas cinco visitas em médias, desvios padrões e graus de significância

\begin{tabular}{|c|c|c|c|c|c|c|}
\hline EORTC & Vbasal & V2 & V3 & V4 & Vfinal & $p^{\star}$ \\
\hline & $\mathrm{N}=110$ & $\mathrm{~N}=92$ & $\mathrm{~N}=69$ & $\mathrm{~N}=59$ & $\mathrm{~N}=70$ & \\
\hline $\begin{array}{l}\text { Saúde geral } \\
\text { (29) }\end{array}$ & $5,37 \pm 1,59$ & $5,39 \pm 1,44$ & $5,29 \pm 1,40$ & $5,46 \pm 1,00$ & $5,83 \pm 1,26$ & 0,265 \\
\hline $\begin{array}{l}\text { Qualidade de } \\
\text { vida (30) }\end{array}$ & $5,28 \pm 1,69$ & $5,33 \pm 1,32$ & $5,43 \pm 1,37$ & $5,43 \pm 1,05$ & $5,80 \pm 1,26$ & 0,217 \\
\hline
\end{tabular}

Em ambos questionários utiliza-se uma escala de Likert com escore de 1 (péssima) a 7 (ótima). EORTC-QLQ30:

The European Organization for Research and Treatment of Cancer; Vbasal: visita basal; V2: visita após 2 meses de quimioterapia; V3: visita após 4 meses de quimioterapia; V4: visita após 6 meses de quimioterapia; Vfinal: visita de seguimento pós quimioterapia; $p$ : grau de significância; *Anova de medidas repetidas (Bonferroni); ** grau de significância $<0,05$ comparando com Vbasal; agrau de significância $<0,05$ entre V2 e Vfinal; $\infty$ grau de significância $<0,05$ entre V3 e Vfinal; § grau de significância $<0,05$ entre V4 e Vfinal; £ grau de significância $<0,05$ entre V2 e V3.

Ao se analizar a evolução temporal de cada resposta $(1-7)$ referente à questão 30 do EORTC-QLQ nota-se que o escore mais alto inicialmente reportado por $31,2 \%$ dos doentes caiu para 16,9\% logo após a quimioterapia porém, após seguimento houve aumento para 37,1\%. (Questão 30. Como você classificaria a sua qualidade de vida, durante a última semana?). Na tabela 15 estão todos estes resultados. 
Tabela 15 - Qualidade de vida dos doentes através de auto-avaliação usando o questionário EORTC-QLQ30, questão 30 (ANEXO 13) que variava de 1 (muito ruim) a 7 (muito boa) em números absolutos $(\mathrm{N})$, porcentagens (\%) e graus de significância avaliados nas cinco visitas

\begin{tabular}{cccccc}
\hline & Vbasal & V2 & V3 & V4 & Vfinal \\
\hline Avaliação & $\mathrm{N}=110$ & $\mathrm{~N}=92$ & $\mathrm{~N}=69$ & $\mathrm{~N}=59$ & $\mathrm{~N}=70$ \\
$\mathbf{1}$ & $3(2,8 \%)$ & $3(3,3 \%)$ & $1(1,5 \%)$ & $1(1,7 \%)$ & $2(2,9 \%)$ \\
$\mathbf{2}$ & $6(5,5 \%)$ & $3(3,3 \%)$ & $0(0,0 \%)$ & $1(1,7 \%)$ & $1(1,4 \%)$ \\
$\mathbf{3}$ & $7(6,4 \%)$ & $8(8,8 \%)$ & $4(5,9 \%)$ & $2(3,4 \%)$ & $6(8,6 \%)$ \\
$\mathbf{4}$ & $10(9,2 \%)$ & $9(9,9 \%)$ & $11(16,2 \%)$ & $9(15,3 \%)$ & $7(10,0 \%)$ \\
$\mathbf{5}$ & $29(26,6 \%$ & $29(31,9 \%)$ & $18(26,5 \%)$ & $22(37,3 \%)$ & $16(22,9 \%)$ \\
$\mathbf{6}$ & $20(18,3 \%)$ & $19(20,9 \%)$ & $18(26,5 \%)$ & $14(23,7 \%)$ & $12(17,1 \%)$ \\
$\mathbf{7}$ & $34(31,2 \%)$ & $20(22,0 \%)$ & $16(23,5 \%)$ & $10(16,9 \%)$ & $26(37,1 \%)$ \\
\hline
\end{tabular}

Em ambos questionários utiliza-se uma escala de Likert com escore de 1 (péssima) a 7 (ótima). EORTC-QLQ30:

The European Organization for Research and Treatment of Cancer; Vbasal: visita basal; V2: visita após 2 meses de quimioterapia; V3: visita após 4 meses de quimioterapia; V4: visita após 6 meses de quimioterapia; Vfinal: visita de seguimento pós quimioterapia; $p$ : grau de significância; * Chi-square test; ** grau de significância <0,05 comparando com Vbasal; agrau de significância <0,05 entre V2 e Vfinal; $\infty$ grau de significância <0,05 entre V3 e Vfinal; § grau de significância <0,05 entre V4 e Vfinal; £ grau de significância <0,05 entre V2 e V3.

Assim como com a questão de qualidade de vida, mesma análise foi realizada com a questão sobre saúde geral (auto-avaliação, questão 29 do anexo 10) e os resultados foram similares. (Questão 29. Como você classificaria a sua saúde em geral, durante a última semana?). A tabela 16 mostra os resultados. 
Tabela 16 - Saúde geral dos doentes através de auto-avaliação usando o questionário EORTCQLQ30, questão 29 (ANEXO 13) que variava de 1 (muito ruim) a 7 (muito boa) em números absolutos $(\mathrm{N})$, porcentagens (\%) e graus de significância avaliados nas cinco visitas

\begin{tabular}{cccccc}
\hline & Vbasal & V2 & V3 & V4 & Vfinal \\
\hline Avaliação & $\mathrm{N}=110$ & $\mathrm{~N}=92$ & $\mathrm{~N}=69$ & $\mathrm{~N}=59$ & $\mathrm{~N}=70$ \\
$\mathbf{1}$ & $4(3,7 \%)$ & $3(3,3 \%)$ & $1(1,5 \%)$ & $1(1,7 \%)$ & $2(2,9 \%)$ \\
$\mathbf{2}$ & $6(5,5 \%)$ & $4(4,3 \%)$ & $0(0,0 \%)$ & $1(1,7 \%)$ & $0(0,0 \%)$ \\
$\mathbf{3}$ & $6(5,5 \%)$ & $8(8,7 \%)$ & $4(5,9 \%)$ & $1(1,7 \%)$ & $1(1,4 \%)$ \\
$\mathbf{4}$ & $11(10,1 \%)$ & $9(9,8 \%)$ & $12(17,6 \%)$ & $12(20,3 \%)$ & $8(11,4 \%)$ \\
$\mathbf{5}$ & $28(25,7 \%)$ & $26(28,3 \%)$ & $20(29,4 \%)$ & $19(32,2 \%)$ & $21(30,0 \%)$ \\
$\mathbf{6}$ & $19(17,4 \%)$ & $21(22,8 \%)$ & $14(20,6 \%)$ & $16(27,1 \%)$ & $11(15,7 \%)$ \\
$\mathbf{7}$ & $35(32,1 \%)$ & $21(22,8 \%)$ & $17(25,0 \%)$ & $9(15,3 \%)$ & $27(38,6 \%)$ \\
\hline
\end{tabular}

Em ambos questionários utiliza-se uma escala de Likert com escore de 1 (péssima) a 7 (ótima). EORTC-QLQ30:

The European Organization for Research and Treatment of Cancer; Vbasal: visita basal; V2: visita após 2 meses de quimioterapia; V3: visita após 4 meses de quimioterapia; V4: visita após 6 meses de quimioterapia; Vfinal: visita de seguimento pós quimioterapia; $p$ : grau de significância; * Chi-square test; ** grau de significância <0,05 comparando com Vbasal; agrau de significância <0,05 entre V2 e Vfinal; $\infty$ grau de significância <0,05 entre V3 e Vfinal; § grau de significância <0,05 entre V4 e Vfinal; £ grau de significância <0,05 entre V2 e V3.

\subsection{Avaliação de ansiedade e depressão}

A escala hospitalar de ansiedade e depressão foi aplicada na visita basal (Vbasal), após quimioterapia (V4) e após seguimento (Vfinal). Essa escala é dividida em 7 questões de ansiedade e 7 questões de depressão. A tabela 17 mostra que houve leve diminuição na ansiedade, após o tratamento e após seguimento. 
Tabela 17 - Avaliação de ansiedade e depressão utilizando-se a Escala de ansiedade e depressão hospitalar avaliadas em três visitas, na visita basal, após tratamento quimioterápico e após seguimento em médias, desvios padrões, valores mínimos e máximos e graus de significância

\begin{tabular}{lcccc}
\hline & Vbasal & V4 & Vfinal & $\boldsymbol{p}^{*}$ \\
& $\mathrm{~N}=110$ & $\mathrm{~N}=59$ & $\mathrm{~N}=70$ & \\
HADS Ansiedade & $5,20 \pm 4,01$ & $4,33 \pm 4,07$ & $4,10 \pm 3,82$ & 0,12 \\
& $0,00-15,00$ & $0,00-19,00$ & $0,00-16,00$ & \\
HADS Depressão & $4,57 \pm 4,70$ & $4,91 \pm 4,58$ & $4,00 \pm 4,57$ & 0,30 \\
& $0,00-19,00$ & $0,00-15,00$ & $0,00-17,00$ & \\
HADS Total & $9,74 \pm 7,88$ & $9,32 \pm 8,12$ & $8,00 \pm 7,64$ & 0,19 \\
& $0,00-29,00$ & $0,00-33,00$ & $0,00-33,00$ & \\
\hline
\end{tabular}

HADS: Escala hospitalar de ansiedade e depressão. Vbasal: visita basal; V2: visita após 2 meses de quimioterapia; V3: visita após 4 meses de quimioterapia; V4: visita após 6 meses de quimioterapia; Vfinal: visita de seguimento pós quimioterapia; DP: desvio padrão; য: maior ou igual. p: grau de significância; *Anova de medidas repetidas; **grau de significância $<0,05$ comparando com Vbasal; agrau de significância $<0,05$ entre V2 e Vfinal; œ grau de significância $<0,05$ entre V3 e Vfinal; § grau de significância $<0,05$ entre V4 e Vfinal; £ grau de significância $<0,05$ entre V2 e V3.

\subsection{Análises de correlações}

Foram realizadas análises de correlações (coeficiente de correlação Spearman) entre as variáveis de dor e qualidade de vida. Foi encontrada correlação positiva da média do ISDN ao final da quimioterapia com idade (rho 0,407; $\mathrm{p}<0,0001$ ); com escore do TNS basal (rho 0,344; $p$ 0,006); com TNS após quimioterapia (rho 0,$493 ; p 0,001$ ) e com TNS pós seguimento (rho 0,586; $p<0,0001$ ). 
Analisando a qualidade de vida a partir do escore de sintomas do instrumento EORTC-QLQ basal foram encontradas correlações positivas entre HADS basal (rho 0,645 $\mathrm{p}<0,0001$ ), HADS pós quimioterapia (rho 0,442; $\mathrm{p}<0,0001$ ) e HADS pós seguimento (rho 0,$423 ; p<0,0001$ ). Foi encontrada correlação positiva entre EORTC-QLQ pós quimioterapia e HADS basal (rho 0,513; $p<0,0001$ ), HADS pós quimioterapia (rho 0,$703 ; p<0,0001$ ) e HADS pós seguimento (rho 0,$633 ; p<0,0001$ ). E selecionando EORTC-QLQ pós seguimento, foram encontradas correlações positivas ao comparar com HADS pós quimioterapia (rho 0,373; p 0,004); com HADS pós seguimento (rho 0,$609 ; p<0,0001$ ); com McGill total pós seguimento (rho 0,348; $p$ 0,004) e com TNS pós seguimento (rho 0,446; p 0,005). 


\section{DISCUSSÃO}

\subsection{Caracterização da amostra estudada de acordo com as variáveis sociodemográficas e clínicas.}

Dos 110 doentes que participaram do estudo, 64 eram do sexo feminino. A idade variou de 29 a 74 anos, com uma média de 55,60. A renda familiar teve uma média de 2.222,45 reais. A maioria dos doentes era casada e tinha ensino fundamental completo.

Em relação às características sociodemográficas dos participantes do estudo, destacou-se um predomínio do sexo feminino (64), com uma média de idade de 55,60 anos (variou de 29 a 74 anos; DP=10,69), 55,0\% com ensino fundamental, com uma renda individual média de $R \$ 1.241,55$ (variou de $R \$ 0$ a $R \$ 8000$; $\mathrm{DP}=1432,49), 49,5 \%$ eram casados, 59,5\% eram católicos. Quanto à situação ocupacional $75,7 \%$ não estavam trabalhando no momento.

Os resultados sociodemográficos e clínicos deste estudo assemelharam-se a de outros estudos realizados no munícipio de São Paulo (Marques, 2006; Souza, 2011; Tacani, 2014). 
No que diz respeito à inclusão de doentes metastáticos, 38,9\% dos doentes não apresentaram doença em outra região do corpo antes de iniciar o tratamento quimioterápico, em $33,3 \%$ dos doentes não foi possível avaliar no momento da primeira consulta, $1,8 \%$ dos doentes não tinham a informação registrada na primeira consulta oncológica. Neste estudo, os locais com maior acometimento de metástases foram fígado (14,7\%), trato gastrointestinal $(11,9 \%)$ e pulmão $(10,0 \%)$. A neoplasia colorretal tem uma preferência em $75 \%$ em ocasionar metástases no fígado (Lupinacci et al, 2013). A incidência de metástases pulmonares que são oriundas de neoplasias extratorácicas varia de $20 \%$ a $54 \%$, dada à intensa vascularização do orgão (Hirakata et al, 1995). As metástases pulmonares estão presentes em $5 \%$ a $15 \%$ quando o sítio primário é o câncer colorretal (Kim et al, 2012). Os tratamentos previamente realizados foram $76,8 \%$ cirúrgico e $58,4 \%$ quimioterapia, sendo esses ainda, considerados os pilares do tratamento oncológico.

Sobre as comorbidades apresentadas pelos doentes no momento de inclusão no estudo verificou-se uma prevalência de 40,9\% com hipertensão arterial, 7,3\% doenças no trato gastro-intestinal (como doença de Crohn) e 14,4\% diabetes melito. Tais valores são condizentes a outros estudos sobre as comorbidades em doentes oncológicos (Pinto, Uga, 2011; Souza, 2011; Santos et al, 2012).

Os 26 estudos aqui analisados foram conduzidos entre 1996 e 2014 (quadro 3). A despeito do número de doentes incluídos, a maior parte (19 estudos) incluiu menos de 100 doentes. As amostras variaram de 16 (Binder et al.,2007) a 2492 
(Land et al.,2007). Para avaliar a neuropatia periférica o instrumento utilizado foi, predominantemente, o National Cancer Institute-Common Terminology Criteria ( $\mathrm{NCl}$ CTC-AE) (Mattioli et al 2005, Argyriou et al 2006, Baek et al 2010, Vincenziet al 2012, Argyriou et al 2012, Cascinu et al 2002, Petrioli et al 2006, Wang et al 2007, Attal et al 2009, Ishibashi et al 2010, Chay et al 2010, Grothey et al 2011, Madajewicz et al 2010, Afonseca et al 2013, Guo et al 2014, Coriat et al 2014, Nagashina et al 2014). O manual NCl-CTC-AE define os graus de neuropatia sensorial periférica como: grau 1: assintomático, observaçãoes apenas clínicas ou diagnósticas, intervenção não indicada; grau 2: sintomas moderados, limitação nas atividades de vida diária; grau 3: sintomas severos, limitação no auto cuidado nas atividades de vida diária; grau 4: risco de morte, intervenções urgentes indicadas; grau 5: morte. Como observado, dor não faz parte da descrição de sintomas em nenhum grau do NCI-CTC-AE.

Dentre os 25 estudos, apenas 9 estudos utilizaram alguma escala específica para a avaliação de neuropatia, dor ou dor neuropática, como demonstrado no quadro 4.

Quadro 4. Instrumentos específicos para avaliar NPIQ e autores que os utilizaram

\begin{tabular}{|l|l|l|l|l|l|l|}
\hline $\begin{array}{l}\text { Instrumento } \\
\text { específico }\end{array}$ & $\begin{array}{l}\text { Oxaliplatin- } \\
\text { Specific } \\
\text { Neurotoxicity } \\
\text { Scale }\end{array}$ & $\begin{array}{l}\text { Inventário } \\
\text { Breve de } \\
\text { Dor (BPI) }\end{array}$ & $\begin{array}{l}\text { Inventário } \\
\text { de Dor } \\
\text { McGill }\end{array}$ & $\begin{array}{l}\text { Neurological } \\
\text { Sympton } \\
\text { Score (NSS) }\end{array}$ & $\begin{array}{l}\text { Neurological } \\
\text { Disability } \\
\text { Score (NDS) }\end{array}$ & $\begin{array}{l}\text { Inventário } \\
\text { de } \\
\text { sintomas } \\
\text { de dor } \\
\text { neuropática } \\
\text { (NPSI) }\end{array}$ \\
\hline Autores & $\begin{array}{l}\text { Argyriou et al } \\
\text { Binder et al } \\
\text { Land et al } \\
\text { Petrioli et al } \\
\text { Chay et al } \\
\text { Grothey et al } \\
\text { Afonseca et al }\end{array}$ & Guo et al & Binder et al & Argyriou et al & Argyriou et al & Attal et al \\
\hline
\end{tabular}


Em relação ao tempo de duração do estudo, Mattioli et al (2005) avaliou os doentes durante 24 meses; Magajewicz et al (2012) por 20 meses; Petrioli et al (2006) por 16 meses; Land et al (2007), Wang et al (2007) e Attal et al (2009) por 18 meses; Guo et al (2014) por 12 meses; Ishibashi et al (2010) por 10 meses; Nagashima et al (2014) por 8 meses. Todos os outros 16 estudos avaliaram durante 6 meses.

Dentre os estudos, 7 deles utilizaram-se de exames para avaliar os sintomas, além dos questionários. Attal et al (2009) e Binder et al (2007) utilizaram teste quantitativo da sensibilidade (QST); Wang et al (2007), Wilson et al (2002) e Hill et al (2010) utilizaram eletroneuromiografia; Cascinu et al (2002) utilizou avaliação de força e reflexos, e condução nervosa sensitiva no nervos sural.

\subsection{Inventario breve de dor (BPI- Brief Pain Inventory)}

Guo et al (2014) utilizaram o instrumento IBD para avaliar a neuropatia. Neste estudo há 4 subgrupos, primeiramente divididos entre os que tomam cisplatina e os que tomam oxaliplatina, e divididos em grupo que recebeu tratamento com ácido alfa-lipóico e o placebo. Aqui utilizou-se o grupo placebo/oxaliplatina pela similaridade com a amostra do presente estudo. Os resultados do estudo de Guo et al e o presente estudo podem ser observados no quadro 6 . 
Quadro 5. Resultados de dois trabalhos que utilizaram o Inventário breve de dor, Guo et al (2014) e presente estudo, contendo as médias de pior dor, dor média e os aspectos de interferência na qualidade de vida: atividade de vida diária, humor, andar, trabalho básico, relacionamentos, sono e capacidade de aproveitar a vida em dois momento, na visita basal e após os 6 meses de tratamento com oxaliplatina

\begin{tabular}{|c|c|c|c|c|}
\hline & Guo et al (20 & 4) $N=29$ & Presente est & Ido $N=110$ \\
\hline IBD & $\begin{array}{l}\text { Pré } \\
\text { Oxaliplatina }\end{array}$ & Pós-Oxaliplatina & $\begin{array}{l}\text { Pré } \\
\text { Oxaliplatina }\end{array}$ & Pós-Oxaliplatina \\
\hline Dor mais intensa & $2,2 \pm 3,0$ & $1,9 \pm 2,9$ & $0,0 \pm 0,0$ & $1,9 \pm 3,1$ \\
\hline Dor média & $1,8 \pm 1,7$ & $1,3 \pm 1,6$ & $0,0 \pm 0,0$ & $1,4 \pm 2,4$ \\
\hline Interferência & & & & \\
\hline $\begin{array}{l}\text { Atividade de vida } \\
\text { diária }\end{array}$ & $1,5 \pm 2,1$ & $1,4 \pm 2,2$ & $0,0 \pm 0,0$ & $0,58 \pm 1,79$ \\
\hline Humor & $1,8 \pm 2,4$ & $1,3 \pm 2,2$ & $0,0 \pm 0,0$ & $0,10 \pm 0,63$ \\
\hline Andar & $1,4 \pm 2,1$ & $1,6 \pm 2,4$ & $0,0 \pm 0,0$ & $0,45 \pm 1,70$ \\
\hline Trabalho básico & $2,4 \pm 3,2$ & $1,7 \pm 2,7$ & $0,0 \pm 0,0$ & $0,77 \pm 216$ \\
\hline Relacionamentos & $1,6 \pm 2,6$ & $1,2 \pm 2,4$ & $0,0 \pm 0,0$ & $0,00 \pm 0,00$ \\
\hline Sono & $2,5 \pm 2,9$ & $1,5 \pm 2,7$ & $0,0 \pm 0,0$ & $0,35 \pm 1,56$ \\
\hline Aproveitar vida & $2,7 \pm 3,4$ & $1,6 \pm 2,8$ & $0,0 \pm 0,0$ & $0,00 \pm 0,00$ \\
\hline
\end{tabular}

IBD: Inventário breve de dor; AVD: Atividade de vida diária. 
No estudo de Guo et al (2014), 6 dos doentes já haviam sido expostos a oxaliplatina anteriormente, o que interferiu nos resultados da visita basal, mais altos do que no presente estudo já que não foram incluídos doentes com exposição prévia à Oxaliplatina. Apesar disso, houve similaridades entre os dois estudos no que se refere à intensidade de dor pós quimioterapia e alguns itens de interferência.

\subsection{Questionário de dor neuropática - 4 (DN4)}

No presente estudo as porcentagens de doentes com DN4 positivo foram $15,22 \%$ na V2, 24,64\% na V3, 21,67\% na V4 e 10,00\% na visita final. Em busca pelo motor de pesquisa PubMed, usando os descritores "DN4, neurophatic pain, chemotherapy, colorrectal cancer" não se obteve resultados, porém retirando o termo "colorrectal" obteve-se 2 estudos. Perez et al (2015) analisou doentes em tratamento quimioterápico para "qualquer tipo de câncer". Dos 358 doentes analisados, 194 (54,2\%) tiveram dor, destes, $39(20,1 \%)$ do tipo neuropática. Em análise com o DN4, $86,8 \%$ tiveram resultado $\geq 4$. Golan-Vered e Pud (2013) avaliaram neuropatia periférica em 40 doentes com câncer de mama com tratamento com paclitaxel. 20 doentes (50\%) tiveram DN4 $\geq 4$. Outro estudo que utilizou o DN4 foi o de Zandonai et al (2016) para validação de um instrumento (CIPNAT) com doentes com câncer (55,1\% colorretal). Neste estudo bicêntrico observou-se que $28,7 \%$ dos participantes 
apresentaram escore positivo no DN4 (DN4 $\geq 4)$ e os sinais e sintomas prevalentes foram dormência $(32,7 \%)$, formigamento $(32,3 \%)$ e hipoestasia a picada da agulha $(27,3 \%)$.

\subsection{Escore total de neuropatia (Total neuropathy score -TNS)}

No presente estudo os escores foram 1,2 (intervalo: 0 -15) na visita basal, 3,6 (variação: 0-16) logo após quimioterapia e 4,1 (variação 0-15) após seguimento. Em um estudo multi-cêntrico, Velasco et al (2014) avaliaram 200 doentes com câncer colorretal em tratamento com oxaliplatina em 3 momentos, na visita basal, durante o tratamento (após 4 ou 6 infusões de OXA) e 1 mês após término da quimioterapia. O estudo durou 18 meses. Foram incluídos doentes maiores de 18 anos, com KPS $\geq 70$, que nunca haviam passado por quimioterapia, função hepática e renal satisfatórias e uma expectativa de vida de pelo menos 9 meses. Os doentes receberam FOLFOX-4, FOLFOX-6 modificado ou XELOX. As doses de oxaliplatina foram reduzidas em até $30 \%$ devido a parestesias e o tempo de infusão se prolongava por até 6 horas devido a toxicidades. Para avaliar a neuropatia foi utilizado o NCl-CTC-AE versão 3 e TNS clínico. Assim como no presente estudo, muitos doentes foram excluídos no decorrer do tratamento. Vinte e três foram excluídos por neuropatia pré-existente, 11 por apresentarem condições que impossibilitariam o exame, 6 por recusa e 2 por outras razões não especificadas. Os doentes eram em maioria homens (60\%) e com idade média 
de $63,67 \pm 8,94$. De acordo com o TNS, $18 \%$ dos doentes desenvolveram neuropatia grau 3, 29,5\% grau 2 e $25 \%$ grau 1. 16,5\% precisou redução de dose de oxaliplatina.

Briani et al (2014) realizaram estudo prospectivo com 91 doentes cujo objetivo era acompanhar a incidência de NPIQ em doentes em tratamento com oxaliplatina para câncer colorretal. A avaliação consistiu em exame TNS clínico na visita basal, após quimioterapia (6 meses) e depois de 2 anos. A avaliação eletrofisiológica foi realizada em 61 dos 91 (69\%) doentes na avaliação 2 (pós quimioterapia), porque 30 doentes recusaram-se (no presente estudo, 12 doentes recusaram-se) 18 dos 91 $(19,8 \%)$ doentes não apresentaram nenhum sintoma de neuropatia ao final da quimioterapia. Evidências clínicas e eletrofisiológicas de NPIQ cumulativa foi documentada em $73(80,2 \%)$ doentes no final do tratamento com oxaliplatina. Doentes com NPIQ eram 44 homens e 29 mulheres, com idade média de 64,3 \pm 8,7 anos, a gravidade da neuropatia foi classificada como grau 1 em 28 dos 73 doentes (38,4\%), grau 2 em $33(45,2 \%)$ e grau 3 em 12 casos (16,4\%). Nenhum doente apresentou grau 3 de neuropatia logo após quimioterapia. Os escores TNS foram 9,0 (intervalo: 2-15) na visita basal e 4.0 (variação: 2-12) após quimioterapia.

O estudo de Briani et al (2014) foi o maior estudo a considerar a evolução desses doentes em um longo período (2 anos após quimioterapia) e diferiu dos resultados anteriores, que caracterizaram a NPIQ como completamente reversível (de Gramont et al., 2000; André et al., 2004), já que detectou em seu 
estudo que apenas $20 \%$ de seus doentes deixaram de apresentar sintomas após os 2 anos. Park et al (2011b) avaliou 24 doentes com câncer colorretal e 79\% destes mantiveram sintomas de NPIQ após uma média de 25 meses. Em um estudo retrospectivo de doentes que receberam pelo menos um ciclo de XELOX para câncer colorretal, $37 \%$ e $28 \%$ tinham NPIQ crônica 6 e 12 meses após a quimioterapia (Storey et al., 2010). Outros estudos avaliaram o curso em longo prazo de NPIQ com o uso de questionários descritivos e testes neurológicos (Brouwers et al, 2009; Vatandoust et al, 2014). Brouwers et al (2009) avaliaram a neuropatia persiste 8 meses após o tratamento com oxaliplatina em 25 sobreviventes de câncer colorretal e descobriram que os sintomas foram lentamente reversível nas mãos, mas não nos pés. Um estudo mais recente em 27 doentes que receberam oxaliplatina para CCR mostrou após 20 meses persistência em 17 doentes (63\%) e dentre eles 12 (44\%) com sintomas moderados ou graves (grau 2 ou grau 3) (Vatandoust et al., 2014).

Em geral, os dados descritos acima têm de ser interpretados com cautela devido limitações, incluindo o desenho retrospectivo, amostras de pequenas dimensões, acompanhamento heterogêneo, alto índice de perdas de seguimento, uso de medidas de resultados descritivos e subjetivos e a falta de avaliação neurológica objetiva. Outra questão importante diz respeito ao difícil monitoramento da NPIQ por mais de 1 ano, principalmente devido às taxas de sobrevida de doentes com câncer colorretal metastático, que não comumente ultrapassam 17,5 meses (Kalofonos et al ., 2005). 


\subsection{Sintomas da NPIQ}

Alguns estudos apontam que a dormência e formigamento estão fortemente relacionados com o desenvolvimento da neuropatia periférica crônica consequente da dose acumulativa da oxaliplatina. A manifestação da dormência e formigamento foi elevada na revisão de literatura (Mathias et al, 2013). Em um levantamento, uma participante descreveu dormência permanente e grave a tal ponto que não sentiu dor ao se ferir com uma faca. E outros, relataram dificuldades em realizar tarefas que demandavam desempenho motor fino e destreza manual (Bennett et al, 2012).

A sensibilidade ao frio está associada a neuropatia periférica aguda ocasionada pela oxaliplatina (Durand et al, 2012). O frio é capaz de desencadear ou exacerbar a neuropatia periférica, deste modo, causa alterações na dieta dos doentes ao evitar a ingestão de alimentos e bebidas frias e, também interfere na preparação dos alimentos ao evitar de manusear a água fria e abrir a geladeira ou refrigerador. Tende a ser um sintoma de curta duração e reversível (Wilson et al, 2002; Argyriou et al, 2008; Vatandoust et al, 2014).

Os sintomas neuropáticos avaliados impactaram as AVDs dos participantes deste estudo, especialmente, no humor, no trabalho básico e capacidade de aproveitar a vida. A abordagem qualitativa do estudo de Bakitas (2007) destaca a visão dos doentes com compromentimento nas AVD pela NPIQ e, nestes relatos foram citados frequentemente a interferência ou interrupção nas atividades rotineiras e de lazer, no trabalho e no papel desempenhado na família. Outros 
estudos também mencionam as mesmas interferências identificadas neste estudo (Sweeney, 2002; Bakitas, 2007; Driessen et al, 2012, Speck et al, 2012, Beijers et al, 2014).

Em um estudo (Leonard, 2005) com 86 adultos portadores de câncer colorretal submetidos à quimioterapia com oxaliplatina, a parestesia foi encontrada (através de exame físico) em $94,3 \%$ dos doentes durante a terapia, e este sintoma acometia principalmente os pés e as mãos. Os autores demonstraram que, após seis ciclos de tratamento, $92 \%$ dos doentes ainda apresentavam dormência e formigamento, e relacionaram este achado ao desenvolvimento de neuropatia crônica decorrente do efeito cumulativo da droga. A incidência desta complicação foi muito semelhante em outros estudos. Em um deles (Ishibashi et al., 2010), foi relatada a ocorrência deste sintoma em 96\% dos indivíduos, enquanto, em outra pesquisa (Chay et al., 2010), dos 27 doentes estudados, 16 apresentaram quadro de parestesia em membros superiores e inferiores. Alterações de sensibilidade secundária à quimioterapia com oxaliplatina foram descritas em um estudo (Gamelin et al., 2007b) com 135 doentes com câncer de cólon e reto, que relatava a ocorrência de disestesia distal em 68 indivíduos, sendo que 9 deles apresentavam ainda disestesia e/ou parestesia na região oral e perioral e 7 evoluíram também com disestesia laringofaríngea. Outras pesquisas citaram também a presença desses sintomas na face e na faringe. Em uma delas (Pietrangeli et al., 2006), foi observado que, dos 18 doentes tratados com a referida droga, 13 apresentaram disestesia distal, perioral e laringofaríngea. Em outra pesquisa (Hill et al., 2010), da mesma forma, foi observada a presença de 
disestesia em faringe, relatada pelos doentes como desconforto respiratório. A maioria dos autores concorda que a fisiopatologia desses sintomas sensitivos ainda não está completamente esclarecida, mas, provavelmente, esses se devem aos efeitos neurotóxicos do acúmulo da oxaliplatina nas células dos gânglios sensitivos dorsais, o que provoca mudanças morfológicas no corpo celular, e pode resultar em axonopatia dos nervos periféricos, especialmente nas fibras grossas mielinizadas, responsáveis pela condução nervosa sensorial (Gamelin et al., 2002; Grothey, 2005). Diversos autores observaram a relação desses sintomas sensitivos com o frio (Leonard et al., 2005; Wilson et al., 2002; Hill et al., 2010). Em ensaio clínico (Attal et al., 2009), com 48 adultos portadores de CCR, os autores relataram a ocorrência de parestesia e disestesia nas mãos desencadeada pelo frio em $96 \%$ dos doentes, e disestesia na laringofaringe em $32 \%$ desses. Em outra pesquisa (Leonard et al., 2005), foi observado que $87.2 \%$ dos doentes apresentavam disestesia na face e nas extremidades, e esta se manifestava como sensibilidade dolorosa ao frio quando os doentes comiam, bebiam ou seguravam objetos frios.

Em análise da duração desse sintoma, os autores perceberam que, após 6 ciclos de tratamento, apenas $68 \%$ dos indivíduos se queixavam deste acometimento, e sugeriram que estes sintomas estão geralmente associados ao fenômeno de hiperexcitabilidade transitória dos nervos periféricos. Achados semelhantes foram encontrados em outros estudos, sendo que, em dois deles (Wilson et al., 2002, Hill et al., 2010) todos os doentes submetidos ao tratamento relataram presença de parestesia induzida pelo frio após a infusão, com duração de três a vinte e um dias, 
enquanto, nas outras pesquisas (Petrioli et al., 2006, Pietrangeli et al., 2006), os autores citaram a ocorrência de disestesia relacionada ao frio em $72 \%$ a $75 \%$ dos doentes, os quais persistiram por dois a cinco dias após a infusão. Esses sintomas, desencadeados ou aumentados pela exposição à temperatura fria, estão relacionados à neuropatia aguda, e, geralmente, são suaves, de curta duração, e completamente reversíveis dentro de horas ou dias (Gamelin et al., 2002, Grothey, 2005). Até o momento, a hipótese mais aceita sugere que estes efeitos agudos se devem à combinação do cálcio com o oxalato liberado pela oxaliplatina na membrana sináptica, provocando alterações nos canais de sódio voltagem-dependentes, com consequente aumento da excitabilidade das células nervosas e musculares (Gamelin et al., 2002, Grothey, 2005, Argyriou et al., 2006, Kono et al., 2009).

Binder et al (2007) avaliaram 16 doentes com câncer tratados com oxaliplatina através do questionário dor McGill, específico para dor e observaram que, dentre estes, 9 apresentaram queixa de dor, e todos relataram associação desta com o frio, provocada pelo ambiente com baixas temperaturas e/ou contato com objetos, líquidos ou ar frio. Em uma pesquisa (Attal et al., 2009), foi descrita, além das alterações de sensibilidade já citadas, a ocorrência de dor nas mãos relacionada ao frio, após cada ciclo de tratamento, em $96 \%$ dos indivíduos estudados. Outros autores (Leonard et al., 2005) verificaram que a dor provocada pelo frio era o sintoma mais comum experimentado pelos doentes durante o tratamento, acometendo mais de $80 \%$ destes. Outro estudo (Land et al., 2007) apresentou uma incidência bem mais baixa desse sintoma que a citada pelos outros autores, de apenas $26 \%$. Esse 
sintoma parece ocorrer pelo fato de que a neurotoxicidade da oxaliplatina é mediada pela sensibilização dos sistemas nociceptivos periféricos e centrais (Binder et al., 2007). Essa droga também exerce efeito significativo no potencial de ação das fibras mielinizadas tipo A delta, responsáveis pela condução do estímulo térmico relacionado ao frio (Attal et al., 2009, Binder et al., 2007).

Além da dor induzida pelo frio, os autores observaram que $60 \%$ dos doentes queixavam-se de dor ao morder os alimentos, devido ao espasmo da musculatura mastigatória. Contrações musculares, como espasmos, rigidez e cãibras musculares foram citados em várias pesquisas (Wilson et al., 2002, Grothey et al., 2010, Lehky et al., 2004, Park et al., 2010). Em dois estudos (Wilson et al., 2002, Land et al., 2007) realizados pelo mesmo grupo de pesquisadores, foi demonstrado, através de avaliação neurológica, que, após infusão da oxaliplatina, sete, entre os dez doentes examinados, mantinham a contração muscular dos extensores das mãos após percussão do nervo interósseo por tempo mais prolongado do que em indivíduos normais.

Em pesquisa (Park et al., 2010) conduzida com 15 doentes com câncer avaliados antes e após infusão da oxaliplatina, foi observado que 13\% destes evoluíram com cãibras e fasciculações em mãos e pés com duração de 2 a 10 dias após aplicação da droga, enquanto $7 \%$ dos indivíduos apresentaram dor e rigidez mandibular. Esses sintomas apresentam semelhança clínica com espasmos tetânicos, os quais são geralmente atribuídos à hiperexcitabilidade dos neurônios 
motores e associados à hipocalcemia e hipomagnesemia (Gamelin et al., 2002). Em análise da neurotoxicidade secundária ao uso da oxaliplatina, autores (Attal et al., 2009)realizaram exame neurológico em 18 doentes do grupo que recebeu esta droga 12,2 meses após o término da quimioterapia. Deste total, 12 indivíduos ainda apresentavam evidência clínica de neuropatia periférica em membros superiores e/ou inferiores, com diminuição ou ausência de reflexos tendíneos em $50 \%$ deles. Outros estudos também relacionaram este sintoma à neurotoxicidade crônica associada a essa droga. Em um deles (Pietrangeli et al., 2006), os pesquisadores estudaram dois grupos de doentes com câncer colorretal avançado em tratamento com oxaliplatina, sendo que o primeiro foi avaliado no momento da infusão, 9 e 18 semanas após início da quimioterapia; enquanto o segundo grupo foi examinado dias após o término da terapia e acompanhado durante 7 meses. Os autores relataram

que 55\% dos doentes apresentaram hiporreflexia dos tendões profundos após 9 semanas, $45 \%$ evoluíram com este sintoma após 18 semanas, e $76 \%$ dos indivíduos ainda apresentavam esse acometimento após 7 meses de seguimento.

\subsection{Inventário de sintomas de dor neuropática (ISDN)}

O uso do ISDN mostrou que a dormência, sensação de alfinetadas e agulhadas e choque elétrico são os sintomas neuropáticos com escore mais intenso. 
Em contrapartida, um estudo com doentes em uso de oxaliplatina identificaram pelo ISDN os sintomas neuropáticos com escore mais elevado na dor evocada pelo frio, formigamento e alfinetadas e agulhadas (Durand et al, 2012). Por meio do ISDN combinado com o Quantitative Sensory Testing (QST), a hiperalgesia (ou alodínia) ao frio foi reconhecida como um possível marcador precoce para a neurotoxicidade causada pela oxaliplatina e o seu alto risco para cronificação (Attal et al, 2009). Zandonai et al (2016) também utilizou o ISDN encontrou a média do escore (0-10) para sensação de dormência de 2,93 $(\mathrm{DP}= \pm 3,36)$, seguido pela sensação de alfinetadas e agulhadas $1,42(\mathrm{DP}= \pm 2,81)$ e dor com sensação de choque elétrico $\operatorname{com} 1,00(\mathrm{DP}= \pm 2,29)$.

Kus et al (2016) analisaram 206 doentes com câncer $(21,1 \%$ do tipo colorretal) em estudo cujo objetivo era avaliar o alívio que administração de venlafaxina traz em relação à neuropatia causada por quimioterapia baseada em taxanos ou oxaliplatina. Os doentes inclusos foram os que já apresentavam grau $\geq 1$ de neuropatia segundo o NCI-CTC-AE, portanto a amostra difere da do presente estudo, porém, pode-se comparar tendo em mente essa diferença de momentos de avaliação. Pode-se utilizar o braço placebo do estudo de Kus et al para comparação com os dados do presente estudo. Aqui serão expressos os resultados dos doentes do grupo oxaliplatina $(n=23)$. Agulhada foi relatada por $56,5 \%$ dos doentes. Dor induzida pelo frio foi relatada em $69,5 \%$. 


\subsection{Questionário de dor McGill reduzido}

No presente estudo a dor foi caracterizada com os descritores do instrumento McGill reduzido como incômoda, aborrecida e capaz de deixar o participante do estudo enjoado. Também identificou-se descritores típicos de neuropatia periférica e dor neuropática como dor com característica de choque e agulhada. $O$ presente estudo usou o questionário McGill reduzido, por isso muitas caracteristicas não foram avaliadas por este, mas sim pelo Inventário de sintomas (ISDN) cuja discussão se encontra nas próximas páginas. O estudo de Binder et al (2007) usou o instrumento McGill reduzido e encontrou como descritores mais relatados a dormência (em 100\% dos doentes), frio $(66,6 \%)$, congelante $(55,5 \%)$, picada $(55,5 \%)$, forte $(100 \%)$ e agulhada (100\%). Intensidades: $2.4 \pm 0.7$ (1-3), $2.4 \pm 0.6$ (1-3), $2.3 \pm 0.8$ (2-3), $2.6 \pm 0.6$ (2-3), $2.3 \pm 1.0(1-3)$ e $1.8 \pm 0.5(1-2)$.

Através deste estudo foi possível mostrar que a neuropatia aguda induzida por oxaliplatina apresentando sintomas de dor é caracterizado por um perfil somatossensitivo específico, isto é, a hiperalgesia mecânica e frio. Além disso, a análise de grupo revelou hiperalgesia de calor adicional e hipoestesia quente. Tomados em conjunto, estes resultados exibem sensibilização nociceptiva no sistema periférico e central, como os mecanismos subjacentes. 


\subsection{Avaliação de qualidade de vida}

Nos últimos anos, cada vez mais ensaios incorporaram o EORTC como um desfecho principal. A Sociedade Americana de Oncologia Clínica afirma que os resultados dos doentes (toxicidade, sobrevivência e qualidade de vida) são mais importantes que os resultados do câncer (taxa de resposta e duração) (Sociedade Americana de Oncologia Clínica, 1996). Estudos que utilizaram o EORTC em doentes com câncer colorretal pós tratamento quimioterápico mostraram que é comum uma piora geral na qualidade de vida (Mayrbäurl et al., 2015; Koeberle et al., 2008; Wintner et al., 2013; Zabernigg et al., 2012). Arraras et al (2013) encontrou pequenas alterações (20-30 pontos) na qualidade de vida global, anomalias do sono e constipação, diarreia, ansiedade e incontinência fecal. Limitações moderadas (> 30 pontos) foram observadas para a frequência urinária, flatulência, impotência, e a função sexual entre homens e mulheres. Esses resultados vão de acordo com outro estudo espanhol (Sanchéz et al., 2012) e também são muito semelhantes aos da população em geral, avaliada por Scott et al em 2008. Em outro estudo (Han et al., 2014) demonstrou que houve piora durante o tratamento, mas que retornava aos valores originais após 3 meses do término da quimioterapia e se manteve durante 12 meses subsequentes. 


\subsubsection{Qualidade de vida e neuropatia}

No estudo presente a qualidade de vida foi avaliada através do questionário EORTC-QLQ e pelo item "interferência" no IBD. Pelo IBD verificou-se interferência significativa no item "humor" e no item atividades de vida diária, principalmente no meio do tratamento quimioterápico (V3). Pelo EORTC-QLQ os resultados não foram significativos estatisticamente. Embora muitos questionários tenham sido desenvolvidos para avaliar neuropatia e qualidade de vida (Driessen et al., 2012; Calhoun et al., 2003; Cella et al., 1993; Postma et al., 2005) poucos estudos investigaram o impacto da NPIQ na qualidade de vida como demonstrado por uma recente revisão de Mols et al (2014). Assim, apenas 8 estudos relataram que a maioria dos doentes tinham sintomas de NPIQ e pior qualidade de vida devido a NPIQ (Driessen et al., 2012; Cella et al., 2003; Kim et al., 2010; Ostchega et al., 1988;

Sorbe et al., 2012; Mols et al., 2013; Grifth et al., 2014; Hershman et al., 2011) e 3 estudos não encontraram uma relação entre NPIQ e qualidade de vida (Calhoun et al., 2003; Morita et al., 2003; Ramchandren et al., 2009). Além disso, outros estudos demonstraram o impacto de NPIQ sobre as atividades de vida diária, mas não avaliaram qualidade de vida especificamente (Park et al., 2011a; Tofthagen et al., 2010). Os estudos que avaliaram a influência direta de NPIQ na qualidade de vida divergem notavelmente em muitos aspectos, como método, população incluída e no modo como NPIQ e qualidade de vida foram avaliadas, o que dificulta a comparação destes estudos. 


\subsection{Escala hospitalar de ansiedade e depressão (HADS)}

No presente estudo os sujeitos foram avaliados e responderam ao questionário HADS em três momentos distintos, na visita basal, ao término do tratamento quimioterápico e após o seguimento. Houve diminuição na pontuação de ansiedade após o acompanhamento de 6 meses (5,38 basal, 5,19 pós quimioterapia e 3,80 final). Em relação à depressão houve pequeno aumento da visita basal para após quimioterapia $(4,51$ para 5,24$)$ seguido de decréscimo após o seguimento (média de 3,79). Utilizando o método de nota igual ou maior que 8 obteve-se para ansiedade $30,9 \%$ no basal, $28,4 \%$ pós quimioterapia e $17,6 \%$ após seguimento e para depressão 25,7\% no basal, $34,6 \%$ após quimioterapia e $16,4 \%$ após seguimento.

Poucos estudos avaliaram os sintomas de ansiedade e depressão usando o questionário HADS em doentes de câncer colorretal. Em busca no site PubMed obteve-se 8 resultados e nenhum nos motores e busca Lilacs e SciElo. Em estudo recente, de 2015, Antoniadis et al mostraram avaliação com o HADS resultando em 15,61 pontos. Neste, não foram descriminados os resultados específicos de depressão e de ansiedade, separadamente. Zhang et al (2014) apresentaram os resultados divididos em ansiedade (média de 6,0 pontos) e depressão (média 4,0). Cardoso et al (2015) avaliaram doentes com diversos tipos de câncer, entre eles o colorretal e não apresentou seus resultados pela média, mas dividiu o resultado em 
dois grupos, com resultado menor que 8 e com resultado maior ou igual a 8 (30\% para ansiedade e $24,1 \%$ depressão). Enfermeiros de Melbourne, Austrália avaliaram sobreviventes ao câncer colorretal após a quimioterapia e acompanharam por 4 semanas, fazendo a segunda avaliação, por contato telefônico. Encontraram decréscimo na depressão (4,93 na visita basal e 3,84 após 4 semanas) e nenhuma diferença significativa em relação a ansiedade (5,29 e 4,78 pontos).

\subsection{Análises de correlações}

Foram realizadas análises de correlações (coeficiente de correlação Spearman) entre as variáveis de dor e qualidade de vida. Foi encontrada correlação positiva de nível moderado da média do ISDN ao final da quimioterapia com a idade significando que doentes com maior idade tiveram maiores escores neste inventário ao fim do estudo. Também foram encontrados valores significativos ao se correlacionar a média do ISDN após a quimioterapia com o escore de neuropatia do TNS basal, pós qt e pós seguimento. A correlação com o escore TNS obtido antes da quimioterapia foi fraca As correlações com os escores ao fim da quimioterapia e ao fim do seguimento foram moderadas e a com maior significância estatística a entre ISDN basal e TNS pós seguimento

Analisando a qualidade de vida a partir do instrumento EORTC-QLQ realizado antes do tratamento quimioterápico (basal) foram encontradas correlações positivas 
moderadas entre o escore de sintomas de ansiedade e depressão (HADS) basal, após quimioterapia e após seguimento, o que mostrou que possivelmente, ospacientes com pior qualidade de vida no basal também apresentaram mais ansiedade e depressão nos três momentos de avaliação do HADS. O escore do EORTC-QLQ pós quimioterapia apresentou correlações moderadas com a escala HADS no basal e no pós seguimento e correlação forte com HADS após quimioterapia, exatamente quando o paciente está com maiores doses de oxaliplatina. Estas correlações indicaram relação entre piora na qualidade de vida e ansiedade e depressão, principalmente logo após a quimioterapia.

Em relação a qualidade de vida pós seguimento, foram encontradas correlações positivas fracas com HADS pós quimioterapian e com McGill total pós seguimento. E correlação moderada com TNS pós seguimento e HADS pós seguimento. Estes resultados mostraram além de relação com ansiedade e depressão, ter piora na qualidade de vida também reflete em piora na neuropatia, após seguimento.

Em estudo publicado em 2008, Ferreira mostrou que citocinas pró inflamatórias IL-6, IL-8, IL- $1 \beta$ e TNF- $\alpha$ têm relação com dor, depressão e piora da qualidade de vida no câncer. Segundo a autora, As citocinas pró-inflamatórias ao serem liberadas sinalizam ao sistema nervoso central induzindo produção central de citocinas, estimulação hipotalâmica e produção de mediadores inflamatórios que induzem dor. Estas citocinas também são capazes de induzir diversos outros 
sintomas emocionais como a depressão (Costanzo et al., 2005; Meyers et al., 2005). Estudos realizados com humanos verificaram que a administração de IL-2 e IFN- $\alpha$ em pacientes com câncer estava associada ao desenvolvimento de sintomas cognitivos e depressivos (Capuron et al., 2000); e a administração de IL6 em homens saudáveis resultou em diminuição da capacidade de concentração, fadiga, alteração do sono, aumento da proteína $C$ reativa e da sensação de indisposição (Spath-Schwalbe et al., 1998). Estudos realizados com humanos verificaram que a administração de IL-2 e IFN- $\alpha$ em pacientes com câncer estava associada ao desenvolvimento de sintomas cognitivos e depressivos (Capuron et al., 2000) A ocorrência destes outros sintomas, em pacientes com dor, provavelmente é resultante do aumento das citocinas induzido pela presença do estímulo doloroso e poderia justificar a baixa qualidade de vida (QVRS) observada entre pacientes com câncer com dor quando comparados a pacientes sem dor (Ferreira et al., 2007a).

Alguns estudos desenvolvidos com pacientes com câncer também corroboram com a hipótese de que o aumento das citocinas estaria associado à piora da qualidade de vida e da capacidade funcional (Costanzo et al., 2005; Meyers et al., 2005; Rich et al., 2005). Um destes estudos foi realizado com pacientes com câncer colorretal. Os autores ao avaliarem a capacidade funcional e a QVRS, utilizando o instrumento QLQ-c30, observaram que o aumento dos níveis circulantes da IL-6 estava associado à menor capacidade funcional, pior qualidade de vida emocional e social e piora do apetite, confirmando a hipótese de 
associação entre aumento dos níveis circulantes de citocinas e piora da QVRS em pacientes com câncer (Rich et al., 2005). 


\section{CONCLUSÃO}

Através deste estudo, conclui-se que:

1. A dor com características neuropáticas e os sintomas neuropáticos foram prevalentes de forma insidiosa até a sua intensificação após 4 meses de quimioterapia e após término da quimioterapia nos pacientes com câncer colorretal submetidos ao tratamento com quimioterápico oxaliplatina. A dor foi do tipo neuropática em $21,67 \%$ dos doentes ao fim da quimioterapia e em 10,00\% após fim do seguimento, segundo o Questionário de Dor Neuropática (DN4). A dor com características neuropáticas manteve-se presente no término do tratamento e durante o período de acompanhamento.

2. Os sintomas e as características da neuropatia periférica e a dor neuropática mais frequentes foram o choque elétrico, o frio doloroso, a dormência e alfinetadas/agulhadas descritas como incômoda, aborrecida e enjoada. Tais sintomas e características se mantiveram até o término do tratamento, exceto o choque elétrico que apresentou um declínio a partir da visita após quimioterapia. 
3. Houve um impacto negativo nas atividades de vida diária, principalmente nas atividades gerais, no trabalho e no humor. E, consequentemente, na qualidade de vida que evidenciou uma queda durante o tratamento, sendo recuperada ao término do tratamento. A ansiedade apresentou uma discreta diminuição após o término do tratamento quimioterápico e após o acompanhamento.

4. Houve correlação positiva entre os sintomas neuropáticos ao término do tratamento com a idade, o escore do TNS basal, TNS após quimioterapia e TNS após o seguimento. Além disso, houve uma correlação positiva entre a qualidade de vida aferida pelo EORTC e os descritores do McGill reduzido. 


\section{REFERÊNCIAS}

- Afonseca SO, Costa Silva MA, Giglio A. Abordagem da neuropatia periférica induzida por quimioterapia. Revista Brasileira de Medicina. 2010.

- Afonseca SO, Cruz FM, Cubero DIG, Lera AT, Schindler F, Okawara M, de SouzaLF, Rodrigues NP, del Giglio A. Vitamin E for prevention of oxaliplatininduced peripheral neuropathy: a pilot randomized clinical Trial. Sao Paulo Med J. 2013; 131(1):35-8

- Aguiar ADF et al. Perfil sociodemográfico e clínico das pacientes em tratamento do câncer mamário. Rev. do Instit de Ciências da Saúde, São Paulo, 2008; 26 (2): 191-195.

- Ahles TA, Saykin AJ. Candidate mechanisms for chemotherapy-induced cognitive changes. Nat Ver Cancer. 2007;7(3):192-201.

- American Cancer Society. The History of Cancer. 2009.

- André T, Boni C, Mounedji-Boudiaf L, Navarro M, Tabernero J, Hickish T, Topham C, Zaninelli M, Clingan P, Bridgewater J, Tabah-Fisch I, de Gramont A, Multicenter International Study of Oxaliplatin/5-Fluorouracil/Leucovorin in the Adjuvant Treatment of Colon Cancer (MOSAIC) Investigators. Oxaliplatin, fluorouracil, and leucovorin as adjuvant treatment for colon cancer. $\mathrm{N}$ Engl $\mathrm{J}$ Med 2004; 350:2343-2351.

- Andre T., Boni C., Navarro M., Tabernero J., Hickish T., Topham C., et al. Improved overall survival with oxaliplatin, fluorouracil, and leucovorin as adjuvant treatment in stage II or III colon cancer in the MOSAIC trial. J Clin Oncol. 2009. 27(19): 3109-3116

- Antoniadis D, Lavrentiadis G, Papadopoulos VN, lerodiakonou I, Garyfallos G. The Validity of the Distress Thermometer in Greek Colon Cancer Patients. Acta Chir Belg. 2015 Nov-Dec;115(6):387-92.

- Argyriou AA, Chroni E, Polychronopoulos P, Iconomou G, Koutras A, Makatsoris $\mathrm{T}$, et al. Efficacy of oxcarbazepine for prophylaxis against cumulative oxaliplatin-induced neuropathy. Neurology 2006;67:2253-5. 
- Argyriou AA, Polychronopoulos P, Iconomou G, Chroni E, Kalofonos HP. A review on oxaliplatin-induced peripheral nerve damage. Cancer Treat Rev. 2007;34(4):368-77.

- Argyriou AA, Briani C, Cavaletti G, Bruna J, Alberti P, Velasco R, Lonardi S, Cortinovis D, Cazzaniga M, Campagnolo M, Santos C, Kalofonos HP. Advanced age and liability to oxaliplatin-induced peripheral neuropathy: post hoc analysis of a prospective study. Eur J Neurol. 2013 May;20(5):788-94. doi: 10.1111/ene.12061. Epub 2012 Dec 17.

- Attal N, Bouhassira D. Translating basic research on sodium channels in human neuropathic pain. J Pain. 2006 Jan;7.

- Attal N, Bouhassira D, Gautron M, Vaillant JN, Mitry E, Lepere C, et al. Thermal hyperalgesia as a marker of oxaliplatin neurotoxicity: A prospective quantified sensory assessment study. Pain 2009;144:245-52.

- Baek KK, Lee J, Park SH, Park JO, Park YS, Lim HY, Kang WK, Cho YB, Yun $\mathrm{SH}, \mathrm{Kim} \quad \mathrm{HC}$, Lee WY, Chun HK. Oxaliplatin-induced chronic peripheral neurotoxicity: a prospective analysis in patients with colorectal cancer. Cancer Res Treat. 2010 Dec;42(4):185-90.

- Becouarn Y, Ychou M, Ducreux M, Borel C, Bertheault-Cvitkovic F, Seitz JF, Nasca S, Nguyen TD, Paillot B, Raoul JL, Duffour J, Fandi A, Dupont-Andre G \& Rougier P. Phase II trial of oxaliplatin as first-line chemotherapy in metastatic colorectal cancer patients. Journal of Clinical Oncology, 1998; 16: 2739-2744.

- Becouarn Y \& Rougier P. Clinical efficacy of oxaliplatin monotherapy: phase II trials in advanced colorectal cancer. Seminars in Oncology, 1998; 25 (Suppl 5): 23-31.

- Benarroch EE, Daube JR, Flemming KD, Westmoreland BF. Chapter 9: The internal regulation system. In: Benarroch $E \mathrm{E}$, Daube $J \mathrm{R}$, Flemming $\mathrm{K} \mathrm{D}$, Westmoreland B F, editors. Mayo clinic medical neurosciences: organized by neurologic systems and levels. 5th ed. Mayo Clinic Scientific Press; 2008. p. 379-80.

- Bleiberg $\mathrm{H}$. Oxaliplatin (L-OHP): a new reality in colorectal cancer. $\mathrm{Br}$ J Cancer. 1998 Jun;77 Suppl 4:1-3. 
- Binder A, Stengel M, Maag R, Wasner G, Schoch R, Moosig F, et al. Pain in oxaliplatin-induced neuropathy - Sensitization in the peripheral and central nociceptive system. Eur J Cancer 2007;43:2658-63.

- Bonassa EMA. Conceitos gerais em quimioterapia antineoplásica. In: Bonassa EMA, Santana TR. Enfermagem em terapêutica oncológica. São Paulo (SP): Atheneu; 2005. p. 3-19.

- Bouhassira D, Attal N, Fermanian J, Alchaar H, Gautron M, Masquelier E, Rostaing S, Lanteri-Minet M, Collin E, Grisart J, Boureau F. Development and validation of the neuropathic pain symptom inventory. Pain 2004;108:248-257.

- Bouhassira D, Attal N, Alchaar H, Boureau F, Brochet B, Bruxelle J, Cunin G, Fermanian J, Ginies P, Grun-Overdyking A, Jafari-Schluep H, Lanteri-Minet M, Laurent B, Mick G, Serrie A, Valade D, Vicaut E. Comparison of pain syndromes associated with nervous or somatic lesions and development of a new neuropathic pain diagnostic questionnaire (DN4). Pain 2005;114:29-36.

- Bouhassira D, Lanteri-Minet M, Attal N, Laurent B, Touboul C: Prevalence of chronic pain with or without neuropathic characteristics in the general population. Pain 2008; 136: 380-387.

- Bouhassira D, Wilhelm S, Schacht A, Perrot S, Kosek E, Cruccu G, Freynhagen R, Tesfaye S, Lledó A, Choy E, Marchettini P, Micó JA, Spaeth M, Skljarevski V, Tölle T. Neuropathic pain phenotyping as a predictor of treatment response in painful diabetic neuropathy: data from the randomized, double-blind, COMBO-DN study. Pain. 2014 Oct;155(10):2171-9.

- Brasil. Estimativas de Incidência de Câncer no Brasil para 2006. INCA, 2006: www.inca.gov.br/estimativas/2006.

- Brezden CB, Phillips KA, Abdolell M, Bunston T, Tannock IF. Cognitive function in breast câncer patients receiving adjuvant chemotherapy. J Clin Oncol. 2000;18(14):2695-701.

- Briani C, Argyriou AA, Izquierdo C, Velasco R, Campagnolo M, Alberti $P$, Frigeni B, Cacciavillani M, Bergamo F, Cortinovis D, Cazzaniga M, Bruna J, Cavaletti G,Kalofonos HP. Long-term course of oxaliplatin-induced polyneuropathy: a prospective 2-year follow-up study. J Peripher Nerv Syst. 2014 Dec;19(4):299-306. 
- Brill S, Ablin JN, Goor-Aryeh I, Hyat K, Slefer A, Buskila D; Tel Aviv-Sourasky Medical Center. Prevalence of fibromyalgia syndrome in patients referred to a tertiary pain clinic. J Investig Med. 2012; 60(4):685-8.

- Brouwers EE, Huitema AD, Boogerd W, Beijnen JH, Schellens JH. Persistent neuropathy after treatment with cisplatin and oxaliplatin. Acta Oncol 2009; 48:832-841.

- Calhoun EA, Welshman EE, Chang $\mathrm{CH}$, et al. Psychometric evaluation of the Functional Assessment of Cancer Terapy/Gynecologic Oncology GroupNeurotoxicity (Fact/GOG-Ntx) questionnaire for patients receiving systemic chemotherapy. Int J Gynecol Cancer. 2003;13:741-748.

- Capuron L, Ravaud A, Dantzer R. Early depressive symptoms in cancer patients receiving interleukin 2 and/or interferon alfa-2b therapy. J Clin Oncol. 2000;18(10):2143-51.

- Cardoso G, Graca J, Klut C, Trancas B, Papoila A. Depression and anxiety symptoms following cancer diagnosis: a cross-sectional study. Psychol Health Med. 2015 Dec 18:1-9.

- Cascinu S, Catalano V, Cordella L, Labianca R, Giordani P, Baldelli AM, et al. Neuroprotective effect of reduced glutathione on oxaliplatin-based chemotherapy in advanced colorectal cancer: a randomized, double-blind, placebo-controlled trial. J Clin Oncol. 2002 Aug 15 20(16):3478-83.

- Cella DF, Tulsky DS, Gray G, et al. Te Functional Assessment of Cancer Terapy scale: development and validation of the general measure. J Clin Oncol. 1993;11:570-579.

- Cella D, Peterman A, Hudgens S, Webster K, Socinski MA. Measuring the side efects of taxane therapy in oncology: the functional assesment of cancer therapy-taxane (FACT-taxane). Cancer. 2003;98:822-831.

- Cersosimo RJ. Oxaliplatin-associated neuropathy: a review. Ann Pharmacother. 2005 Jan;39(1):128-35.

- Chay WY, Tan SH, Lo YL, Ong YK, Ng HC, Gao F, et al. Use of calcium and magnesium infusions in prevention of oxaliplatin induced sensory neuropathy. Asia- Pac J Clin Oncol 2010;6:270-7. 
- Chollet P, Bensmaine MA, Brienza S, Deloche C, Cure H, Caillet H \& Cvitkovic E. Single agent activity of oxaliplatin in heavily pretreated advanced epithelial ovarian cancer. Annals of Oncology. 1996 ; 7: 1065-1070.

- Chu E, DeVita VT. Physicians' Cancer Chemotherapy Drug Manual.Jones and Bartlett Publishers, Boston/Toronto/London/Singapore, 2001, 584 pp

- Cleeland C, Ryan K. Pain assessment: global use of the Brief Pain Inventory. Ann Acad Med Singapore 1994; 23(2):129-138.

- Costanzo E, Lutgendorf S, Sood A, Anderson B, Sorosky J, Lubaroff D. Psychosocial factors and interleukin-6 among women with advanced ovarian cancer. Cancer. 2005;104(2):305-13.

- Coriat R, Alexandre J, Nicco C, Quinquis L, Benoit E, Chéreau C, Lemaréchal H, Mir O, Borderie D, Tréluyer JM, Weill B, Coste J, Goldwasser F, Batteux F. Treatment of oxaliplatin induced peripheral neuropathy by intravenous mangafodipir. J Clin Invest. 2014 Jan;124(1):262-72.

- Cvitkovic E. A historical perspective on oxaliplatin: rethinking the role of platinum compounds and learning from near misses. 1998. Seminars in Oncology, 25 (Suppl 5): 1-3.

- de Andrade DC, Teixeira MJ, Galhardoni R, Ferreira KASL, Malieno PB, Scisci N, Riechelmann RP, Teixeira WGJ, Saragiotto DF, Silva VA, Raicher I, de Castro I, Parravano D, Fukushima JT, Lefaucheur JP, Bouhassira D, Macarenco RSS, de Mello ES, Hoff PM. A phase III, randomized, double-blind, placebo-controlled trial to evaluate the efficacy and safety of pregabalin in the prevention and reduction of oxaliplatin-induced painful neuropathy (PreOx). Poster apresentado no Congresso "ASCO Annual Meeting" da American Society of Clinical Oncology, 2015.

- de Gramont A, Vignoud J, Tournigand C, Louvet C, Andre T, Varette C, Raymond E, Moreau S, Le Bail N \& Krulik M. Oxaliplatin with high dose folinic acid and 5-fluorouracil 48-h infusion in pretreated metastatic colorectal cancer. European Journal of Cancer. 1997, 33: 214-219.

- de Gramont A, Figer A, Seymour M, Homerin M, Hmissi A, Cassidy J, Boni C, Cortes-Funes H, Cervantes A, Freyer G, Papamichael D, Le Bail N, Louvet C, Hendler D, de Braud F, Wilson C, Morvan F \& Bonetti A. Leucovorin and fluorouracil with or without oxaliplatin as first-line treatment in advanced colorectal cancer. Journal of Clinical Oncology. 2000; 18: 2938-2947. 
- Diaz-Rubio E, Sastre J, Zaniboni A, Labianca R, Cortes-Funes H, de Braud F, Boni C, Benavides M, Dallavalle G \& Homerin M. Oxaliplatin as single agent in previously untreated colorectal carcinoma patients: a phase II multicentric study. Annals of Oncology. 1998; 9: 105-108.

- Driessen CM, de Kleine-Bolt KM, Vingerhoets AJ, Mols F, Vreugdenhil G. Assessing the impact of chemotherapy-induced peripheral neurotoxicity on the quality of life of cancer patients: the introduction of a new measure. Support Care Cancer. 2012;20:877-881

- Dworkin RH, Backonja M, Rowbotham MC, Allen RR, Argoff CR, Bennett GJ, Bushnell MC, Farrar JT, Galer BS, Haythornthwaite JA, Hewitt DJ, Loeser JD, Max MB, Saltarelli M, Schmader KE, Stein C, Thompson D, Turk DC, Wallace MS, Watkins LR, Weinstein SM. Advances in neuropathic pain: diagnosis, mechanisms, and treatment recommendations. Arch Neurol. 2003 Nov;60(11):1524-34. Review.

- Extra JM, Marty M, Brienza S \& Misset JL. Pharmacokinetics and safety profile of oxaliplatin. Seminars in Oncology. 1998; 25 (Suppl 5): 13-22.

- Ferreira KASL, Kimura M, Teixeira MJ, da Nóbrega JCM, Graziani SR. Impact of pain on symptoms, functional performance and on health-related quality of life of cancer patients. 2007 International Society for Quality of Life Research meeting abstracts [ www.isoqol.org/2007mtgabstracts.pdf] Quality of Life Research Suppl., A103, Abstract\#1781;2007a; Toronto, Canada.

- Ferreira KASL. Dor e qualidade de vida relacionada à saúde de pacientes com câncer: influência das citocinas pró-inflamatórias TNF- $\alpha$, IL-6, IL-8 e IL -1 $\beta$ [tese]. São Paulo: Escola de Enfermagem; 2008 [acesso 2016-05-02]. Disponível em: http://www.teses.usp.br/teses/disponiveis/7/7139/tde04032008-092629/.

- Ferreira KASL, Teixeira MJ, Mendonza TR, Cleeland CS. Validation of Brief Pain Inventory to Brazilian patients with pain. Support Care Cancer. 2010 Mar 10.

- Fink D, Nebel S, Aebi S, Zheng H, Cenni B, Nehme A, Christen RD \& Howell $\mathrm{SB}$. The role of mismatch repair in platinum drug resistance. Cancer Research. 1996; 56: 4881-4886. 
- Galvez R, Rejar J, Perez M, Gomez M: Prevalencia del dolor neuropático en España: Implicaciones clínicas, laborales y asistenciales. Med Clin 125:221229, 2005

- Gamelin E, Gamelin L, Bossi L, Quasthoff S. Clinical aspects and molecular basis of oxaliplatin neurotoxicity: current management and development of preventive measures. Seminars in Oncology 2002;29(15):21-33.

- Gamelin L. Predictive factors of oxaliplatin neurotoxicity: the involvement of the oxalate outcome pathway. Clin. Cancer Res 13. 6359-6368. 2007.

- Gamelin L, Capitain O, Morel A, Dumont A, Traore S, Anne LB, et al. Predictive Factors of Oxaliplatin Neurotoxicity: The Involvement of the Oxalate Outcome Pathway. Clin Cancer Res 2007b;13(21):6359-68

- Garicochea B, Vasconselos e Silva R, Corri G, Maranho IC, Cutait R. Hereditary colorectal cancer: identification and management of affected families. Grupo editorial Moreira JR. São Paulo, 2004.

- Giacchetti S, Perpoint B, Zidani R, Le Bail N, Faggiuolo R, Focan C, Chollet P, Llory JF, Letourneau Y, Coudert B, Bertheault-Cvitkovic F, Larregain-Fournier D, Le Rol A, Walter S, Adam R, Misset JL \& Levi F. Phase III multicenter randomized trial of oxaliplatin added to chronomodulated fluorouracilleucovorin as first-line treatment of metastatic colorectal cancer. Journal of Clinical Oncology. 2000; 18: 136-147.

- Gilron I, Bailey JM, Tu D, Holden RR, Jackson AC, Houlden RL. Nortriptyline and gabapentin, alone and in combination for neuropathic pain: a double-blind, randomised controlled crossover trial. Lancet, v. 374, p.1252-61, 2009.

- Gimenez, DL. Quimioterapia. In: Ikemori, E. H. A. et al. Nutrição em oncologia. $1^{a}$ - ed. São Paulo: Lemar. 2003; p. 179-188.

- Golan-Vered Y, Pud D. Chemotherapy-induced neuropathic pain and its relation to cluster symptoms in breast cancer patients treatedwith paclitaxel. Pain Pract. 2013 Jan;13(1):46-52.

- Grifth KA, Couture DJ, Zhu S, et al. Evaluation of chemotherapyinduced peripheral neuropathy using current perception threshold and clinical evaluations. Support Care Cancer. 2014;22:1161-1169.

- Grisold W, Cavaletti G, Windebank AJ. Peripheral neuropathies from chemotherapeutics and targeted agents: diagnosis, treatment, and prevention. Neuro Oncol. 2012 Sep;14 Suppl 4:iv45-54. 
- Grothey A. Clinical Management of oxaliplatin-associated neurotoxicity. Clin Colorec Cancer 2005;5(1):38-46.

- Grothey A, Nikcevich DA, Sloan JA, Kugler JW, Silberstein PT, Dentchev T, Wender DB, Novotny PJ, Chitaley U, Alberts SR, Loprinzi CL. Intravenous calcium and magnesium for oxaliplatin-induced sensory neurotoxicity in adjuvant colon cancer: NCCTG N04C7. J Clin Oncol. 2011 Feb $1 ; 29(4): 421-7$.

- Guo Y, Jones D, Palmer JL, Forman A, Dakhil SR, Velasco MR, Matthias Weiss M, Gilman P, Mills GM, Noga SJ, Eng C, Overman MJ, Fisch MJ. Oral alpha-lipoic acid to prevent chemotherapy-induced peripheral neuropathy: a randomized, double-blind, placebo-controlled Trial. Support Care Cancer, 2014, 22:1223-1231.

- Harden N, Cohen M. Unmet needs in the management of neuropathic pain. J Pain Symptom Manage. 2003 May;25(5 Suppl):S12-7. Review.

- Habr-Gama A. Colorectal cancer: the importance of its prevention. Arq Gastroenterol. 2005 Jan-Mar;42(1):2-3. Epub 2005 Jun 22.

- Hecktheuer SR. Alteracoes neurocomportamentais induzidas por agentes antineoplasicos: efeitos da administracao aguda da cisplatina sobre a memória aversiva em ratos [dissertacao]. Porto Alegre: Universidade Federal do Rio Grande do Sul, Faculdade de Medicina, Programa de Pos-Graduacao em Medicina: Ciencias Medicas; 2009.

- Hershman DL, Weimer LH, Wang A, et al. Association between patient reported outcomes and quantitative sensory tests for measuring long-term neurotoxicity in breast cancer survivors treated with adjuvant paclitaxel chemotherapy. Breast Cancer Res Treat. 2011;125:767-774.

- Hill A, Bergin P, Hanning F, Thompson P, Findlay M, Damianovich D. Detecting acute neurotoxicity durind platinum chemotherapy by neurophysiological assessment of motor nerve hyperexcitability. BMC Cancer 2010, 10:451 doi:10.1186/1471-2407-10-451.

- Huang JS, Wu CL, Fan CW, Chen WH, Yeh KY, Chang PH. Intravenous glutamine appears to reduce the severity of symptomatic platinum-induced neuropathy: a prospective randomized study. J Chemother. 2015 Aug;27(4):235-40. 
- INCA - Instituto Nacional de Câncer. Coordenação de Prevenção e Vigilância. A situação do câncer no Brasil/Ministério da Saúde, Secretaria de Atenção à Saúde, Instituto Nacional de Câncer, Coordenação de Prevenção e Vigilância. -Rio de Janeiro: INCA, 2006

- INCA - Instituto Nacional de Câncer José Alencar Gomes da Silva. Coordenação de Prevenção e Vigilância Estimativa 2016: incidência de câncer no Brasil / Instituto Nacional de Câncer José Alencar Gomes da Silva - Rio de Janeiro: INCA, 2015.

- Institut Jules Bordet (Association Hospitalière de Bruxelles - Centre des Tumeurs de ULB). The History of Cancer. Retrieved 2010-11-19.

- International Union Against Cancer: Introduction UICC. Global Cancer Control. Geneve, Switzerland, UICC, 2005

- Ishibashi K, Okada N, Miyazaki T, Sano M, Ishida H. Effect of calcium and magnesium on neurotoxicity and blood platinum concentrations in patients receiving mFOLFOX6 therapy: a prospective randomized study. Int $\mathrm{J}$ Clin Oncol. 2010 Feb;15(1):82-7.

- Jensen TS, Baron R. Translation of symptoms and signs into mechanisms in neuropathic pain. Pain. 2003 Mar;102(1-2):1-8.

- Junior E, Souza M: Epidemiologia da dor cronica e dor neuropatica: desenvolvimento de questionário para inquéritos populacionais. RBM 60:610615, 2003

- Ishibashi K, Okada N, Miyazaki T, Sano M, Ishida H. Effect of calcium and magnesium on neurotoxicity and blood platinum concentrations in patients receiving mFOLFOX6 therapy: a prospective randomized study. Int $\mathrm{J}$ Clin Oncol 2010;15:82-7.

- Janinis J, Papakostas P, Samelis G, Skarlos D, Papagianopoulos P \& Fountzilas G (2000). Second-line chemotherapy with weekly oxaliplatin and high-dose 5-fluorouracil with folinic acid in metastatic colorectal carcinoma: a Hellenic Cooperative Oncology Group (HeCOG) phase II feasibility study. Annals of Oncology, 11: 163-167.

- Jensen TS, Baron R. Translation of symptoms and signs into mechanisms in neuropathic pain. Pain. 2003 Mar;102(1-2):1-8. 
- Jensen TS, Baron R, Haanpää M, Kalso E, Loeser JD, Rice AS, Treede RD. A new definition of neuropathic pain.Pain. 2011 Oct;152(10):22045.doi:10.1016/j.pain.2011.06.017.

- Kalofonos HP, Aravantinos G, Kosmidis P, Papakostas P, Economopoulos T, Dimopoulos M, Skarlos D, Bamias A, Pectasides D, Chalkidou S, Karina M, Koutras A, Samantas E, Bacoyiannis C, Samelis GF, Basdanis G, Kalfarentzos F, Fountzilas G. Irinotecan or oxaliplatin combined with leucovorin and 5fluorouracil as first-line treatment in advanced colorectal cancer: a multicenter, randomized, phase II study. Ann Oncol. 2005; 16:869-877.

- Kasper D, Fauci A, Hauser S, Longo D, Jameson JL, Loscalzo J. Harrison's principles for internal medicine. 19th Edit. New York: Mc Graw Hill Education; 2015

- Kautio, A. L. et al. Amitriptyline in the prevention of chemotherapy-induced neuropathic symptoms. Anticancer Res.2003; 29, 2601-2606.

- Kee W, Masters Steedman S, Middaugh SJ. Medication Quantification Scale (MQS): update of detriment weights and medication additions. AJPM. 1998;8:83-88.

- Kim BJ, Park HR, Roh HJ, et al. Chemotherapy-related polyneuropathy may deteriorate quality of life in patients with B-cell lymphoma. Qual Life Res. 2010;19:1097-1103.

- Kono T, Mamiya N, Chisato N, Ebisawa Y, Yamazaki H, Watari J, et al. Efficacy of shajinkigan for peripheral neurotoxicity of oxaliplatin in patients with advanced or recurrent colorectal cancer. Hindwai Pub Corp. 2009;2011:1093110

- Kraychete DC, Sakata RK. Neuropatias Periféricas Dolorosas. Rev Bras Anestesiol. 2011; 61: 5: 641-658

- Krarup-Hansen A, Helweg-Larsen S, Schmalbruch H, Rorth M, Krarup C. Neuronal involvement in cisplatin neuropathy: prospective clinical and neurophysiological studies. Brain. 2007 Apr 130(Pt 4):1076-88.

- Kus T, Aktas G, Alpak G, Kalender ME, Sevinc A, Kul S, Temizer M, Camci C. Efficacy of venlafaxine for the relief of taxane and oxaliplatin-induced acute neurotoxicity: a single-center retrospective case-control study. Support Care Cancer. 2016 May;24(5):2085-91

- Land SR, Kopec JA, Cecchini RS, Ganz PA, Wieand HS, Colangelo LH, et al. Neurotoxicity from oxaliplatin combined with weekly bolus fluourouracil and 
leucovorin as surgical adjuvant chemotherapy for stage II and III colon cancer: NSABP C-07. J Clin Oncol 2007;25(16):2205-11.

- Lehky TJ, Leonard GD, Wilson RH, Grem JL, Floeter MK. Oxaliplatin--induced urotoxicity: Acute hyperexcitability and chronic neuropathy. Muscle Nerve 2004;29:387-92.

- Leonard GD, Wright MA, Quinn MG, Fioravanti S, Harold N, Schuler B, et al. Survey of oxaliplatin-associated neurotoxicity using an interview-based questionnaire in patients with metastatic colorectal cancer. BMC Cancer 2005;5:116-26.

- Levi F, Misset JL, Brienza S, Adam R, Metzger G, Itzakhi M, Caussanel JP, Kunstlinger $F$, Lecouturier $S$ \& Descorps-Declere A. A chronopharmacologic phase II clinical trial with 5-fluorouracil, folinic acid, and oxaliplatin using an ambulatory multichannel programmable pump: High antitumor effectiveness against metastatic colorectal cancer. Cancer. 1992; 69: 893-900.

- Lima JLMV. Tradução e validação do "cuestionario de afrontamento al dolor crónico reducido (CAD-R)" na pessoa com dor crônica 2008.

- Liu JJ, Jamieson SM, Subramaniam J, Ip V, Jong NN, Mercer JF, et al. Neuronal expression of copper transporter 1 in rat dorsal root ganglia: association with platinum neurotoxicity. Cancer Chemother Pharmacol. 2009 Sep;64(4):847-56.

- Livingston PM, Craike MJ, White VM, Hordern AJ, Jefford M, Botti MA, Lethborg C, Oldroyd JC. A nurse-assisted screening and referral program for depression among survivors of colorectal cancer: feasibility study. Med $\mathrm{J}$ Aust. 2010 Sep 6;193(5 Suppl):S83-7.

- Loprinzi CL, Qin R, Dakhil SR, Fehrenbacher L, Flynn KA, Atherton P, Seisler D, Qamar R, Lewis GC, and Grothey A. Phase III Randomized, PlaceboControlled, Double-Blind Study of Intravenous Calcium and Magnesium to Prevent Oxaliplatin-Induced Sensory Neurotoxicity (N08CB/Alliance). Journalof Clinical Oncology. 2014.

- MacDonald JS \& Astrow AB. Adjuvant therapy of colon cancer. Seminars in Oncology. 2001; 28: 30-40.

- Machover D, Diaz-Rubio E, de Gramont A, Schilf A, Gastiaburu JJ, Brienza S, Itzhaki M, Metzger G, N'Daw D, Vignoud J, Abad A, Francois E, Gamelin E, Marty M, Sastre J, Seitz JF \& Ychou M. Two consecutive phase II studies of 
oxaliplatin (L-OHP) for treatment of patients with advanced colorectal carcinoma who were resistant to previous treatment with fluoropyrimidines. Annals of Oncology, 1996; 7: 95-98.

- Madajewicz S, Waterhouse DM, Ritch OS, Khan MQ, Higby DJ, Leichman CG, Malik SK, Hentschel P, Gill JF, Zhao L, Nicol SJ. Multicenter, randomized phase II trial of bevacizumab plus folinic acid, fluorouracil, gemcitabine (FFG) versus bevacizumab plus folinic acid, fluorouracil, oxaliplatin (FOLFOX4) as first-line therapy for patients with advanced colorectal câncer. Invest New Drugs. 2012, 30:772-778.

- Mamenta EL, Poma EE, Kaufmann WK, Delmastro DA, Grady HL \& Chaney SG. Enhanced replicative bypass of platinum-DNA adducts in cisplatinresistant human ovarian carcinoma cell lines. Cancer Research. 1994; 54: 3500-3505.

- Manji H. Toxic neuropathy. Curr Opin Neurol. 2011 Oct;24(5):484-90. doi: 10.1097/WCO.0b013e32834a94b6

- Martyn CN, Hughes RAC. Epidemiology of peripheral neuropathy. Journal of Neurology, Neurosurgery, and Psychiatry 1997;62:310-318

- Mateos RG: Abordaje Actual del Dolor Neuropatico. Madrid, Master Line \& Prodigio SL, 2003.

- Mattioli R, Massacesi C, Recchia F, Marcucci F, Cappelletti C, Imperatori L, Pilone A, Rocchi M, Cesta A, Laici G, Bonsignori M, Lippe P. High activity and reduced neurotoxicity of bi-fractionated oxaliplatin plus 5fluorouracil/leucovorin for elderly patients with advanced colorectal cancer. Ann Oncol. $2005 \mathrm{Jul} ; 16(7): 1147-51$.

- Max MB. Towards physiologically based treatment of patients with neuropathic pain. Pain. 1990 Aug;42(2):131-7.

- McCarberg BH, Billington R. Consequences of neuropathic pain: quality-of-life issues and associated costs. Am J Manag Care. 2006;12(9 Suppl):S263-8.

- Merskey H, Bogduk N, editors. Classification of chronic pain: descriptions of chronic pain syndromes and definitions of pain terms. $2^{\text {nd }}$ ed. Seattle: IASP Press; 1994.

- Meyers C, Albitar M, Estey E. Cognitive impairment, fatigue, and cytokine levels in patients with acute myelogenous leukemia or myelodysplastic syndrome. Cancer. 2005;104(4):788-93. 
- Ministério da Saúde. Secretaria de Atenção à Saúde. Instituto Nacional de Câncer. Coordenação de Prevenção e Vigilância. Estimativa 2002: Incidência de câncer no Brasil. Rio de Janeiro: INCA, 2001.

- Ministério da Saúde. Instituto Nacional de Câncer. TNM, Classificação de Tumores Malignos, 2004.

- Ministério da Saúde. Secretaria de Atenção à Saúde. Instituto Nacional de Câncer. Coordenação de Prevenção e Vigilância. Estimativa 2006: Incidência de câncer no Brasil. Rio de Janeiro: INCA, 2005.

- Ministério da Saúde. Secretaria de Atenção à Saúde. Instituto Nacional de Câncer. Coordenação de Prevenção e Vigilância de Câncer. Estimativas 2008: Incidência de Câncer no Brasil. Rio de Janeiro: INCA, 2007.

- Mihajlović J, Pechlivanoglou P, Miladinov-Mikov M, Zivković S, Postma MJ. Cancer incidence and mortality in Serbia 1999-2009. BMC Cancer. 2013 Jan 15;13:18. doi: 10.1186/1471-2407-13-18.

- Mols F, Beijers T, Lemmens V, van den Hurk CJ, Vreugdenhil G, van de PollFranse LV. Chemotherapy-induced neuropathy and its association with quality of life among 2- to 11-year colorectal cancer survivors: results from the population-based PROFILES registry. J Clin Oncol. 2013;31:2699-2707.

- Mols F, Beijers AJM, Vreugdenhil G, Van de Poll-Franse LV. Chemotherapyinduced peripheral neuropathy and its association with quality of life: A systematic review. Support Care Cancer. 2014;22:2261-2269.

- Moss, Ralph W. Galen on Cancer. Cancer Decisions. Moss in turn attributes this reason for the name to Paul of Aegina, 7th Century AD, quoted in Michael Shimkin, Contrary to Nature, 2004. Washington, D.C.: Superintendent of Document, DHEW Publication No. (NIH) 79-720, p. 35.

- Morita S, Kobayashi K, Eguchi K, et al. Infuence of clinical parameters on quality of life during chemotherapy in patients with advanced non-small cell lung cancer: application of a general linear model. Jpn J Clin Oncol. 2003;33:470-476.

- Nagashima M, Ooshiro M, Moriyama A, Sugishita Y, Kadoya K, Sato A, Kitahara T, Takagi R, Urita T, Yoshida Y, Tanaka H, Oshiro T, Okazumi $\mathrm{S}$, Katoh R. Efficacy and tolerability of controlled release oxycodone for oxaliplatin induced peripheral neuropathy and the extension of FOLFOX 
therapy in advanced colorectal cancer patients. Support Care Cancer. 2014 Jun;22(6):1579-84.

- Nassini R. Oxaliplatin elecits mechanical and cold allodynia in rodents via TRPA1 receptor stimulation. 2011. Pain 152. 1621-1631.

- Nebuloni DR, Mak MP, Souza FH, Saragiotto DF, Júlio T, DE Castro G Jr, Sabbaga J, Hoff PM. Modified FLOX as first-line chemotherapy for metastatic colorectal cancer patients in the public health system in Brazil: Effectiveness and cost-utility analysis. Mol Clin Oncol. 2013 Jan;1(1):175-179.

- Organização Pan-Americana da Saúde (OPAS) 2002.

- Ostchega Y, Donohue M, Fox N. High-dose cisplatin-related peripheral neuropathy. Cancer Nurs. 1988;11:23-32.

- Pachman DR, Barton DL, Watson JC, Loprinzi CL. Chemotherapy-induced peripheral neuropathy: Prevention and treatment. Clin Pharmacol Ther. 2011;90:377-87

- Park SB, Lin CS, Krishnan AV, Goldstein D, Friedlander ML, Kiernan M. Utilizing natural activity to dissect the pathophysiology of acute oxaliplatininduced neuropathy. Experimen Neurol 2010;227:120-27.

- Park SB, Lin CS, Krishnan AV, Goldstein D, Friedlander ML, Kiernan MC. Long-term neuropathy after oxaliplatin treatment: challenging the dictum of reversibility. Oncologist. 2011a;16:708-716.

- Park SB, Lin CS, Krishnan AV, Goldstein D, Friedlander ML, Kiernan MC (2011b). Long-term neuropathy after oxaliplatin treatment: challenging the dictum of reversibility. Oncologist 16:708-716

- Pérez C, Sánchez-Martínez N, Ballesteros A, Blanco T, Collazo A, González F,Villoria. Prevalence of pain and relative diagnostic performance of screening tools for neuropathic pain in cancer patients: A cross-sectional study. Eur J Pain. 2015 Jul;19(6):752-61.

- Perry MC. The Chemotherapy Sourcebook, 3ª- ed. Philadelphia: Lippincott Williams e Wilkins. 2001.

- Perrot S, Vicaut E, Servant D, Ravaud P. Prevalence of fibromyalgia in France: a multi-step study research combining national screening and clinical confirmation: The DEFI study (Determination of Epidemiology of Flbromyalgia). BMC Musculoskelet Disord. 2011; 12:224. 
- Peters CM, Jimenez-Andrade JM, Kuskowski MA, Ghilardi JR, Mantyh PW. An evolving cellular pathology occurs in dorsal root ganglia, peripheral nerve and spinal cord following intravenous administration of paclitaxel in the rat. Brain Re. 2007. 1168:46-59.

- Petrioli R, Paolelli L, Marsili S, Civitelli S, Francini E, Cioppa T, et al. Folfox-4 stop and go and capecitabine manteinance chemotherapy in the treatment of metastatic colorectal cancer. Oncology 2006;70:345-50.

- Pietrangeli A, Leandri M, Terzoli E, Jandolo B, Garufi C. Persistence of highdose Oxaliplatin-induced neuropathy at long-term follow-up. Eur Neurol 2006;56:13-6.

- Pimenta CAM. Atitudes de doentes com dor crônica frente à dor [tese livredocência]. São Paulo: Escola de Enfermagem, Universidade de São Paulo; 1999.

- Postma TJ, Aaronson NK, Heimans JJ, et al. Te development of an EORTC quality of life questionnaire to assess chemotherapyinduced peripheral neuropathy: the QLQ-CIPN20. Eur J Cancer. May 2005;41:1135-1139.

- Ramchandren S, Leonard M, Mody RJ, et al. Peripheral neuropathy in survivors of childhood acute lymphoblastic leukemia. J Peripher Nerv Syst. 2009;14:184-189.

- Rao, R. D. et al. Efficacy of gabapentin in the management of chemotherapyinduced peripheral neuropathy: a phase 3 randomized, double-blind, placebocontrolled, crossover trial (N00C3). Cancer 110, 2110-2118 (2007).

- Rao, R. D. et al. Efficacy of lamotrigine in the management of chemotherapyinduced peripheral neuropathy: a phase 3 randomized, double-blind, placebocontrolled trial, N01C3. Cancer 112, 2802-2808 (2008).

- Raymond E, Djelloul C, Buquet-Fagot F, Mester E \& Gespach C. Synergy between the non-classical thymidase synthase inhibitor AG337 (Thymitaq) and cisplatin in human colon and ovarian cancer cells. Anticancer Drugs. 1996; 7: 752-757

- Raymond E, Chaney SG, Taamma A \& Cvitkovic E. Oxaliplatin: A review of preclinical and clinical studies. Annals of Oncology. 1998ª ; 9: 1053-1071.

- Raymond E, Lawrence R, Izbicka E, Faivre S \& Von Hoff DD. Activity of oxaliplatin against human tumor colony forming units. Clinical Cancer Research. 1998b; 4: 1021-1029. 
- Rich T, Innominato PF, Boerner J, Mormont MC, lacobelli S, Baron B et al. Elevated serum cytokines correlated with altered behavior, serum cortisol rhythm, and dampened 24-hour rest-activity patterns in patients with metastatic colorectal cancer. Clin Cancer Res. 2005;11(5):1757-64.

- Sá K, Baptista AF, Matos MA, Lessa I. Prevalence of Chronic Pain and Associated Factors in the Population of Salvador, Bahia. Rev Saúde Pública, 2008.

- Saif MW, Reardon J. Management of oxaliplatin-induced peripheral neuropathy. Ther Clin Risk Manag. 2005 Dec 1(4):249-58.

- Sakurai M. Oxaliplatin-induced neuropathy in the rat: involvement of oxalate in cold hyperalgesia but not mechanical allodynia. Pain 2009.147. 165-174.

- Santos JG, Brito JO, de Andrade DC, Kaziyama VM, Ferreira KA, Souza I, Teixeira MJ, Bouhassira D, Baptista AF. Translation to Portuguese and validation of the Douleur Neuropathique 4 questionnaire. J Pain. 2010 May;11(5):484-90. Epub 2009 Dec 16.

- Scheithauer W. Progress in adjuvant and palliative_chemotherapy_of colorectal cancer: current status and perspectives. Wien Klin Wochenschr. 1993;105(20):568-79. Review. German.

- Schestatsky P. Definition, diagnosis and treatment of neuropathic pain. Rev HCPA 2008;28(3).

- Schofield P, Gough K, Ugalde A, Carey M, Aranda S, Sanson-Fisher R. Cancer Treatment Survey (CaTS): development and validation of a new instrument to measure patients' preparation for chemotherapy and radiotherapy. Psychooncology. 2012 Mar;21(3):307-15. doi: 10.1002/pon.1896. Epub 2010 Dec 20.

- Scuteri A. NGF protects dorsal root ganglion neurons from oxaliplatin by modulating JNK/Sapk and ERK1/2. 2010. Neurosci. Lett. 486, 141-145.

- Sisignano M, Baron R, Scholich K, Geisslingeret G et al. Mechanism-based treatment for chemotherapyinduced peripheral neuropathic pain. Nat. Rev. Neurol. 10, 694-707 (2014); published online 4 November 2014.

- Smith, E. M, Pang H, Cirrincione C, Fleishman S, Paskett ED, Ahles T, Bressler LR, Fadul CE, Knox C, Le-Lindqwister N, Gilman PB, Shapiro CL et al. Effect of duloxetine on pain, function, and quality of life among patients 
with chemotherapy-induced painful peripheral neuropathy: a randomized clinical trial. JAMA. 2013 Apr 3; 309(13): 1359-1367.

- Sociedade Brasileira de Cancerologia. Câncer de Cólon: Tratamento Quimioterápico. Diretrizes Clínicas na Saúde Suplementar. 2011.

- Sorbe B, Grafund M, Nygren L, et al. A phase II study of docetaxel weekly in combination with carboplatin every three weeks as frst line chemotherapy in stage IIB-IV epithelial ovarian cancer: neurological toxicity and quality-of-life evaluation. Int J Oncol. 2012;40:773-781.

- Spath-Schwalbe E, Hansen K, Schmidt F, Schrezenmeier H, Marshall L, Burger $\mathrm{K}$ et al. Acute effects of recombinant human interleukin-6 on endocrine and central nervous sleep functions in healthy men. $J$ Clin Endocrinol Metab. 1998;83(5):1573-9.

- Starlin N, Chau I, Norman AR, Tait D, Iveson T, Hill M, Hickish T, Lofts F, Jodrell D, Cunningham D. A randomized comparison between six months of bolus fluorouracil (5 FU) leucovorin (LV) and twelve weeks of protracted venous infusion (PVI ) $5 \mathrm{FU}$ as adjuvant treatment in colorectal cancer: an update with 5 years follow-up. Proc Am Soc Clin Oncol. 2004. 23:25.

- Storey DJ, Sakala M, McLean CM, Phillips HA, Dawson LK, Wall LR, Fallon MT, Clive S. Capecitabine combined with oxaliplatin (CapOx) in clinical practice: how significant is peripheral neuropathy? Ann Oncol. 2010; 21:16571661.

- Stubblefield MD, Burstein HJ, Burton AW, Custodio CM, Deng GE, Ho M, et al. NCCN task force report: management of neuropathy in cancer. J Natl Compr Canc Netw. 2009 Sep 7 Suppl 5:S1-S26 quiz S7-8.

- Sullivan MJL, Bishop SR, Pivik J.The pain catastrophizing scale: development and validation. 1995. Psychological Assessment; 7: 524-532.

- Taieb S, Trillet-Lenoir V, Rambaud L, Descos L, Freyer G. Lhermitte sign and urinary retention, atypical presentation of oxaliplatin neurotoxicity in four patients. Cancer. 2002;94:2434-40

- Tannock IF, Ahles TA, Ganz PA, Van Dam FS. Cognitive impairment associated with chemotherapy for cancer: report of a workshop. J Clin Oncol. 2004;22(11):2233-9. 
- Teixeira MJ. Fisiopatologia da dor. In: Neto AO. Dor: princípios e prática. Porto Alegre: Artmed, 2009. p. 145-175.

- Tofthagen C. Patient perceptions associated with chemotherapy-induced peripheral neuropathy. Clin J Oncol Nurs. 2010;14:E22-28.

- Torrensa N, Smith BH, Bennett MI, Lee AJ: The epidemiology of chronic pain of predominantly neuropathic origin. Results from a general population survey. J Pain 4:281-293, 2006.

- Treede RD, Jensen TS, Campbell JN, Cruccu G, Dostrovsky JO, Griffin JW, Hansson P, Hughes R, Nurmikko T, Serra J. Neuropathic pain: redefinition and a grading system for clinical and research purposes. Neurology. 2008 Apr 29;70(18):1630-5.

- Vandamme M, Pauwels W, Bleecker J. Acta Clin Belg. 2014 Dec 19A case of delayed oxaliplatin-induced pseudo-obstruction: an atypical presentation of oxaliplatin neurotoxicity.

- Vatandoust S, Joshi R, Pittman KB, Esterman A, Broadbridge V, Adams J, Singhal N, Yeend S, Price TJ. A descriptive study of persistent oxaliplatininduced peripheral neuropathy in patients with colorectal cancer. Support Care Cancer. 2014; 22:513-518.

- Vera G, Castillo M, Cabezos PA, Chiarlone A, Martin MI, Gori A, et al. Enteric neuropathy evoked by repeated cisplatin in the rat. Neurogastroenterol Motil. 2011;23:370-8.

- Velasco R, Bruna J, Briani C, Argyriou AA, Cavaletti G, Alberti P, Frigeni B, Cacciavillani M, Lonardi S, Cortinovis D, Cazzaniga M, Santos C, Kalofonos HP. Early predictors of oxaliplatin-induced cumulative neuropathy in colorectal cancer patients. J Neurol Neurosurg Psychiatry. 2014 Apr;85(4):392-8. doi: 10.1136/jnnp-2013-305334. Epub 2013 Jun 29.

- Vincenzi B, Frezza AM, Schiavon G, Spoto C, Addeo R, Catalano V, Graziano F, Santini D, Tonini G. Identification of clinical predictive factors of oxaliplatininduced chronic peripheral neuropathy in colorectal cancer patients treated with adjuvant Folfox IV. Support Care Cancer. 2013; 21:131-1319

- Wafai L, Taher M, Jovanovska V, Bornstein JC, Dass CR, Nurgali K. Effects of oxaliplatin on mouse myenteric neurons and colonic motility. Front Neurosci. 2013;7:30. 
- Wang WS, Lin JK, Lin TC, Chen WS, Jiang JK, Wang HS, et al. Oral glutamine is effective for preventing oxaliplatin-induced neuropathy in colorectal cancer. The Oncologist 2007;12(3):312-9.

- Wieneke MH, Dienst ER. Neuropsychological assessment of cognitive functioning following chemotherapy for breast cancer. Psychooncology. 1995;4:61-6.

- Wilson RH, Lehky T, Thomas RR, Quinn MG, Floeter MK, Grem JL. Acute oxaliplatin-induced peripheral nerve hyperexcitability. J Clin Oncol. 2002 Apr $1 ; 20(7): 1767-74$.

- WHO, World Health Organization, 2008.

- Woolf CJ, Bennett GJ, Doherty M, Dubner R, Kidd B, Koltzenburg M, Lipton R, Loeser JD, Payne R, Torebjork E. Towards a mechanismbased classification of pain? Pain. 1998 Sep;77(3):227-9.

- Woolf CJ, Mannion RJ. Neuropathic pain: aetiology, symptoms, mechanisms, and management. Lancet. 1999 Jun 5;353(9168):1959-64. Review.

- Woolf SH. A smarter strategy? Reflections on fecal DNA screening for colorectal cancer. N Engl J Med. 2004 Dec 23;351(26):2755-8.

- Xiao WH, Zheng H, Bennett GJ. Characterization of oxaliplatin-induced chronic painful peripheral neuropathy in the rat and comparison to the neuropathy induced by paclitaxel. Neuroscience. 2012;203:194-206.

- Xu XT, Dai ZH, Xu Q, Qiao YQ, Gu Y, Nie F, Zhu MM, Tong JL, Ran ZH. Safety and efficacy of calcium and magnesium infusions in the chemoprevention of oxaliplatin-induced sensoryneuropathy in gastrointestinal cancers. J Dig Dis. 2013 Jun;14(6):288-98.

- Zhang $\mathrm{M}$, Zheng M, Liu W, Wen $\mathrm{Y}$, Wu X, Liu Q. The influence of demographics, psychological factors and self-efficacy on symptom distress in colorectal cancer patients undergoing post-surgical adjuvant chemotherapy. Eur J Oncol Nurs. 2015 Feb;19(1):89-96. doi: 10.1016/j.ejon.2014.08.002. Epub 2014 Sep 13.

- Zheng $\mathrm{H}$, Xiao $\mathrm{WH}$, Bennet GJ. Functional deficits in peripheral nerve mitochondria in rats with paclitaxel and oxaliplatin evoked painful neuropathy. 2011. Exp. Neurol. 232, 154-161. 
- Zhu Y, Yang J, Jiao S, Ji T. Ganglioside-monosialic acid (GM1) prevents oxaliplatin-induced peripheral neurotoxicity in patients with gastrointestinal tumors. World J Surg Oncol. 2013 Jan 25;11:19. doi: 10.1186/1477-7819-11-19. 


\section{ANEXOS}

\section{Anexo 1}

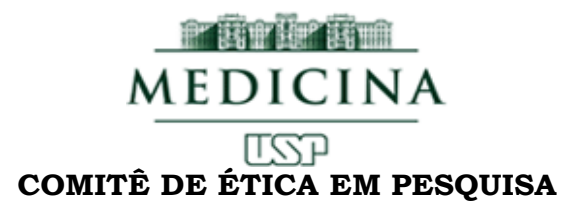

O Comitê de Ética em Pesquisa da Faculdade de Medicina da Universidade de São Paulo, em sessão de o9.o2.2011, APROVOU o Protocolo de Pesquisa $\mathrm{n}^{\mathrm{o}}$ oo7/11 intitulado: "Ensaio clínico, randomizado, duplo-cego, fase 3 , controlado com placebo, para avaliar a eficácia e segurança da pregabalina na prevenção e redução da neuropatia dolorosa induzida por oxaliplatina" e seus anexos, apresentado pelo Instituto do Câncer do Estado de São Paulo "Octavio Frias de Oliveira"

Cabe ao pesquisador elaborar e apresentar ao CEP-FMUSP, os relatórios parciais e final sobre a pesquisa.

Pesquisador (a) Responsável: Daniel Ciampi de Andrade Pesquisador (a) Executante: Manoel Jacbsen Teixeira

CEP-FMUSP, o9 de fevereiro de 2011.

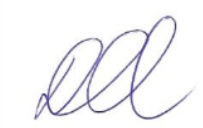

Prof. Dr. Daniel Romero Muñoz Vice-coordenador Comitê de Ética em Pesquisa 


\title{
ClinicalTrials.gov Protocol Registration System
}

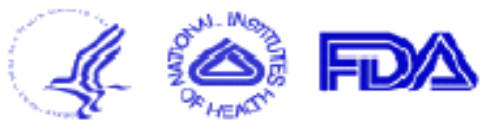

\author{
Protocol Registration Receipt \\ $04 / 26 / 2010$
}

\section{Trial to Evaluate The Efficacy and Safety Of Pregabalin In Prevention and Reduction of Oxaliplatin-Induced Painful Neuropathy (Preox) (PreOx)}

This study is not yet open for participant recruitment.

Verified by University of Sao Paulo, April 2010

\begin{tabular}{|r|l|}
\hline Sponsor: & University of Sao Paulo \\
\hline Collaborators: & Pfizer \\
\hline Information provided by: & University of Sao Paulo \\
\hline ClinicalTrials.gov Identifier: & \\
\hline
\end{tabular}

\section{Purpose}

Oxaliplatin $(\mathrm{Ox})$ is part of most treatment regimens for colorectal cancer. However, it may induce side effects. such as a specific injury to peripheral nerves called neuropathy. Ox-induced neuropathy is frequently painful. The presence of pain after its administration may hamper the full chemotherapeutic treatment of patients with colorectal cancer receiving this agent. Recently, it has been suggested that the appearance of acute neuropathy after oxaliplatin $(\mathrm{Ox})$ infusion could predict the distal polyneuropathy seen some months after treatment. These two adverse events related to Ox treatment probably share different mechanistic backgrounds. However, recent experimental data suggest that both types of peripheral neuropathies are able to induce central sensitization, a major step to the occurrence of chronic pain. Pregabalin is a molecule used to teat neuropathic pain since it can diminish the peripheral sensitization seen in this painful condition. Recently, it has also been shown that pregabalin can be used to treat neuropathic pain related to Ox treatment. In the present study. we will test the hypothesis that Pregabalin administrated exclusively for three days before and three days after the Ox infusion is able to prevent the occurrence of pain secondary to both the acute and chronic Ox-associated neuropathies. In the classical FLOX chemotherapeutic reaimen. Ox is infused in nine sessions durina a six-month period. Patients 
Anexo 3

\section{Patilatitill \\ MEDICINA \\ COMITÊ DE ÉTICA EM PESQUISA}

\section{CIÊNCIA}

O Comitê de Ética em Pesquisa da Faculdade de Medicina da Universidade de São Paulo, em sessão de 11 de Outubro de 2012, TOMOU ClÊNCIA do(s) documento(s) abaixo mencionado(s) no Protocolo de Pesquisa $n^{\circ}$ 007/11, intitulado: "Ensaio clínico, randomizado, duplo-cego, fase 3 , controlado com placebo, para avaliar a eficácia e segurança da pregabalina na prevenção e redução da neuropatia dolorosa induzida por oxaliplatina" apresentado pelo Departamento de Neurologia.

- Inclusão como colaboradora da enfermeira Nathalia Scisci; a mesma irá desenvolver sua dissertação de mestrado sobre neuropatia periférica e dor com o projeto "Incidência e características da dor neuropática e da neuropatia periférica em pacientes submetidos a tratamento quimioterápico com Oxaliplatina".

Pesquisador (a) Responsável: Dr. Daniel Ciampi de Andrade

CEP-FMUSP, 11 de Outubro de 2012

$$
\text { Rluemm. }
$$

Prof. Dr. Roger Chammas

Coordenador

Comitê de Ética em Pesquisa 
INSTITUTO DO CANCER DO ESTADO DE SÃO PAULO

Octávio Frias de Oliveira

Secretaria de Estado da Saúde

Faculdade de Medicina da Universidade de São Paulo

TERMO DE CONSENTIMENTO LIVRE E ESCLARECIDO

DADOS DE IDENTIFICAÇÃO DO SUJEITO DA PESQUISA OU RESPONSÁVEL LEGAL

1. NOME:
DOCUMENTO DE IDENTIDADE N
DATA NASCIMENTO:
ENDERECYO
BAIRRO:
CEP:

DADOS SOBRE A PESQUISA

1. TITULO DO PROTOCOLO DE PESQUISA: “ Estudo Clínico, randomizado, duplo-cego, fase III, controlado com placebo, para avaliar a eficácia e segurança da pregabalina na prevenção e redução da neuropatia dolorosa induzida por oxaliplatina." (PRE-OX)

PESQUISADOR : Dr. Daniel Ciampi de Andrade

CARGO/FUNÇÃO: Médico Neurologista INSCRIÇÃO CONSELHO REGIONAL NN 108232

UNIDADE: ICESP

3. AVALIAÇÃO DO RISCO DA PESQUISA:

$\begin{array}{ll}\text { RISCO MINIMO } \square & \text { RISCO MÉDIO } X \\ \text { RISCO BAIXO } \square & \text { RISCO MAIOR } \square\end{array}$

4.DURAÇĀO DA PESQUISA : 1 ano

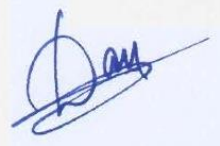

Termo de Consentimento Livre e Esclarecido, de 11 de Novembro de 2010 


\section{INSTITUTO DO CANCER DO ESTADO DE SÃO PAULO Octávio Frias de Oliveira \\ Secretaria de Estado da Saúde \\ Faculdade de Medicina da Universidade de São Paulo}

1 - Justificativa e os objetivos da pesquisa

Você foi convidado a participar desta pesquisa pois possui um câncer colo-retal que será tratado um tipo de quimioterápico chamado Oxaliplatina. Em alguns doentes, a oxaliplatina pode provocar uma alteração nos nervos, chamada de neuropatia, que pode provocar uma dor crônica. Esta pesquisa tem como objetivo testar a segurança de um remédio chamado de pregabalina para tentar prevenir o desenvolvimento de uma dor crônica causada pela Oxaliplatina.

$\mathbf{2}$ - procedimentos que serão utilizados e propósitos, incluindo a identificação dos procedimentos que são experimentais

Metade das pessoas que participarão desta pesquisa receberá a medicação pregabalina ou placebo (medicação sem efeito ativo). Caso aceite participar do estudo, você será solicitado a tomar a medicação nos três dias antes e tres dias depois da infusão de oxaliplatina. Serão feitas avaliações periódicas dos efeitos colaterais e da presença ou não e da gravidade da neuropatia. Estas avaliações serão feitas através de entrevista e por exames da função dos nervos.

\section{3 - Desconfortos e riscos esperados}

Os desconfortos e riscos esperados deste estudo estão relacionados aos eventuais efeitos colaterais da pregabalina que podem incluir tontura, sonolência, boca seca, dor de cabeça, ganho de peso ou outros efeitos adversos da medicação durante o seu uso.

\section{4 - Benefícios que poderão ser obtidos}

O beneficio esperado com o estudo é o de reduzir a chance do desenvolvimento de dor crônica relacionada a lesão dos nervos pela Oxaliplatina.

5 - Procedimentos alternativos que possam ser vantajosos para o indivíduo

Este trabalho não modificará o seu tratamento para o Câncer. Seu médico continuará tratando você normalmente.

\section{6- Garantia de Acesso}

Em qualquer etapa do estudo, você terá acesso aos profissionais responsáveis pela pesquisa para esclarecimento de eventuais dúvidas. O principal investigador é o Dr. Daniel Ciampi que pode ser encontrado no endereço: Av. Dr. Arnaldo, 251 - 12 andar - CEP: 01246-000 Telefone(s) 11-3893-2617. Se você tiver alguma consideração ou dúvida sobre a ética da pesquisa, entre em contato com o Comitê de Ética em Pesquisa FMUSP (CEP) - Instituto Oscar Freire da FMUSP - Avenida Dr. Arnaldo 455, 1a andar, CEP: 01246903 no telefone 11- 3061-8004 ou no email: cep.fmusp@hcnet.usp.br

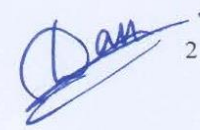




\section{INSTITUTO DO CANCER DO ESTADO DE SÃO PAULO Octávio Frias de Oliveira \\ Secretaria de Estado da Saúde}

\section{Faculdade de Medicina da Universidade de São Paulo}

7 - É garantida a liberdade da retirada de consentimento a qualquer momento e deixar de participar do estudo, sem qualquer prejuizo à continuidade de seu tratamento na Instituição;

8 - Direito de confidencialidade

As informações obtidas serão analisadas em conjunto com outros pacientes, não sendo divulgado a identificação de nenhum paciente;

9 - Direito de ser mantido atualizado sobre os resultados parciais das pesquisas, quando em estudos abertos, ou de resultados que sejam do conhecimento dos pesquisadores;

10 - Despesas e compensações: não há despesas pessoais para o participante em qualquer fase do estudo, incluindo exames e consultas. Também não há compensação financeira relacionada à sua participação. Se existir qualquer despesa adicional, ela será absorvida pelo orçamento da pesquisa.

11 - O Pesquisar se compromete a utilizar os dados e o material coletado somente para esta pesquisa.

Acredito ter sido suficientemente informado a respeito das informações que li ou que foram lidas para mim, descrevendo o estudo: "Ensaio clínico, randomizado, duplo cego, fase III, controlado com placebo, para avaliar a eficácia e segurança da pregabalina na prevenção e redução da neuropatia dolorosa induzida pó oxaliplatina". Eu discuti com o Dr. Daniel Ciampi, sobre a minha decisão em participar nesse estudo. Ficaram claros para mim quais são os propósitos do estudo, os procedimentos a serem realizados, seus desconfortos e riscos, as garantias de confidencialidade e de esclarecimentos permanentes. Ficou claro também que minha participação é isenta de despesas e que tenho garantia do acesso a tratamento hospitalar quando necessário. Concordo voluntariamente em participar deste estudo e poderei retirar o meu consentimento a qualquer momento, antes ou durante o mesmo, sem penalidades ou prejuizo ou perda de qualquer benefício que eu possa ter adquirido, ou no meu atendimento neste Serviço.

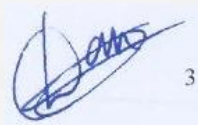


INSTITUTO DO CANCER DO ESTADO DE SÃO PAULO

Octávio Frias de Oliveira

Secretaria de Estado da Saúde

Faculdade de Medicina da Universidade de São Paulo

Assinatura do paciente/representante legal

Data 11

Assinatura da testemunha

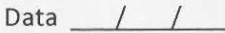

para casos de pacientes menores de 18 anos, analfabetos, semi-analfabetos ou portadores de deficiência auditiva ou visual.

(Somente para o responsável do projeto)

Declaro que obtive de forma apropriada e voluntária o Consentimento Livre e Esclarecido deste paciente ou representante legal para a participação neste estudo.

Assinatura do responsável pelo estudo

Data 11 
Anexo 5. Ficha de avaliação sócio-demográfica

\begin{tabular}{|l|l|c|}
\hline I.DADOS SÓCIODEMOGRAFICOS \\
\hline SEXO & IDADE & DATA DE NASCIMENTO \\
\hline 1.masculino () 2.feminino () & & $/$ \\
\hline
\end{tabular}

NÍVEL EDUCACIONAL:

$\begin{array}{lll}\text { 1. Analfabeto }(\text { ) } & \text { 2. Ensino médio ( ) } & \text { 3. Ensino fundamental ( ) } \\ \text { 4.Superior ( ) } & \text { 5.pós-graduação ( ) }\end{array}$

ESTADO CIVIL:

1.solteiro( ) 2.casado( ) 3.união consensual( ) 4.separado( ) 5.divorciado( ) 6.viúvo( )

SITUAÇÃO CONJUGAL: 1.Com companheiro( ) 2.sem companheiro( )

RELIGIÃO:

1.ateu( ) 2.evangélico( ) 3.católico( ) 4.espírito( ) 5.Outro

PRATICANTE: SITUAÇÃO DE TRABALHO:

0. não( ) 1.empregado( ) 2.desempregado( ) 3.aposentado( ) 4.dona de casa( )

1. $\operatorname{sim}($ ) 5.autônomo( ) 6.estudante( ) 7.Licença saúde( ) 8.informal( )

Você está trabalhando atualmente? 0.não ( ) 1.sim ( )

\section{RENDA:}

I.individual(mensal):R\$

II.Suficiente para suprir necessidades? 0.não ( ) 1.sim ( )

\begin{tabular}{l|l}
\hline Ill.familiar (mensal): R\$ & IV.No de pessoas que vivem com esta renda:
\end{tabular}

VI.Você é o principal responsável pelo sustento de sua família? 0.não ( ) 1.sim ( )

\section{CASO VOCÊ NÃO TENHA RENDA PRÓPRIA}

I. Como você se mantém?

1. ajuda da família ( ) 2. ajuda de instituição ( ) qual?

3. ajuda de vizinhos ou amigos ( ) 4 4. ajuda de pessoas estranhas $($ ) COMO AVALIA A SUA SAÚDE DE FORMA GERAL
1. muito ruim( )
2.ruim( )
3. nem ruim nem boa( )
4. Boa( )
5. muito boa ( )

\section{DADOS CLÍNICOS}


1.Diagnóstico (Tipo de Câncer):

2.Tempo de diagnostico:__ meses ._ Data da Biopsia: ___ I _ 3. Estadiamento

4. Extensão da doença: 1 tumor local ( ) 2. Disseminação regional ( ) 3.Disseminação distante ou sistêmica ( )

5. Metastase: 1. osso ( ) $\quad$ 2. TGI ( ) $\quad$ 3. Cérebro( ) $\quad$ 4.pulmão ( ) $\quad$ 5.SG ( ) 6.SU $\quad$ 7. Coluna vertebral ( ) 8.

Fígado ( ) 10. Outros

6. Tratamentos realizados: há quanto tempo?
1. QT ( )
m 2.QT via oral ( )
m 3. RT( )
m
4.Hormônio ( )
m 6. BT ()

m 5.Cirurgia ( )

\section{Você tem alguma das seguintes doenças:}

\begin{tabular}{|l|l|l|}
\hline 1. Diabetes Mellitus & Não $^{0}$ & Sim $^{1}$ \\
\hline 2. Cerebrovascular & & \\
\hline 3. Hipertensão arterial & & \\
\hline 4. Doenças vascular periférica & & \\
\hline 5. Doença renal crônica & & \\
\hline 6. Neoplasia maligna & & \\
\hline 7. Doença cardiocirculatória & & \\
\hline 8. Doença hepática & & \\
\hline 9.Depressão & & \\
\hline 10. Doença do trato gastrointestinal & & \\
\hline 11. Doença autoimune & & \\
\hline 12.0utras:----------------------------- & & \\
\hline
\end{tabular}

\section{KARNOFSKY PERFORMANCE STATUS (KPS):}

(Escala de Desempenho Funcional)

4.Escala de ZUBROD - ECOG: 


\section{EXAME FISÍco}

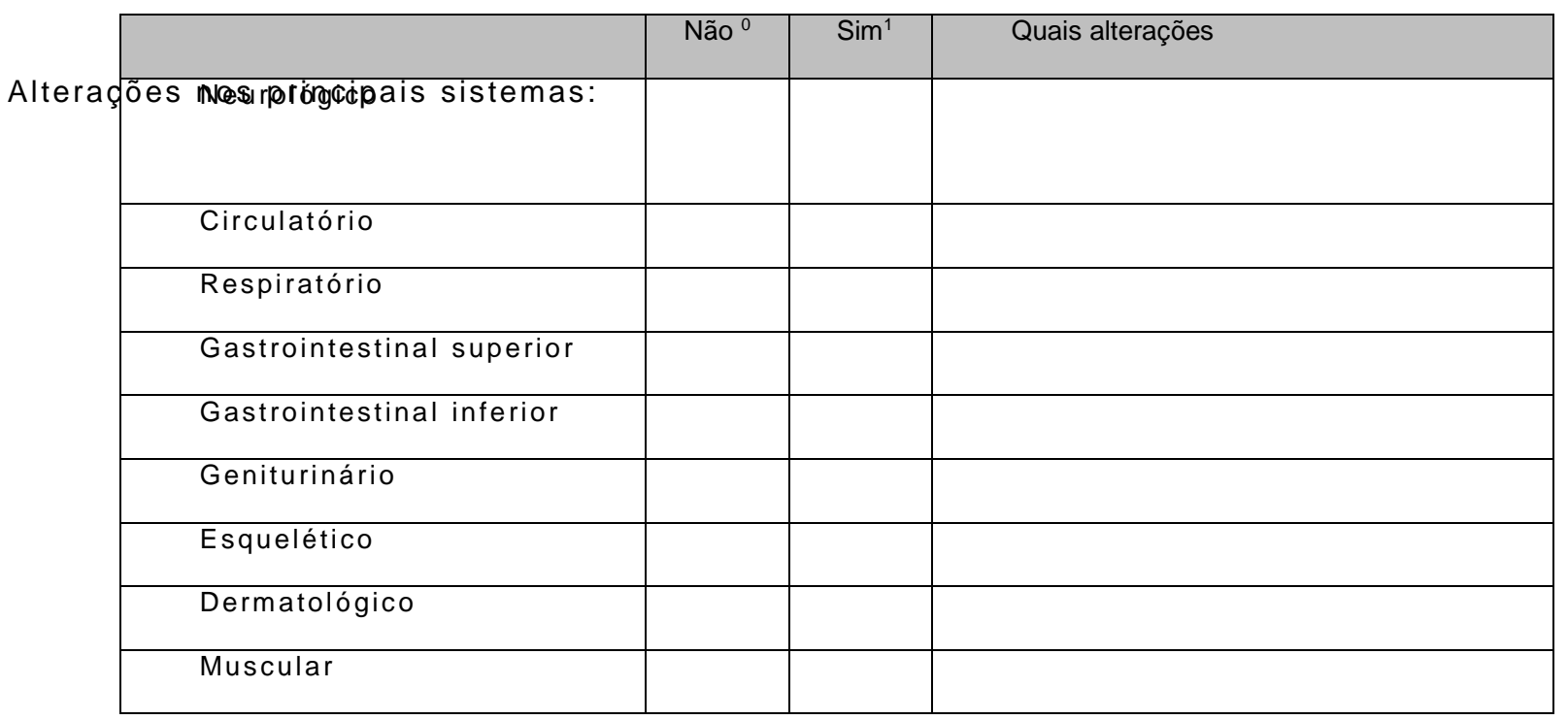

\section{SINAIS VITAIS}

1. Pressão Arterial:

2.FC:

3.FR:

4. Temperatura: 


\section{Anexo 6}

\section{Questionário para Diagnóstico de Dor Neuropática 4 - DN4 ${ }^{1}$}

\section{Versão Brasileira 1.023}

Por favor, nas quatro perguntas abaixo, complete o questionário marcando uma resposta para cada número:

\section{ENTREVISTA DO PACIENTE}

Questão 1: A sua dor tem uma ou mais das seguintes características?

1 - Queimação

2 - Sensação de frio dolorosa

3 - Choque elétrico

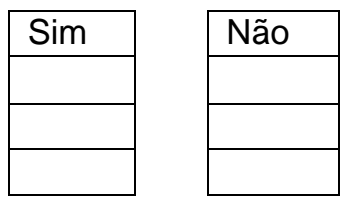

Questão 2: Há presença de um ou mais dos seguintes sintomas na mesma área da sua dor?

4 - Formigamento

5 - Alfinetada e Agulhada

6 - Adormecimento

7 - Coceira
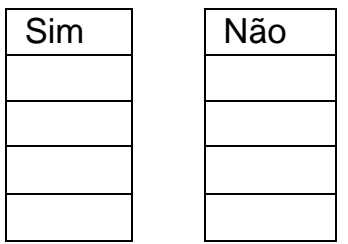

\section{EXAME DO PACIENTE}

Questão 3. A dor está localizada numa área onde o exame físico pode revelar uma ou mais das seguintes caraterísticas?

8- Hipoestesia ao toque

9- Hipoestesia a picada de agulha
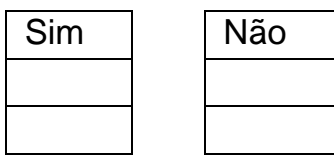

Questão 4. Na área dolorosa, a dor pode ser causada ou aumentada por:

10 - Escovação

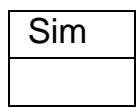

Não 


\begin{tabular}{|l|l|l|}
\hline \multicolumn{3}{|c|}{ McGILL breve } \\
\hline Dimensão & Presente & Ausente \\
\hline $\begin{array}{l}\text { Sensorial } \\
\text { 1.Latejante }\end{array}$ & & \\
\hline 2.Pontada & & \\
\hline 3.Choque & & \\
\hline 4.Fina-Agulhada & & \\
\hline 5.Fisgada & & \\
\hline 6.Queimação & & \\
\hline 7.Espalha & & \\
\hline 8.Dolorida & & \\
\hline $\begin{array}{l}\text { Afetivo } \\
\text { 9.Cansativa-exaustiva }\end{array}$ & & \\
\hline 10.Enjoada & & \\
\hline 11.Sufocante & & \\
\hline 12.Apavorante-Enlouquecedora & & \\
\hline 13.Aborrecida & & \\
\hline $\begin{array}{l}\text { Avaliativo } \\
\text { 14.que incomoda }\end{array}$ & & \\
\hline 15.Insuportável & & \\
\hline
\end{tabular}

Intensidade da dor presente da Dor

Localização

$\begin{array}{lllllllllll}0 & 1 & 2 & 3 & 4 & 5 & 6 & 7 & 8 & 9 & 10\end{array}$

Sem Dor

Pior Dor

Possível
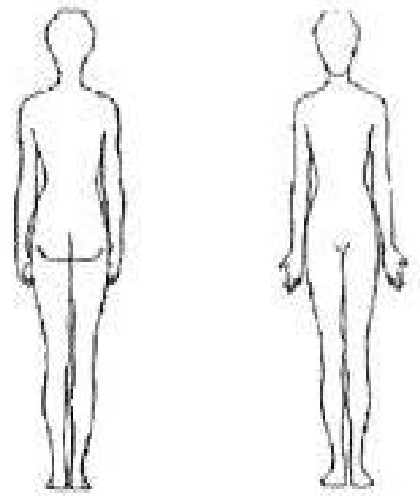


\section{Inventário de Sintomas de Dor Neuropática (NPSI)}

Você tem sofrido de dor devido a lesão ou doença do sistema nervoso. Esta dor pode ser de diversos tipos. Você pode ter dor espontânea, ex: dor na ausência de qualquer estímulo, que pode ser duradoura ou ocorrer em ataques breves. Você pode também ter dor provocada ou aumentada por leve toque, pressão ou contato com o frio na área dolorosa. Você pode sentir um ou mais tipos de dor. Este questionário foi desenvolvido para ajudar o seu médico a melhor avaliar e tratar diferentes tipos de dor que possa sentir.

Nós queremos saber se você sente dor espontânea, isto é dor sem qualquer estímulo. Para cada uma das seguintes questões, por favor selecione o número que melhor descreve a sua gravidade média da dor espontânea durante as últimas 24 horas. Selecione o número 0 se você não sentiu tal dor (circule 0 número apenas).

Q1. A sua dor dá a sensação de queimação?

$\begin{array}{lllllllllllll}\text { Não queima } & 0 & 1 & 2 & 3 & 4 & 5 & 6 & 7 & 8 & 9 & 10 & \text { A pior }\end{array}$

Queimadura

Imaginável

Q2. A sua dor dá a sensação de apertar?

\begin{tabular}{ccccccccccccc} 
Não aperta & 0 & 1 & 2 & 3 & 4 & 5 & 6 & 7 & 8 & 9 & 10 & $\begin{array}{c}\text { Aperta } \\
\text { O pior } \\
\text { Imaginável }\end{array}$ \\
\hline
\end{tabular}

Q3. A sua dor dá a sensação de pressão?

$\begin{array}{ccccccccccccc}\text { Sem pressão } & 0 & 1 & 2 & 3 & 4 & 5 & 6 & 7 & 8 & 9 & 10 & \begin{array}{c}\text { A pior } \\ \text { pressão } \\ \text { Imaginável }\end{array}\end{array}$

Q4. Durante as últimas 24 horas, a sua dor espontânea tem estado presente:

Selecione a resposta que melhor descreve o seu caso

$\begin{array}{ll}\text { Permanentemente } & \text { ( ) } \\ \text { Entre } 8 \text { e } 12 h & (\text { ) } \\ \text { Entre } 4 \text { e } 7 h & (\text { ) } \\ \text { Entre } 1 \text { e } 3 h & (\text { ) } \\ \text { menos que } 1 h & (\text { ) }\end{array}$

Nós queremos saber se você teve ataques breves de dor. Para cada uma das seguintes questões, por favor, selecione o número que melhor descreve a gravidade média dos seus ataques de dor durante as últimas 24 horas. Selecione o número 0 se você não sentiu tal dor (circule um número apenas).

Q5 A sua dor dá a sensação de choque elétrico?

$$
\text { Sem choque elétrico } \quad 0 \begin{array}{llllllllllll}
\text { Opior } & 1 & 3 & 4 & 5 & 6 & 7 & 8 & 9 & 10 & \begin{array}{c}
\text { Choque elétrico } \\
\text { imaginável }
\end{array}
\end{array}
$$


Q6 A sua dor dá a sensação de apunhalar?

Sem apunhalar

$$
\begin{array}{llllllllllll}
0 & 1 & 2 & 3 & 4 & 5 & 6 & 7 & 8 & 9 & 10 & \begin{array}{c}
\text { A Pior } \\
\text { punhalada } \\
\text { imaginável }
\end{array}
\end{array}
$$

Q7. Durante as últimas 24 horas, quantos destes ataques de dor teve? Selecione a resposta que melhor descreve o seu caso.

$\begin{array}{ll}\text { Mais de } 20 & (\text { ) } \\ \text { Entre } 11 \text { e } 20 & \text { ( ) } \\ \text { Entre } 6 \text { e } 10 & \text { ( ) } \\ \text { Entre } 1 \text { e } 5 & \text { ( ) } \\ \text { Sem ataque de dor }\end{array}$

Nós queremos saber se você sente dor provocada ou aumentada por leve toque, pressão, contacto com frio na área onde dói. Para cada das seguintes questões, por favor selecione o número que melhor descreve a gravidade media da dor provocada durante as últimas 24 horas. Selecione o número 0 se você não sentiu tal dor (circule um número apenas).

Q8. A sua dor é provocada ou aumentada por um leve toque na área dolorosa?

Sem dor $\begin{array}{llllllllllll}0 & 1 & 2 & 3 & 4 & 5 & 6 & 7 & 8 & 9 & 10 & \text { A pior dor }\end{array}$

Imaginável

Q9. A sua dor é provocada ou aumentada por pressão na área dolorosa?

Sem dor $\begin{array}{lllllllllllll}0 & 1 & 2 & 3 & 4 & 5 & 6 & 7 & 8 & 9 & 10 & \text { A pior dor }\end{array}$

Imaginável

Q10. A sua dor é provocada ou aumentada por contacto com algo frio na área dolorosa?

$\begin{array}{lllllllllllll}\text { Sem dor } & 0 & 1 & 2 & 3 & 4 & 5 & 6 & 7 & 8 & 9 & 10 & \text { Pior dor }\end{array}$

Imaginável

Nós queremos saber se você sente sensações anormais na zona onde dói. Para cada uma das seguintes questões, por favor selecione o número que melhor descreve a gravidade média das sensações anormais durante as últimas 24 horas. Selecione o número 0 se você não sentiu tal dor (circule um número apenas).

Q11. Sente alfinetadas e agulhadas?

$\begin{array}{llllllllllllll}\text { Sem alfinetes nem agulhas } & 0 & 1 & 2 & 3 & 4 & 5 & 6 & 7 & 8 & 9 & 10 & \text { Os piores }\end{array}$ alfinetadas

Q12. Sente Dormente?

e agulhadas

I Imagináveis

$\begin{array}{lllllllllllll}\text { Sem Dormência } & 0 & 1 & 2 & 3 & 4 & 5 & 6 & 7 & 8 & 9 & 10 \quad \text { O mais dormente }\end{array}$ Imaginável 
Inventário Breve de Dor

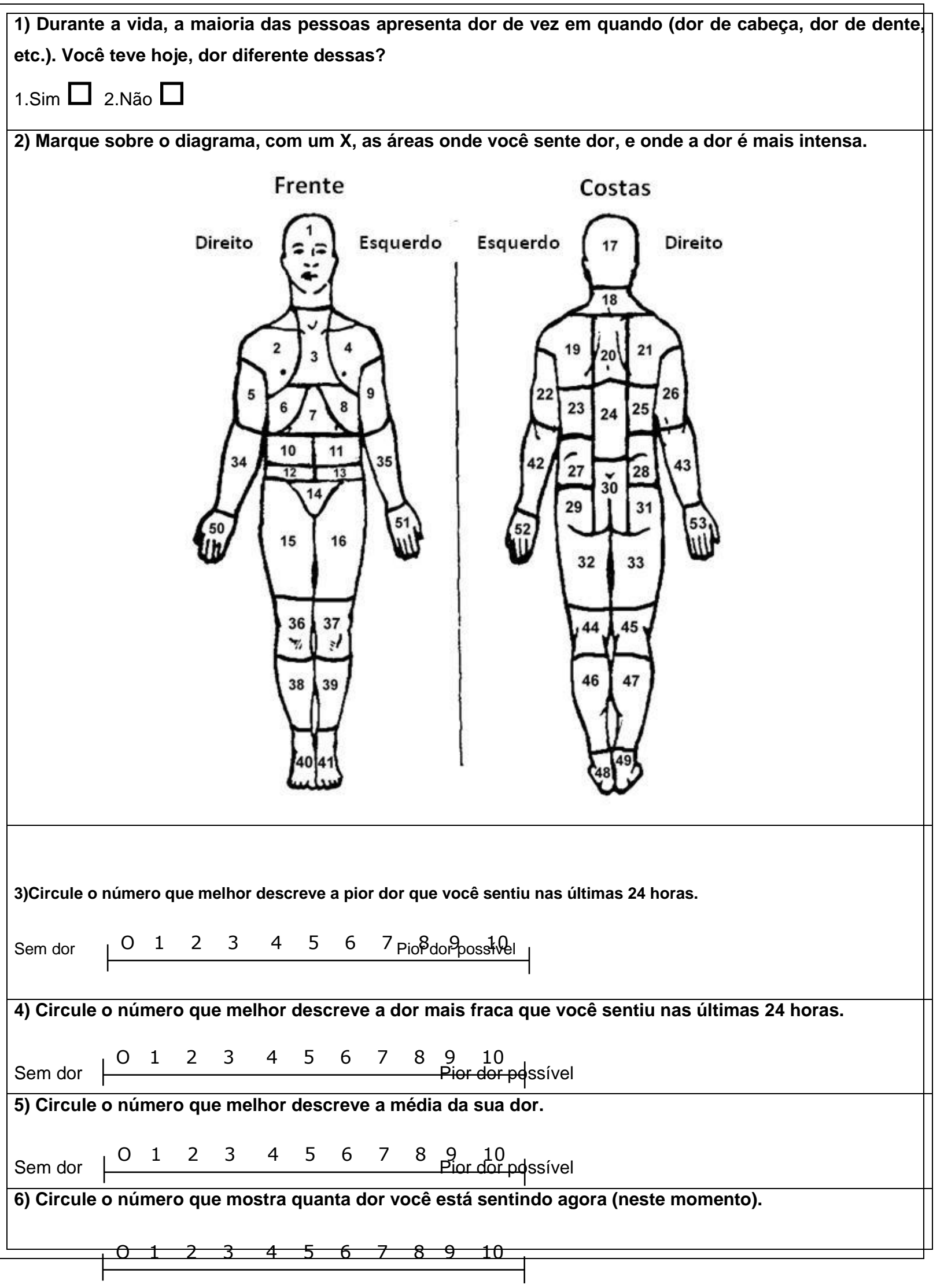




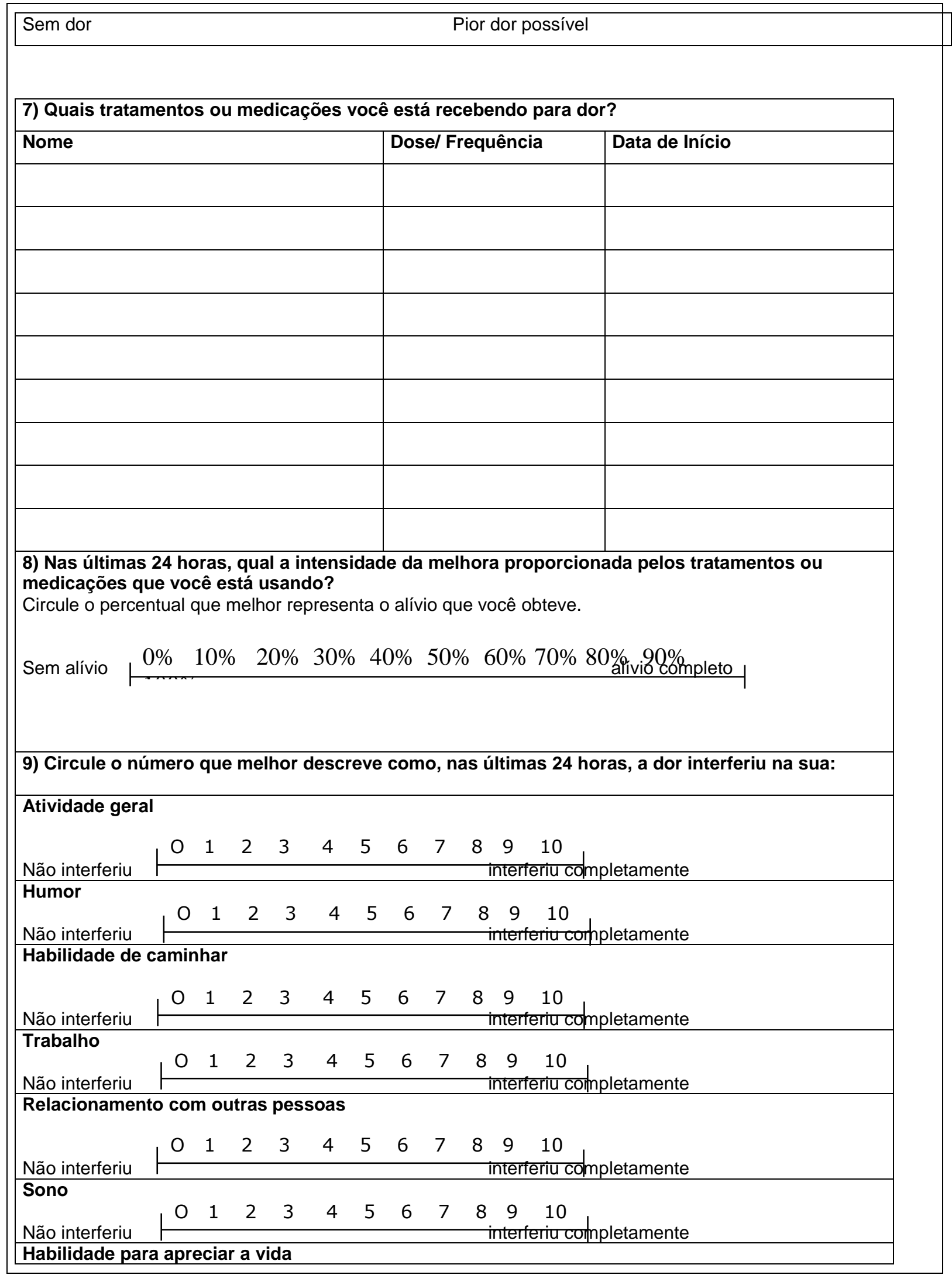




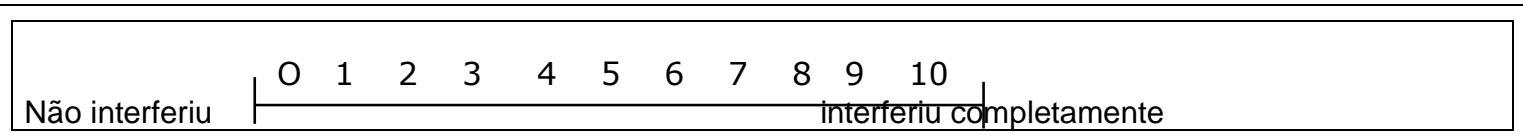




\section{Escala Hospitalar de Ansiedade e Depressão (HADS)}

Este questionário ajudará o seu médico, a saber, como você está se sentindo. Leia todas as frases. Marque com um " $X$ " a resposta que melhor corresponder a como você tem se sentido na ÚLTIMA SEMANA. Não é preciso ficar pensando muito em cada questão. Neste questionário as respostas espontâneas têm mais valor do que aquelas em que se pensa muito. Marque apenas uma resposta para cada pergunta.

A 1) Eu me sinto tenso ou contraído:

3 ( ) A maior parte do tempo

2 ( ) Boa parte do tempo

1 ( ) De vez em quando

0 ( ) Nunca

D 2) Eu ainda sinto gosto pelas mesmas coisas de antes:

0 ( ) Sim, do mesmo jeito que antes

1 ( ) Não tanto quanto antes

2 ( ) Só um pouco

3 ( ) Já não sinto mais prazer em nada

A 3) Eu sinto uma espécie de medo, como se alguma coisa ruim fosse acontecer:

3 ( ) Sim, e de um jeito muito forte

2 ( ) Sim, mas não tão forte

1 ( ) Um pouco, mas isso não me preocupa

0 ( ) Não sinto nada disso

D 4) Dou risada e me divirto quando vejo coisas engraçadas:

0 ( ) Do mesmo jeito que antes

1 ( ) Atualmente um pouco menos

2 ( ) Atualmente bem menos

3 ( ) Não consigo mais

A 5) Estou com a cabeça cheia de preocupações:

3 ( ) A maior parte do tempo

2 ( ) Boa parte do tempo

1 ( ) De vez em quando

0 ( ) Raramente

D 6) Eu me sinto alegre:

3 ( ) Nunca

2 () Poucas vezes

1 ( ) Muitas vezes

0 ( ) A maior parte do tempo

A 7) Consigo ficar sentado à vontade e me sentir relaxado:

0 ( ) Sim, quase sempre

1 ( ) Muitas vezes

2 ( ) Poucas vezes

3 ( ) Nunca

D 8) Eu estou lento para pensar e fazer as coisas: 
3 ( ) Quase sempre

2 ( ) Muitas vezes

1 ( ) De vez em quando

0 ( ) Nunca

A 9) Eu tenho uma sensação ruim de medo, como um frio na barriga ou um aperto no estômago:

0 ( ) Nunca

1 ( ) De vez em quando

2 ( ) Muitas vezes

3 ( ) Quase sempre

D 10) Eu perdi o interesse em cuidar da minha aparência:

3 ( ) Completamente

2 ( ) Não estou mais me cuidando como deveria

1 ( ) Talvez não tanto quanto antes

0 ( ) Me cuido do mesmo jeito que antes

A 11) Eu me sinto inquieto, como se eu não pudesse ficar parado em lugar nenhum:

3 ( ) Sim, demais

2 ( ) Bastante

1 ( ) Um pouco

0 ( ) Não me sinto assim

D 12) Fico esperando animado as coisas boas que estão por vir:

0 ( ) Do mesmo jeito que antes

1 ( ) Um pouco menos do que antes

2 ( ) Bem menos do que antes

3 ( ) Quase nunca

A 13) De repente, tenho a sensação de entrar em pânico:

3 ( ) A quase todo momento

2 ( ) Várias vezes

1 ( ) De vez em quando

0 ( ) Não sinto isso

D 14) Consigo sentir prazer quando assisto a um bom programa de televisão, de rádio ou quando leio alguma coisa:

0 ( ) Quase sempre

1 ( ) Várias vezes

2 ( ) Poucas vezes

3 ( ) Quase nunca 
Total Neuropathy Score (TNS)

Escore Total de Neuropatia

\begin{tabular}{|c|c|c|c|c|c|}
\hline \multicolumn{6}{|c|}{ ESCORE } \\
\hline Parâmetros & 0 & 1 & 2 & 3 & 4 \\
\hline $\begin{array}{l}\text { Sintomas } \\
\text { Sensoriais }\end{array}$ & Nada & $\begin{array}{c}\text { Sintomas } \\
\text { limitados nos } \\
\text { dedos dos pés }\end{array}$ & $\begin{array}{l}\text { Sintomas } \\
\text { estendidos para } \\
\text { tornozelos e } \\
\text { punhos }\end{array}$ & $\begin{array}{c}\text { Sintomas } \\
\text { estendidos para } \\
\text { cotovelos e joelhos }\end{array}$ & $\begin{array}{l}\text { Sintomas acima dos } \\
\text { joelhos ou cotovelos, ou } \\
\text { funcionalmente } \\
\text { incapacitante }\end{array}$ \\
\hline Sintomas Motor & Nada & $\begin{array}{l}\text { Dificuldade } \\
\text { Leve }\end{array}$ & $\begin{array}{l}\text { Dificuldade } \\
\text { moderada }\end{array}$ & $\begin{array}{l}\text { Necessita de ajuda/ } \\
\text { assistência }\end{array}$ & Paralisia \\
\hline $\begin{array}{c}\text { Sintomas } \\
\text { Autonômicos }\end{array}$ & 0 & 1 & 2 & 3 & 4 ou 5 \\
\hline $\begin{array}{l}\text { Pinos de } \\
\text { Sensibilidades }\end{array}$ & Normal & $\begin{array}{l}\text { Reduzido nos } \\
\text { dedos dos pés }\end{array}$ & $\begin{array}{c}\text { Reduzido até o } \\
\text { punho e } \\
\text { tornozelo }\end{array}$ & $\begin{array}{l}\text { Reduzido até o } \\
\text { cotovelo e joelho }\end{array}$ & $\begin{array}{l}\text { Reduzido acima do } \\
\text { cotovelo e joelho }\end{array}$ \\
\hline $\begin{array}{l}\text { Sensibilidade } \\
\text { Vibratória }\end{array}$ & Normal & $\begin{array}{l}\text { Reduzido nos } \\
\text { dedos dos pés }\end{array}$ & $\begin{array}{l}\text { Reduzido até os } \\
\text { punhos e } \\
\text { tornozelos }\end{array}$ & $\begin{array}{l}\text { Reduzido até os } \\
\text { cotovelos e joelho }\end{array}$ & $\begin{array}{l}\text { Reduzido acima dos } \\
\text { cotovelo e oelhos }\end{array}$ \\
\hline Força & Normal & Fraqueza leve & $\begin{array}{l}\text { Fraqueza } \\
\text { moderada }\end{array}$ & $\begin{array}{c}\text { Fraqueza } \\
\text { Grave/intensa }\end{array}$ & Paralisia \\
\hline Reflexos & Normal & $\begin{array}{l}\text { Reflexos nos } \\
\text { tornozelos } \\
\text { reduzidos }\end{array}$ & $\begin{array}{l}\text { Reflexos nos } \\
\text { tornozelos } \\
\text { ausentes }\end{array}$ & $\begin{array}{c}\text { Reflexos nos } \\
\text { tornozelos ausentes } \\
\text { e outros reduzidos }\end{array}$ & $\begin{array}{l}\text { Todos os reflexos } \\
\text { ausentes }\end{array}$ \\
\hline $\begin{array}{l}\text { Sensações } \\
\text { Vibratórias (QST) }\end{array}$ & $\begin{array}{l}\text { Normal de } \\
125 \% \text { ULN }\end{array}$ & $\begin{array}{c}126 \% \text { a } 150 \% \\
\text { ULN }\end{array}$ & $\begin{array}{c}151 \% \text { a } 200 \% \\
\text { ULN }\end{array}$ & 201 a $300 \%$ ULN & $>300 \%$ ULN \\
\hline Amplitude Sural & $\begin{array}{c}\text { Normal/reduzi } \\
\text { do de }<5 \% \\
\text { LLN }\end{array}$ & $\begin{array}{c}76 \text { a } 95 \% \text { de } \\
\text { LLN }\end{array}$ & $\begin{array}{c}51 \text { a } 75 \% \text { de } \\
\text { LLN }\end{array}$ & 26 a $50 \%$ de LLN & 0 a $25 \%$ de LLN \\
\hline $\begin{array}{l}\text { Amplitude } \\
\text { Peroneal }\end{array}$ & $\begin{array}{c}\text { Normal/reduzi } \\
\text { do de }<5 \% \\
\text { LLN }\end{array}$ & $\begin{array}{c}76 \text { a } 95 \% \text { de } \\
\text { LLN }\end{array}$ & $\begin{array}{c}51 \text { a } 75 \% \text { de } \\
\text { LLN }\end{array}$ & 26 a $50 \%$ de LLN & 0 a $25 \%$ de LLN \\
\hline
\end{tabular}

QST = Teste Quantitativo Sensorial

ULN = Limite Superior de Normalidade

LLN = Limite Inferior de Normalidade 


\section{EORTC QLQ-C30 (version 3)}

Nós estamos interessados em alguns dados sobre você e sua saúde. Responda, por favor, a todas as perguntas fazendo um círculo no número que melhor se aplica a você. Não há respostas certas nem erradas. A informação que você fornecer permanecerá estritamente confidencial.

Por favor, preencha as iniciais do seu nome: $\square \square \square$

Sua data de nascimento (dia, mês, ano):

Data de hoje (dia, mês, ano):

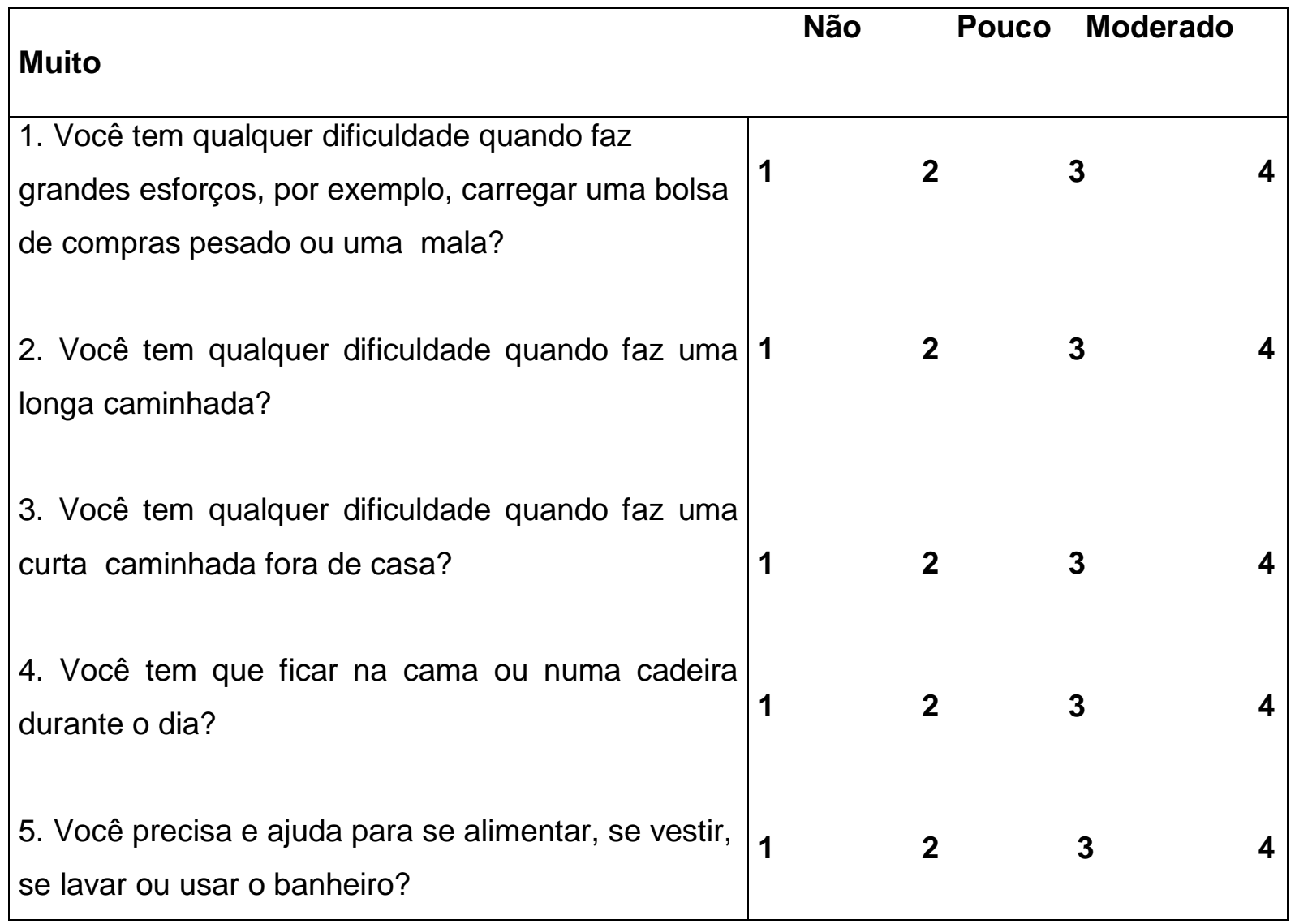

Durante a última semana:

Muito

Não Pouco Moderado 


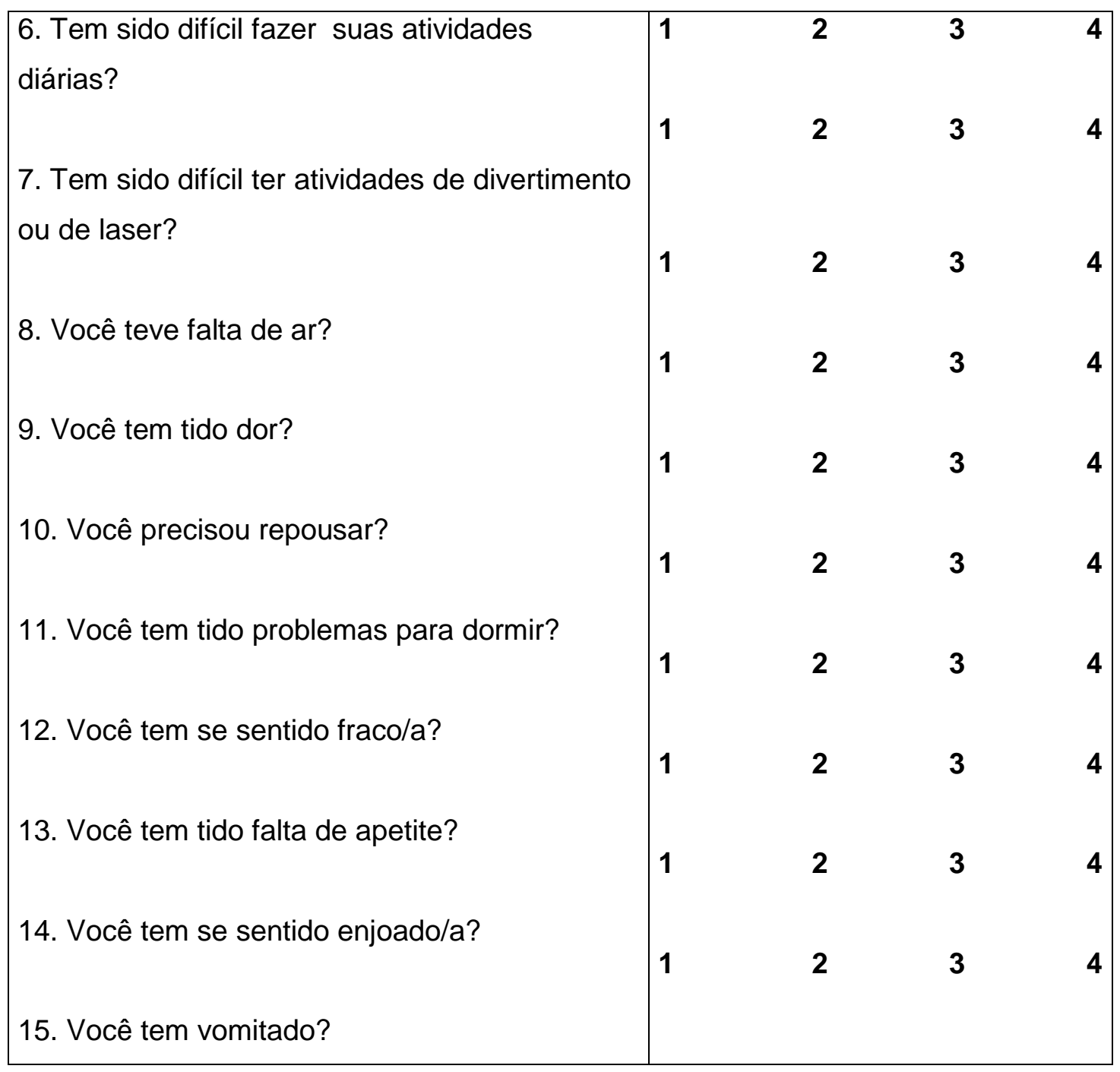

Durante a última semana:

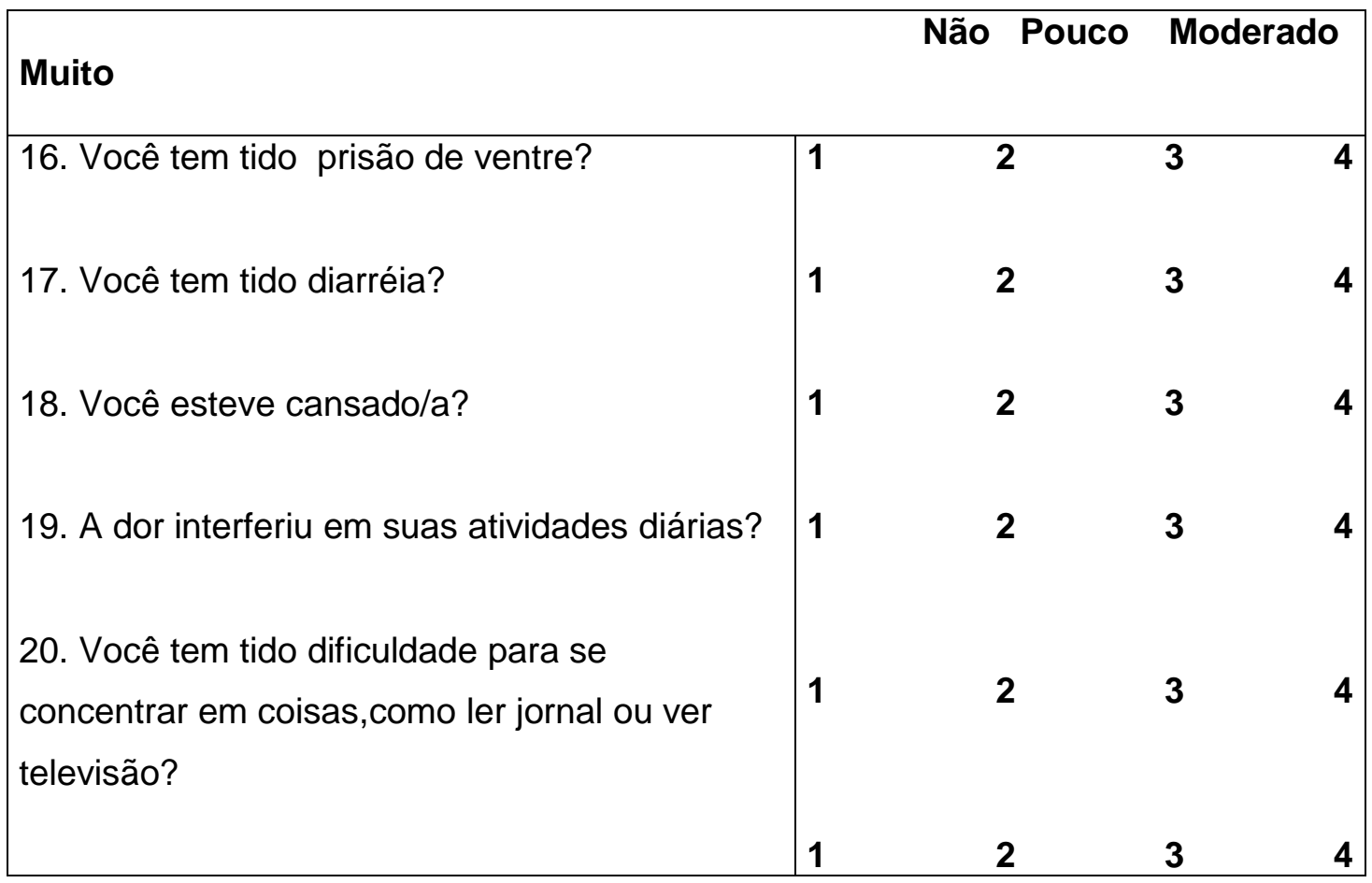




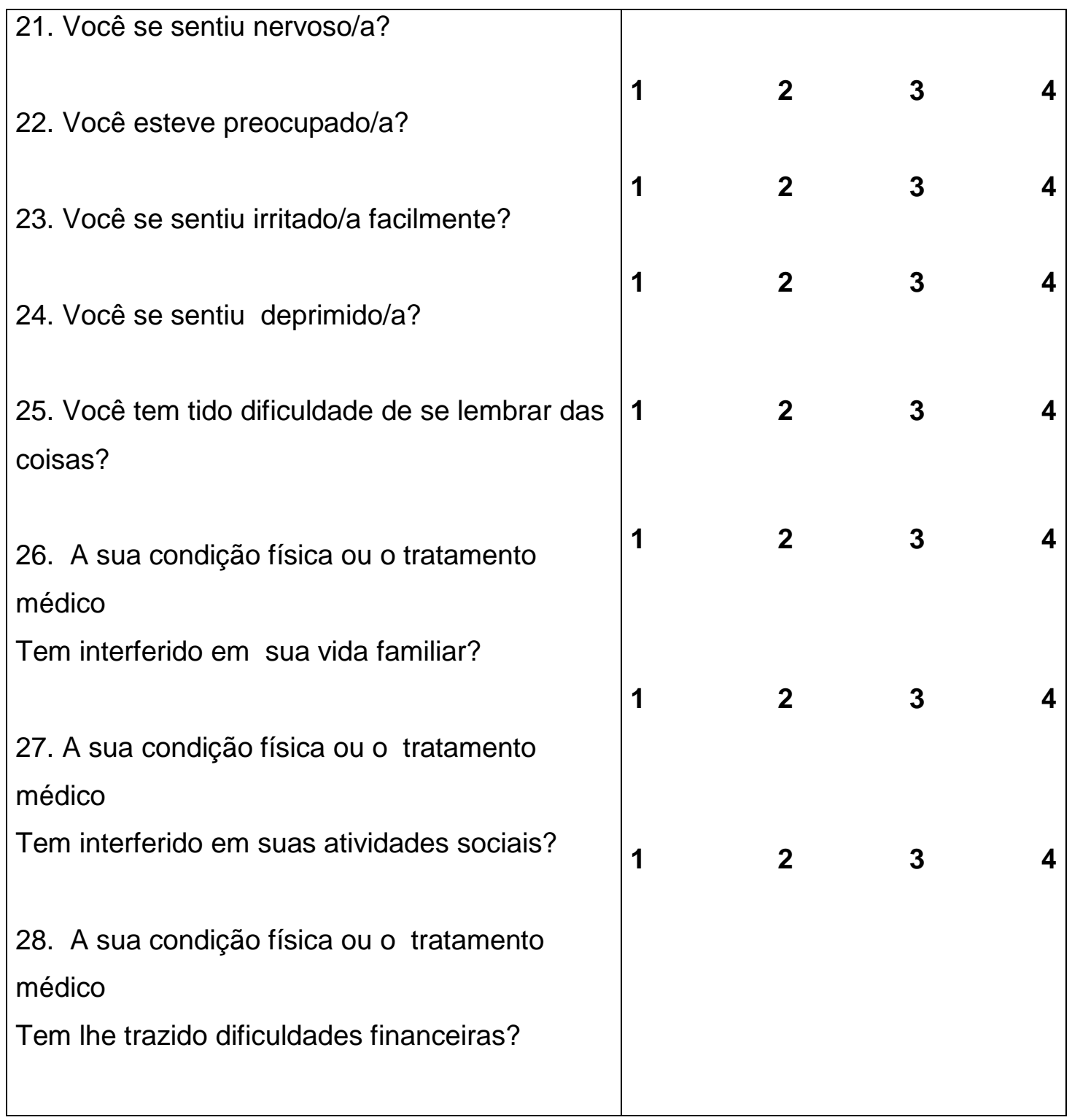

Para as seguintes perguntas, por favor, faça um círculo em volta do número entre 1 e 7 que melhor se aplica a você.

29. Como você classificaria a sua saúde em geral, durante a última semana?
Péssima
2
3
4
5
6
Ótima

30. Como você classificaria a sua qualidade de vida geral, durante a última semana?

$\begin{array}{rrrrrrc}1 & 2 & 3 & 4 & 5 & 6 & 7 \\ \text { Péssima } & & & & & & \text { Ótima }\end{array}$


